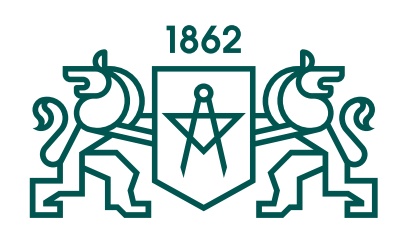

RIGA TECHNICAL UNIVERSITY

Antons Kolmičkovs

\title{
ELECTRIC FIELD EFFECT ON COMBUSTION OF PELLETIZED BIOMASS IN SWIRLING FLOW
}

Summary of the Doctoral Thesis

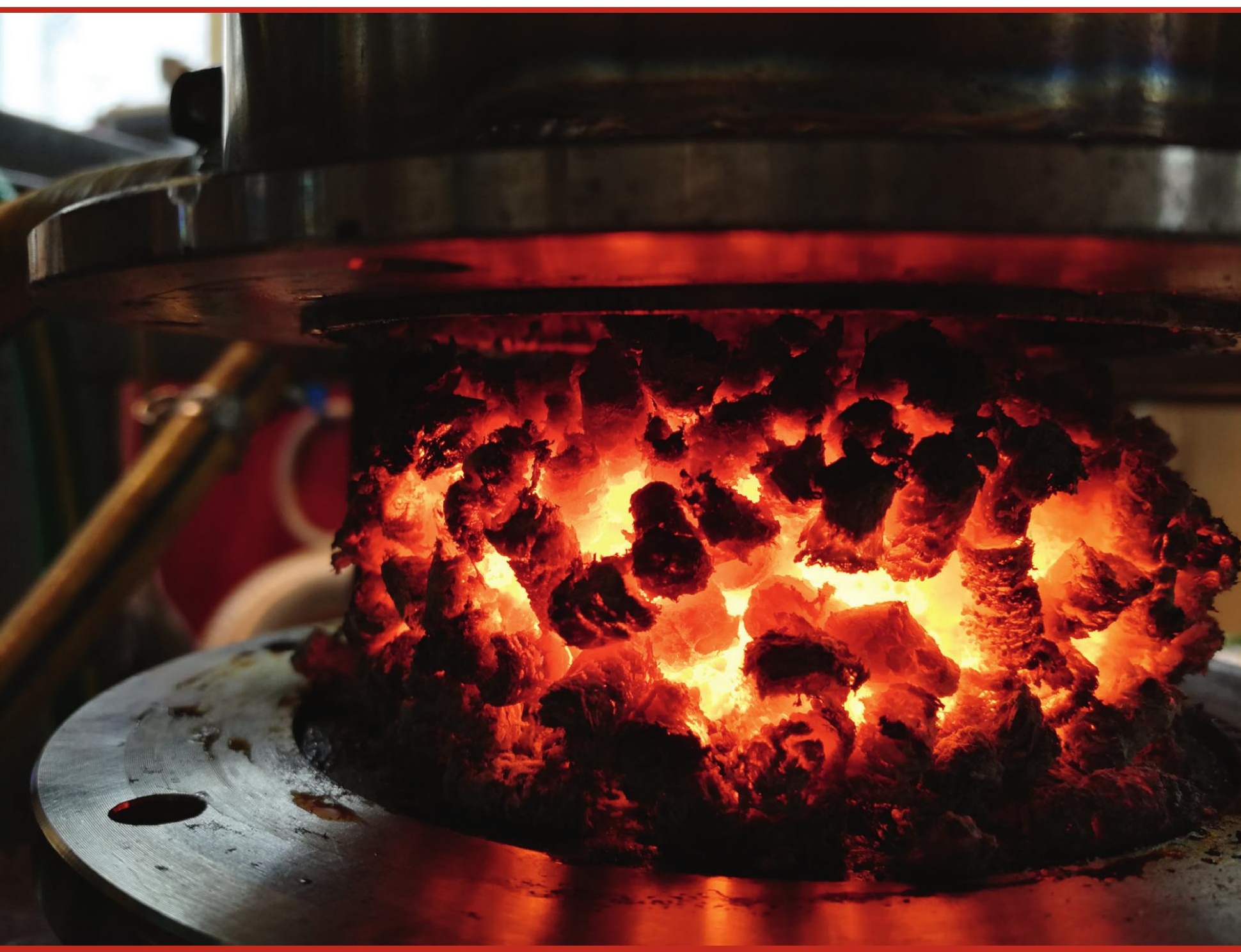

RTU Press

Riga 2022 
RIGA TECHNICAL UNIVERSITY

Faculty of Mechanical Engineering, Transport and Aeronautics

Institute of Mechanics and Mechanical Engineering

\author{
Antons Kolmičkovs \\ Doctoral Student of the Study Programme \\ "Engineering Technology, Mechanics and Mechanical Engineering"
}

\title{
ELECTRIC FIELD EFFECT ON COMBUSTION OF PELLETIZED BIOMASS IN SWIRLING FLOW
}

Summary of the Doctoral Thesis

Scientific Supervisors

Lead Researcher Dr. sc. ing.

INESA BARMINA

Docent Dr. sc. ing. SERGEJS VOSTRIKOVS

RTU Press

Riga 2022 
Kolmičkovs A. Electric Field Effect on Combustion of Pelletized Biomass in Swirling Flow. Summary of the Doctoral Thesis. - Riga: RTU Press, 2022.$53 \mathrm{p}$.

Published in accordance with the decision of the Promotion Council "P-04" of 19 October 2021, Minutes No. 47.

Cover photo by Antons Kolmičkovs.

The Thesis has been developed in collaboration with the Laboratory of Heat and Mass Transfer of Institute of Physics of University of Latvia and with the Department of Heat Power and Heat Engineering of Riga Technical University

The Doctoral Thesis was developed with the financial support of ERDF project „Improvement and control of pelletized biomass combustion process dynamics in electric field" 2DP/2.1.1.1.0/APIA/VIAA/004 and "Co-firing of biomass with electrodynamic process control for clean and effective energy production" SAM 1.1.1.1/16/A/004.

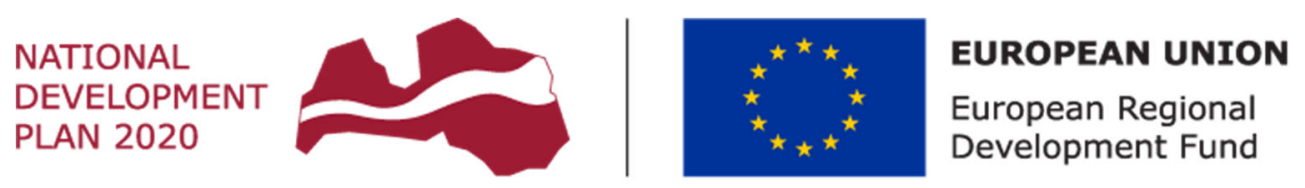

I N V E S T ING IN YOUR FUTURE

https://doi.org/10.7250/9789934227257

ISBN 978-9934-22-725-7 (pdf) 


\section{DOCTORAL THESIS PROPOSED TO RIGA TECHNICAL UNIVERSITY FOR THE PROMOTION TO THE SCIENTIFIC DEGREE OF DOCTOR OF SCIENCE}

To be granted the scientific degree of Doctor of Science (Ph. D.), the present Doctoral Thesis has been submitted for the defence at the open meeting of RTU Promotion Council on 4 February 2022 at 14:30 at the Faculty of Mechanical Engineering, Transport and Aeronautics of Riga Technical University, 6B Kipsalas Street, Room 521.

OFFICIAL REVIEWERS

Assoc. Professor Dr. sc. ing. Vitalijs Beresnevics

Riga Technical University

Senior Research Scientist Ph. D. Dmitri Neshumayev

Tallinn University of Technology, Estonia

Researcher Ph. D. Michal Špiláček

Brno University of Technology,

Czech Republic

\section{DECLARATION OF ACADEMIC INTEGRITY}

I hereby declare that the Doctoral Thesis submitted for review to Riga Technical University for the promotion to the scientific degree of Doctor of Science (Ph. D.) is my own. I confirm that this Doctoral Thesis had not been submitted to any other university for the promotion to a scientific degree.

Name Surname (signature)

Date:

The Doctoral Thesis has been written in Latvian. It consists of Introduction, 4 chapters, Conclusions, 63 figures, 18 tables, 118 formulas, 12 appendices; the total number of pages is 177 , including appendices. The Bibliography contains 277 titles. 


\section{ANNOTATION}

Keywords: combustion, biomass, wheat straw, softwood, peat, electric field, electrodynamic control

The Doctoral Thesis examines the control of the swirling flame flow dynamics with an external static electric field (electric field-driven flame dynamics) firing the gaseous products of thermal decomposition of pelletized straw, woody biomass, and peat with the aim of more efficient heat production with a decrease of flue gas emissions. The relevance of the work is related to the goals set by the EU for 2030 and is in line with the development strategy of the Latvian RIS3, including increasing energy efficiency, diversifying biofuels, using $\mathrm{CO}_{2}$-neutral energy, and developing smart technologies to obtain clean energy from local energy resources of Latvia. The scientific novelty of the research is in the combined use of an external electric field, the biomass of various origins, and a swirling flame flows to produce heat during the combustion of a pelletized solid biofuel for efficient mixing of the gaseous components of the fuel-air mixture.

To achieve the goal of the Thesis, experimental studies of the effect of an electric field on the processes of thermal decomposition of pelletized solid fuel (wheat straw, coniferous wood and peat), the kinetics of the formation of volatile products, the processes of combustion kinetics and the dynamics of a swirling flame flow were carried out in order to evaluate the effect of an external electric field on the variable parameters - flame temperature, swirling flow velocity components, fuel-air mixture composition and the amount of heat released during the thermal decomposition of biomass and combustion of gaseous substances. The Thesis summarizes the research carried out at the Institute of Physics of the University of Latvia (IPUL) within the framework of projects funded by the European Regional Development Fund (ERDF). The results of the research were presented at international scientific conferences and have been published in periodic journals indexed in international scientific databases. The purpose of the published (16) articles was a verification of the experimental methodology and the results by the international scientific community.

The Introduction of the Doctoral Thesis defines the aims and tasks of the Thesis, evaluates its topicality and scientific novelty, describes its practical significance, provides a brief overview of the presentation of the research results at various international scientific conferences, and lists the publications in indexed scientific journals. The first chapter summarizes the information on thermal decomposition processes of pelletized solid fuel, the combustion kinetics of volatiles, ion formation mechanisms, the formation of swirling flame flow, and its behaviour in the electric field. The second chapter describes the experimental research and measurement methodology. The results of the research of thermal decomposition and combustion processes of biomass of different origins are summarized in the third chapter, but the engineer-economic calculation together with the approbation results are presented in the fourth chapter. The obtained conclusions and proposals for further development of technology are summarized in the conclusions of the work. 


\section{CONTENTS}

ANNOTATION

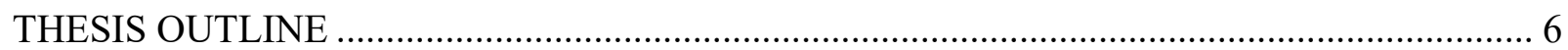

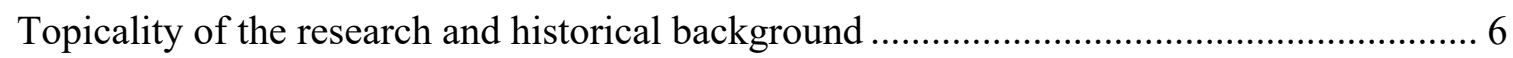

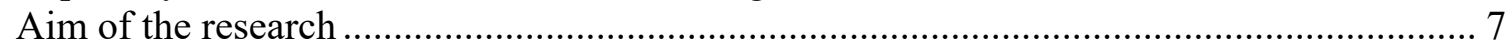

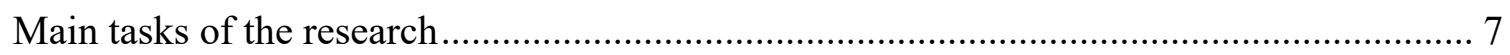

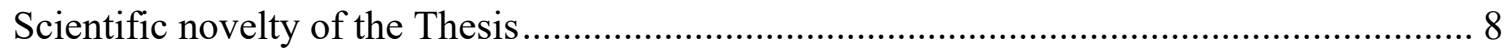

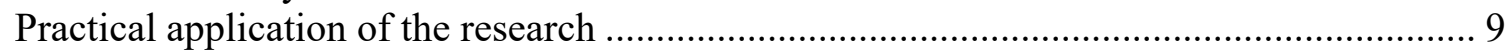

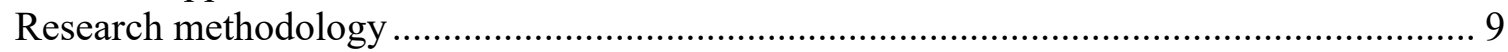

The scope of the research and application of the obtained results ........................................ 10

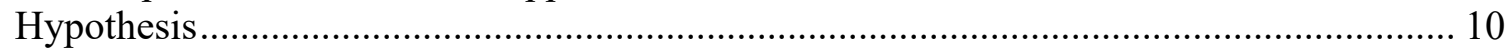

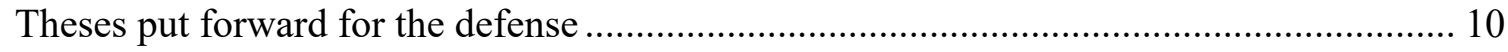

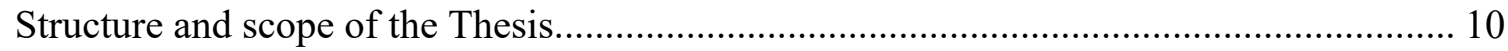

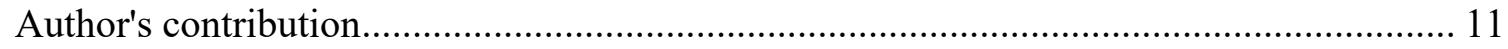

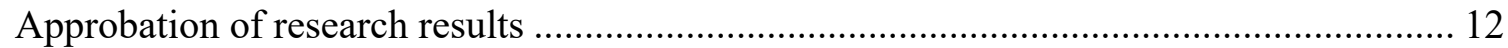

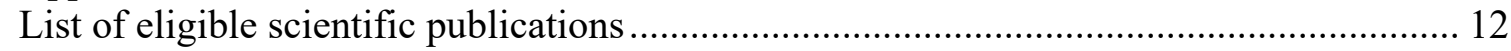

1. Evaluation of theory and topical studies of heat production processes .................................. 14

1.1. Properties of the thermal decomposition of plant biomass pellets ................................ 14

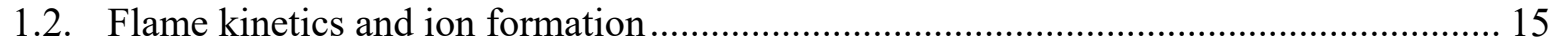

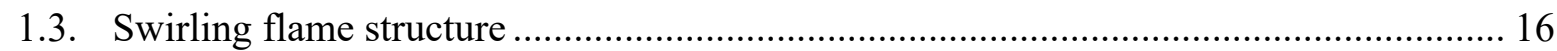

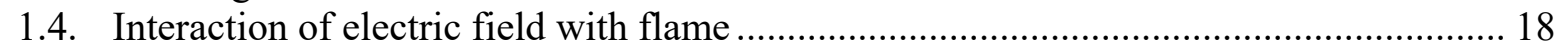

1.5. Analytical assessment of the effect of electric volume force ......................................... 19

2. Construction, testing methodology and validation of experimental equipment ...................... 20

2.1. Description of the experimental setup and equipment ................................................ 23

2.2. Description of the equipment for approbation of technology prototype ........................ 24

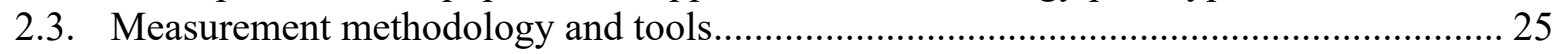

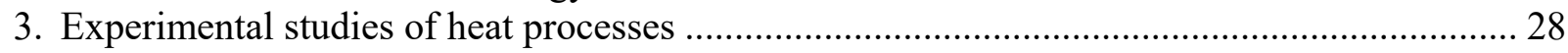

3.1. Characterization of straw, wood biomass, and peat samples ...................................... 28

3.2. Pelletized biomass combustion process without an electric field applied...................... 29

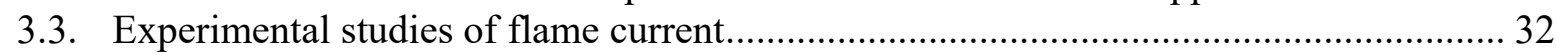

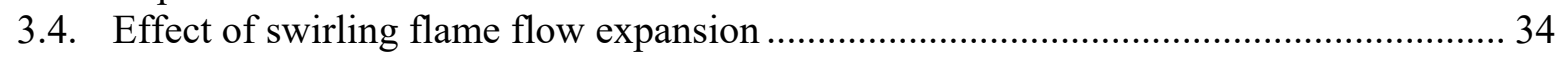

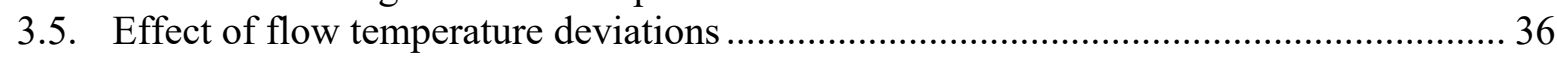

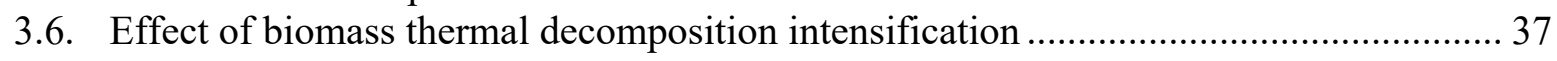

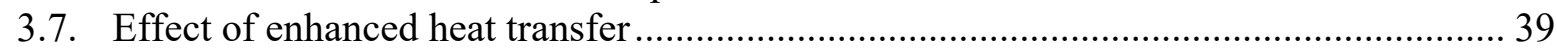

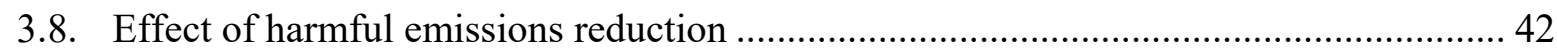

4. Approbation and evaluation of new technology prototype with industrial pellet burner ......... 44

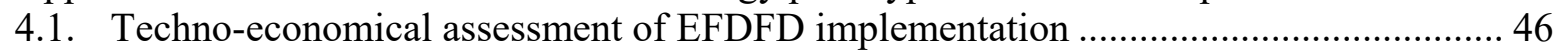

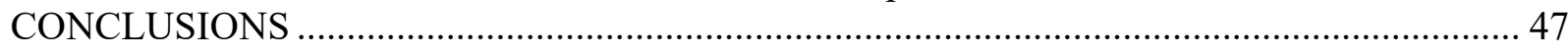

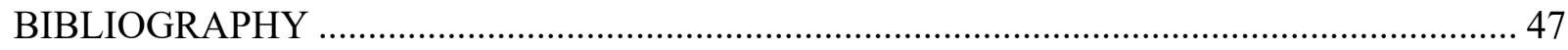




\section{THESIS OUTLINE}

\section{Topicality of the research and historical background}

In 2019, the European Commission set new energy policies for the period up to 2030: to cut $\mathrm{CO}_{2}$ in GHG emissions by $40 \%$, increase the share of renewable energy resources by $32 \%$, and improve energy efficiency by $32 \%$ compared to the level of the $1990 \mathrm{~s}[1]$. There is a challenge to cut the utilization of fossil fuel and implementing its alternatives in the energy market, i. e. biomass. Following the "zero-emissions" guidelines, the demand for high-quality wood biomass for energy production is growing rapidly - from 17 to 24 million tons between 2013 and 2017 (AEBIOM), however, fuel production rates changed only from 14 to 18 million tons [2]. Considering the emission quotas set by the EU, small businesses and households in Latvia started to use low-power pellet heat devices which burn high-quality sawdust pellets. However, the market is experiencing a recession in the production of woody biomass and the active development of its imports [2]. Due to the growing demand for high-quality pellets, there is a shortage in the wood pellet market, and the question of diversification of pelletized biofuel is raised. When assessing the possibilities of using these alternative resources, the use of agricultural biomass is proposed (wheat and rice straw), the resources of which reach up to 1500 million tons per year [3].

The utilization of a low-quality (or raw) biomass (up to $45 \%$ in the EU [2]) is limited in small household boilers. The use of low-quality pellets reduces the heat capacity of the fuel, increases the formation of tar deposits on the boiler walls, the formation of ash and vitrification [4]. The use of low-quality fuel in the combustion process is also associated with the formation of destructive [5] and corrosive substances [6], which shortens the service life of the equipment and increases maintenance/repair costs. Moreover, the utilization of agricultural biomass is limited by the significant diversity of physical (water content, density, shape) and physicochemical characteristics (calorific value, elemental and chemical composition, ash content) [7]. This diversity leads to instability in heat production processes and reduces the predictability of the results.

To ensure more stable combustion and gasification processes using biomass of different origins, biomass processing (pelletizing, briquetting) is gradually developing, which help to control the density, predict the elemental composition and calorific value [8]. Biomass pre-treatment is usually performed, which grants the opportunity to reduce the moisture content in the biomass and intensify the formation of volatile substances, their ignition and combustion [9]. In parallel with the research related to the improvement of the parameters characterizing the fuel, the research related to the improvement and stabilization of the combustion process parameters is carried out. Swirls are actively used to stabilize the gas fuel combustion processes. The classic swirling flow is formed in the combustion chamber employing the air vortex supply nozzles located in the center of the channel. However, a different structure of the flame swirl is observed if the airflow is supplied tangentially from the walls of a burner to the center: with pronounced compression at the base of the flame and slight expansion in the middle [10]. The use of vortex flow is already being used in low-power pellet burners [11], but its implementation is limited by careful aerodynamic 
modeling in the combustion chamber. Failure to comply with the aerodynamic regime causes several side effects, i.e. leakage of unreacted substances from the combustion zone with enhanced cooling of the pellet surface [12], [13] due to compression and elongation of the flame.

Research on the electrical nature of the flame [14], [15] and the "ionic wind" effect of the flame [16], in the 20th century gave an impulse to study the interaction of the electric field and a flame, as well as the control of the combustion parameters [17]-[20]. It was found that the use of electric field and flame interaction effects (assumed heat and mass transfer in the field direction) allows controlling flame stability, the length [21], shape [22], the efficiency of combustion and heat production processes, as well as the composition of flue gas [23], [24]. The effects manifested in an eclectic field strongly depend on the nature of charged particles (electrons, ions, and products of their interaction [15], [14]), their number and charge density distribution in the flame [25], which, sequentially, depends on the type of fuel, combustion conditions and kinetics [26], [27]. Currently, there is no unified model for simulating the kinetics of combustion and ion formation concerning all the types of fuel, since the numerical results strongly depend also on the combustion conditions, kinetic parameters, and the direction of the reactions [28]. Therefore, an experimental study aimed at the practical application of flame-electric field interactions continues today.

The Thesis considers the efficient use of local bio-resources (waste from the woodworking industry and agriculture), their diversification and mitigation of the negative consequences of the diversity of their composition by regulating the combustion process, implementing the effect of the interaction of the electric field and swirling flame flow, thereby increasing the combustion efficiency and reducing the polluting emissions into the atmosphere.

\section{Aim of the research}

The aim of the Thesis is to study, develop a theory and optimize the effect of direct current electric field on the combustion of pelletized biomass fuel in swirling flame flow (electric fielddriven flame dynamics, hereinafter - EFDFD) by applying experimental identification methods of combustion processes as well as multi-phase continuous mechanical particles and physicochemical transformation theories.

\section{Main tasks of the research}

1. Evaluations of existing multiphase continuous environmental rotational motion and various biomass physico-chemical transformation theories and experimental studies were carried out with the aim to use them in the analysis of effect of the DC electric field (with a strength of up to $1 \mathrm{kV} \cdot \mathrm{cm}^{-1}$ ), parametric improvement of existing technology and processes, as well as in the development of prototype equipment.

2. A new integrated electrodynamic control equipment has been designed, manufactured, and tested in operation for combustion of pelletized biomass (wheat straw, softwood biomass and peat).

3. Physical experiments were performed with the newly developed experimental equipment to evaluate the efficiency of burning various biomass pellets. The experimental results were 
evaluated by describing the effect of the electric field on the changes in flame temperature, flow rate and composition, as well as on the amount of heat produced during the biomass combustion process.

4. Practical approbation of prototype equipment of electrodynamic control technology with industrial pellet burner up to $20 \mathrm{~kW}$ has been performed.

\section{Scientific novelty of the Thesis}

It is for the first time in the scientific information space that the regularities of the integrated interaction of low intensity (up to $1 \mathrm{kV} \cdot \mathrm{cm}^{-1}$ ) perpendicular direct current electric field and a swirling flame of pelletized biomass of various origins are described (Table 1), evaluating the effect of this interaction on biomass thermal decomposition and devolatilization, combustion propagation and burnout of the volatiles, heat-mass transfer processes and the formation of flue gas emissions.

Table 1

\section{Principal comparison of the experimental research}

\begin{tabular}{|c|c|c|c|c|c|c|c|}
\hline Author & Scale & Fuel & $\begin{array}{l}\text { Combustion } \\
\text { mixture }\end{array}$ & Flow & : & 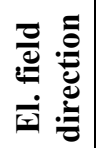 & 들 \\
\hline $\begin{array}{c}\text { J.F. Weinberg, J. Lawton, } \\
\text { P. J Mayo }\end{array}$ & $\begin{array}{c}\text { micro; } \\
\text { meso }\end{array}$ & gas & diffuse & $\begin{array}{l}\text { lamin.; } \\
\text { turb. }\end{array}$ & $\checkmark$ & $\begin{array}{l}\downarrow \downarrow ; \\
\rightarrow \downarrow\end{array}$ & $\begin{array}{l}\text { aver.; } \\
\text { high }\end{array}$ \\
\hline $\begin{array}{l}\text { D. C. Murphy, M. Sánchez-Sanz, } \\
\text { C. Fernandez-Pello, }\end{array}$ & micro & gas & premixed & lamin. & & $\begin{array}{l}\downarrow \downarrow ; \\
\rightarrow \downarrow\end{array}$ & high \\
\hline S. D. Marcum, B. N. Ganguly & micro & gas & diffuse & lamin. & $\checkmark$ & $\downarrow \downarrow$ & aver. \\
\hline $\begin{array}{l}\text { M. J. Papac, D. Dunn-Rankin, } \\
\text { F. B. Carleton, Y.C. Chien }\end{array}$ & $\begin{array}{l}\text { micro; } \\
\text { meso }\end{array}$ & gas & premixed; diffuse & lamin. & $\checkmark$ & $\downarrow \downarrow$ & aver. \\
\hline S. Karnani, J. A. Tinajero & micro & gas & diffuse & lamin. & & $\downarrow \downarrow$ & $\begin{array}{l}\text { aver.; } \\
\text { low }\end{array}$ \\
\hline J. Van den Boom, A. Verhasselt & micro & gas & premixed & lamin. & & $\downarrow \downarrow$ & high \\
\hline $\begin{array}{l}\text { Y. Xiong, D. G. Park, B. J. Lee, } \\
\text { S. H. Chung, M. S. Cha }\end{array}$ & micro & gas & premixed; diffuse & lamin. & & $\downarrow \downarrow$ & $\begin{array}{l}\text { aver.; } \\
\text { low }\end{array}$ \\
\hline D. Turlājs, I. Barmina & meso & gas & diffuse & $\begin{array}{l}\text { lamin.; } \\
\text { turb. }\end{array}$ & $\checkmark$ & $\rightarrow \downarrow$ & aver. \\
\hline $\begin{array}{l}\text { M. Zake, R. Valdmanis, } \\
\text { A. Līckrastiņa }\end{array}$ & meso & $\begin{array}{l}\text { gas, woody } \\
\text { biomass }\end{array}$ & diffuse & $\begin{array}{l}\text { swirling } \\
\text { flow }\end{array}$ & $\checkmark$ & $\rightarrow \downarrow$ & aver. \\
\hline N. Zeltiņš, O. Krickis & meso & gas & premixed & $\begin{array}{l}\text { lamin.; } \\
\text { turb. }\end{array}$ & & $\rightarrow \downarrow$ & $\begin{array}{l}\text { aver.; } \\
\text { high }\end{array}$ \\
\hline $\begin{array}{c}\text { A. Kolmičkovs, I. Barmina, } \\
\text { S. Vostrikovs, M. Zaķe, } \\
\text { R. Valdmanis }\end{array}$ & $\begin{array}{l}\text { meso, } \\
\text { macro }\end{array}$ & \begin{tabular}{|c|} 
straw, woody \\
biomass and \\
peat
\end{tabular} & diffuse & $\begin{array}{l}\text { swirling } \\
\text { flow }\end{array}$ & $\checkmark$ & $\rightarrow \downarrow$ & low \\
\hline
\end{tabular}

\footnotetext{
low $<1 \mathrm{kV} \cdot \mathrm{cm}^{-1} ;$ average $\mathrm{E}^{\prime} \approx[1 ; 6] \mathrm{kV} \cdot \mathrm{cm}^{-1} ;$ high $>6 \mathrm{kV} \cdot \mathrm{cm}^{-1}$.
} 


\section{Practical application of the research}

The use of renewable resources (biomass of various types) in thermal energy production is important because it can potentially help to limit the global warming through the reforestation, promoting the more efficient use of the local energy resources and contributing to the country's energetic independence. Besides, some EU directives call for newer methods of energy production through more efficient utilization of renewable energy sources.

The conclusion on the practical significance of the research was provided by the Latvian Federation of Woodworking Industry: JSC "Latvijas Finieris", "PATA AB" Ltd., "Vika Wood" Ltd., "Latgran" Ltd., "Graanul Invest" Ltd. The results obtained in the study provide both scientific and practical contribution to promoting renewable energy resources, conducting in-depth research, evaluating the possibilities of electric field application to control the dynamics of combustion of pelletized biomass of various types, and developing new smart technology to control the energy production process with improved efficiency and composition of flue gas. The Thesis summarizes important recommendations for further improvement, implementation and safety of this technology. Also, the analysis of significant differences in the composition of the biomass of different types has been performed, evaluating their influence on the formation of thermal decomposition processes and the dynamics of the combustion process. The literature review includes information on mechanisms of ion formation in the process of biomass pyrolysis and combustion of volatile substances, the distribution of ion concentration and the formation of "ion wind". The research is relevant not only for industry professionals but is also useful as educational material.

\section{Research methodology}

To carry out experimental studies of the complex effect of an external DC electric field and a swirling flame flow on the process of thermochemical decomposition of pelletized biomass of different origins, a classical experiment is carried out with one variable - a positive potential from $0 \mathrm{kV}$ to $1.8 \mathrm{kV}$ an axially symmetric $100 \mathrm{~mm}$ wire electrode with a limited ion current up to $7 \mathrm{~mA}$. The research methodology is based on the application of modern measuring instruments: temperature sensors for calorimetric measurements of the flow of cooling water; thermocouples for local measurement of the flame temperature; an IR spectrometer for measuring the composition of the products of thermal decomposition of biomass; a flue gas analyzer for measuring the content combustion emissions; electric probes for local current measurements; a pitot probe for observing local changes in flow dynamics, etc. For a comprehensive study of various parameters, experimental studies were carried out assessing the reproduction and evaluating the accuracy of the measurement results. The experience of internationally recognized authors in certain fields is studied to process, evaluate and interpret the results of interdisciplinary work. 


\section{The scope of the research and application of the obtained results}

The results of the dissertation research, obtained using the batch low-power $(4 \mathrm{~kW})$ experimental setup, have been validated for the continuous operation on the mesoscale pilot setup with a cylindrical combustion chamber and a thermal power up to $20 \mathrm{~kW}$. The Thesis provides valuable information on the technique of positioning the electrode in the flame and field-induced effects arising in the reaction zone of the products of thermal decomposition of biomass, which opens up the possibility of transferring and approbation of research results to industrial-scale burners using a swirling flame flow to stabilize combustion process and increase its efficiency.

\section{Hypothesis}

It is possible to control thermal decomposition rate of biomass, the formation rate of combustible volatiles and their ignition, the composition and structure of the combustion zone by influencing the dynamics of the swirling flame flow with the impact of an external DC electric field, thus intensifying the processes of heat and mass transfer in the direction of the field, thereby increasing the efficiency of heat production with reduced relative harmful emission.

\section{Theses put forward for the defense}

1. The elemental and chemical composition of the biomass of different types (straw, wood, peat) determines significant variations in the thermal decomposition and combustion processes.

2. In the external DC electric field, in addition to the expanded combustion zone by $15-20 \%$ and shortened length of the flame by $50 \%$, the downward vortex is intensified (S from 0.6 to 1.1), providing improved mixing of the swirling airflow with the axial flow of volatiles.

3. As a result of variations of the dynamics of the swirling flame flow, the axial flow velocity decreases from $1 \mathrm{~m} \cdot \mathrm{s}^{-1}$ to $0.3 \mathrm{~m} \cdot \mathrm{s}^{-1}$, increasing the residence time of combustible volatile substances in the reaction zone, and consequently, improving their burnout by 36-37\%.

4. The changes in the rate of thermochemical conversion of biomass (by $20 \%$ ) at the initial stage of the combustion are related to the intensification of the devolatilization (by 20-40\%).

5. An electric field induced variation of the fractions of products of biomass thermal decomposition and combustion, an increase in the combustion efficiency (by 4-10\%), as well as the intensification of the mass transfer of charged species to heating surfaces increase the heat produced during the total biomass thermochemical conversion process by $3-10 \%$.

\section{Structure and scope of the Thesis}

The Doctoral Thesis is based on a systematic six-year work at the IPUL within the framework of EU funded projects. The research results are summarized in 16 thematically united scientific articles which are cited in international periodical journals. The purpose of these publications is to inform society about the research results and obtain international recognition for the reliability of the chosen measurement methodology and the results obtained. The Thesis consists of an introduction, three main chapters, conclusions and proposals for further technology development. 
The introduction emphasizes the relevance of the research, defines the objectives and tasks, and provides information on the scientific novelty and practical applicability of the work. The first chapter analyzes the influence of diversity of the chemical composition of various biomass on the process of formation of the products of biomass thermal decomposition, and on the dynamics of the formation of a swirling flame. It also analyzes the influence of various transformations of hydrocarbons on the ionization of the flame and the formation of ionic current. It studies the influence of the degree of flame ionization and the distribution of ion concentration on the heat and mass transfer caused by the "ionic wind" in the electric field direction. The second chapter describes the equipment used in experimental studies, measuring instruments, measurement techniques, measurement limits and sensitivity, assessment of the reliability and repeatability of experimental results. The results of the experimental study are provided in the third chapter. The fourth chapter presents the results of approbation on a more powerful boiler device, provides an economic evaluation of the technology, recommendations for its further development, the application of the technology and safety measures when working with electric fields. The conclusions section emphasizes the main results of the research and provides answers to the research tasks. The bibliography section gives a bibliographic description of the sources of information used.

\section{Author's contribution}

The experimental work was carried out at the IPUL - Laboratory of Heat and Mass Transfer supervised by Dr. phys. Maija Zaķe and Dr. ing. sc. Inesa Barmina. The author of the Thesis, together with the laboratory staff (R. Valdmanis, S. Vostrikov), participated in experimental work, data processing and analysis of the results. This work was also supported by the Institute of Mathematics and Computer Sciences: Dr. habil. math. Harijs Kalis, Dr. math. Maxim Marinaki and Mg. math. Liva Ozola. The testing of biomass was performed at the Latvian Institute of Wood Chemistry.

The author took part in all stages of the research and mastered all methods of measuring and data processing. His main contribution was to the midIR spectral study of the products of biomass thermal decomposition, assessing a variety of the chemical content of biomass and its effect on devolatilization and volatiles combustion. Within the framework of the projects, a team of researchers developed a new experimental setup $(4 \mathrm{~kW})$ with an improved aerodynamic regime to study the effect of electric field on the swirling flame formation dynamics, as well as a pilot device for approbation testing of the technology with a low-power industrial burner (up to $20 \mathrm{~kW}$ ). The author of the Thesis prepared a deep and comprehensive analysis taking into account the results of previous studies carried out at the IUPF and LIWC institutes and the summary of the literature on thermochemical transformations of the products of biomass thermal decomposition and on the interaction of a flame species with an external DC electric field. The author of the work, together with colleagues, compiled the analysis and conclusions of the research in scientific articles and 
presented them at national and international conferences thanks to the financial support from the LUFI and ERDF projects.

\section{Approbation of research results}

In the course of the research, the author has participated in 4 scientific projects and 5 international conferences, published the results of the work in 21 scientific articles (16 are relevant to this Thesis). Two Know-Hows were reviewed and accepted by the Academic Council of the Institute of Physics of the University of Latvia, as well as one user license application has been submitted.

\section{List of eligible scientific publications}

1. Kalis, H., Kolmičkovs, A., Marinaki, M., Valdmanis, R. Mathematical Modelling and Experimental Study of Straw Co-Firing with Gas Using Electric Field Control of Combustion Characteristics. In: 19th International Scientific Conference "Engineering for Rural Development": Proceedings, May 20-22, 2020, Jelgava: Latvia, pp. 1059-1064. DOI: 10.22616/ERDev.2020.19.TF250

2. Barmina, I., Kolmičkovs, A., Valdmanis, R., Vostrikovs, S., Zake, M. The Effect of Electric Field Configuration on the Thermo-Chemical Conversion of Straw Pellets. Latvian Journal of Physics and Technical Sciences, 2020, Vol. 57, No. 4, pp. 65-76. DOI:10.2478/lpts-20200022

3. Barmina, I., Kalis, H., Kolmičkovs, A., Marinaki, M., Ozola, L., Strautins, U., Valdmanis, R., Zake, M. Mathematical Modelling and Experimental Study of Straw Co-Firing with Gas. Mathematical Modelling and Analysis, 2019, Vol. 24, No. 4, pp. 507-529. DOI:10.3846/mma.2019.031

4. Barmina, I., Kolmičkovs, A., Valdmanis, R., Zake, M., Vostrikovs, S., Kalis, H., Strautins, U. "Electric Field Effect on the Thermal Decomposition and Co-combustion of Straw with Solid Fuel Pellets" Energies, 2019, Vol. 12, No. 8, pp. 1522-1542. DOI:10.3390/en12081522

5. Barmina, I., Kolmičkovs, A., Valdmanis, R., Vostrikovs, S. "Electrodynamic Control of Straw Co-Firing with Propane" In: 18th International Scientific Conference "Engineering for Rural Development": Proceedings, May 22-24, 2019, Jelgava: Latvia, pp. 1319-1324. DOI: 10.22616/ERDev2019.18.N022

6. Barmina, I., Kolmičkovs, A., Valdmanis, R., Zaķe, M., Kalis, H., Strautiņš, U. "Electric Field Effect on the Thermal Decomposition and Co-Combustion of Straw Pellets with Peat" Chemical Engineering Transactions, 2018, vol. 70, pp. 1267-1272. DOI: 10.3303/CET1870212

7. Barmina, I., Kolmičkovs, A., Valdmanis, R., Zaḳe, M., Kalis, H., Strautiņš, U. "Kinetic Study of the Thermal Decomposition and Co-Combustion of Straw Pellets with Coal" Chemical Engineering Transactions, 2018, vol. 70, pp. 247-252. DOI: $10.3303 / \mathrm{CET} 1870042$ 
8. Barmina, I., Kolmičkovs, A., Valdmanis, R., Zake, M., Kalis, H., Marinaki, M. "Experimental Study and Mathematical Modelling of Straw CoFiring with Peat" Chemical Engineering Transactions, 2018, vol. 65, pp. 91-96. DOI: 10.3303/CET1865016

9. Kalis, H., Kolmičkovs, A., Marinaki, M., Ozola, L. "Development of Combustion Dynamics at Co-Combustion of Straw with Wood" In: 17th International Scientific Conference "Engineering for Rural Development": Proceedings, Latvia, Jelgava, 23-25 May, 2018. Jelgava, Latvia, pp. 1322-1328. DOI: 10.22616/ERDev2018.17.N114

10. Barmina, I., Kolmičkovs, A., Valdmanis, R., Zaķe, M. "Co-Firing of Straw with Electrodynamic Process Control for Clean and Effective Energy Production" In: European Biomass Conference and Exhibition Proceedings, Sweden, Stockholm, 12-15 June, 2017. pp. 579-592. DOI: 10.5071/25thEUBCE2017-2BV.1.22

11. Barmina, I., Kolmičkovs, A., Valdmanis, R., Zaķe, M., Kalis, H. "Experimental and Numerical Studies of Electric Field Effects on Biomass Thermo-chemical Conversion" Chemical Engineering Transactions, 2016, vol. 50, pp. 121-126. DOI: 10.3303/CET1650021

12. Barmina, A. Kolmickovs, R. Valdmanis, M. Zake. "Electrodynamic control of combustion dynamics and swirling flame structure at thermochemical conversion of biomass" in Proceedings of the $7^{\text {th }}$ Baltic Heat Transfer Conference, Tallinn, 2015, pp. 169-174. Available: www.ttu.ee/public/p/projektid/bhtc2015/7th_BHTC_Technical_Programme.pdf

13. Barmina, A. Kolmickovs, R. Valdmanis, M. Zake. "Combustion dynamics of swirling flame at thermochemical conversion of biomass" in Chemical Engineering Transactions, Milan, 2015, Vol. 43. DOI: 10.3303/CET1543109

14. Barmina, A. Kolmickovs, R. Valdmanis, M. Zake. "Control of combustion dynamics by an electric field" in Chemical Engineering Transactions, Milan, 2015, Vol. 43, pp. 973-978. DOI: $10.3303 /$ CET1543163

15. M. Zake, I. Barmina, A. Kolmickovs, R. Valdmanis. "Electric field impact on the biomass gasification and combustion dynamics" in International Journal of Mechanical, Aerospace, Industrial, Mechatronic and Manufacturing Engineering, Stockholm, 2015, Vol. 9, No. 7. DOI: 10.1999/1307-6892/10001811

16. Barmina, A. Kolmickovs, R. Valdmanis, S. Vostrikovs, M. Zake. "Electric field control of biomass gasification" in Engineering for Rural Development, Jelgava, 2015, pp. 510-515. Available: tf.llu.lv/conference/proceedings2015/Papers/083_Kolmickovs.pdf

Other author's publications can be accessed at https://ortus.rtu.lv/science/lv/experts/12778. 


\section{EVALUATION OF THEORY AND TOPICAL STUDIES OF HEAT PRODUCTION PROCESSES}

\subsection{Properties of the thermal decomposition of plant biomass pellets}

The process of burning solid fuel of plant origin includes interrelated processes: heating of biomass, drying, thermal decomposition of the main components (hemicellulose, cellulose, lignin), the formation of volatile substances (up to $60 \%$ ), their ignition and thermochemical transformation, as well as transformation of charred biomass (up to $17 \%$ ) with two-phase reactions on the surface.

The initiation of the combustion of biomass pellets and its rate is determined by the physical processes of drying (which largely depends on the size and density of pellet particles) and endothermic processes of biomass devolatilization. To maintain the devolatilization, it is necessary to supply heat, since the amount of heat supplied determines the rate of formation of volatiles [29]. The origin of biomass determines its thermal decomposition properties and the amount of volatile products [30], [31]. Variations in the process of thermal decomposition of woody [32] and straw [33] pellets are mainly ruled by the different distribution of volatile matter and solid phase. Nevertheless, some deviations in the process are also regulated by the chemical structure of hemicellulose [34]. The structure of the hemicellulose of softwood (Gal-Glu-Man) provides an improved release of volatiles from the biomass during the flame formation stage. Indeed, the structure of wheat straw hemicellulose (Glu-Uro-Ara-Xyl) increases the formation of the char phase and slightly reduces the rate of volatiles formation during devolatilization. On the other hand, the structure of peat, in principle, determines the differences between the processes of devolatilization and the formation of a char phase, since at least one-third of the dry mass of peat compose humic and fulvic acids [35], which have a highly aromatized structure, that determines a reduced content of volatile matter and an increased content of fixed carbon [36].

The distribution of the flame temperature [37], [38] determines the composition of products of the thermal decomposition and the rate of transformation of combustible substances. Therefore, it is necessary to maintain the temperature in the reaction layer of the pellets above $700 \mathrm{~K}$ [6]. The heat balance, between endothermic processes of biomass decomposition [29] and exothermic processes of conversion of volatile substances [39], determines the ignition rate of volatiles, which, sequentially, affects the kinetics and dynamics of flame formation. The greater amount of volatiles is produced during the biomass thermal decomposition, the more intense the flame is formed [40].

Bearing in mind the differences in the chemical composition of various types of pellets [41] [43], their content of volatile matter [32], [41], [43] and the thermal effects occurring during the decomposition of the biomass components [29], [31], [44], it can be concluded that the longest flame at combustion of wood and straw is determined by the intense decomposition of holocellulose [29], [31], [32], with the intense formation of a flow of volatiles [45], [46], the ignition of which is delayed by the endothermic thermal effect of cellulose decomposition [29], [30]. On the contrary, a reduced content of volatile matter in peat, but an increased amount of fixed 
carbon [43], provides the uniform formation of combustible substances [47], improved flow heating and its faster ignition [37], [38].

Since the solid charred phase (the product of the last stage of thermal decomposition of pellets) consists of $95 \%$ carbon [45], its oxidation requires a great amount of oxygen [48], which must be supplied directly to the surface of the char [49]. The charred phase oxidation process uniformly releases a large amount of heat (up to $33 \mathrm{MJ} \cdot \mathrm{kg}^{-1}$ ) [30], that balances the endothermic processes of devolatilization of biomass during its hollocelulose thermal decomposition, thereby providing a self-sustaining process of biomass combustion and flame formation. For a detailed analysis of the characteristic parameters and structure of biomass read Section 1.1 of the Thesis.

\subsection{Flame kinetics and ion formation}

The composition of the mixture of volatiles produced at the thermal decomposition of biomass is variable. Still, the main components are $\mathrm{CO}_{2}(27-32 \%), \mathrm{CO}(12-23 \%), \mathrm{H}_{2}(1-14 \%), \mathrm{CH}_{4}(0.5-$ $4 \%$ ), $\mathrm{C}_{2} \mathrm{H}_{2}$ (up to $1 \%$ ) un $\mathrm{C}_{2} \mathrm{H}_{4}$ (up to $0.5 \%$ ) [45], [46]. The oxidation reactions of main gaseous products $\left(\mathrm{H}_{2}\right.$ and $\left.\mathrm{CO}\right)$ of the thermal decomposition of biomass are branched-chain reactions, the rates of which are mainly determined by the reaction mechanism and the number of active centers (formation of $\mathrm{H}$ and $\mathrm{OH}$ radicals). Due to its fast combustion kinetics, hydrogen burns almost instantaneously in a flame base, in comparison with CO. Unfortunately, its radical participates in $\mathrm{CO}$ oxidation reactions, therefore its presence in the flame flow is severe [50], [51]. Oxidation of hydrocarbons $\left(\mathrm{CH}_{4}, \mathrm{C}_{2} \mathrm{H}_{4}\right.$, or $\left.\mathrm{C}_{2} \mathrm{H}_{2}\right)$ is generally similar to the oxidation of hydrogen and carbon monoxide and also includes them as part of their thermochemical transformation. The mechanisms involving most of the series of reactions were developed by simulating dozens/hundreds of simultaneous chemical reactions [52]. A variation in the conditions of the combustion process influences the kinetic parameters of the reactions that may even switch the direction of the reactions and their sequence. The kinetics of the combustion is most influenced by external factors, such as the fuel-air rate and temperature [28].

The combustion of the biomass char is determined by the reactions of carbon gasification [53] and oxidation [48]. These reactions are slowed down by the complex sorption, diffusion processes [49], [54], and complex red-ox reactions, which complicate surface reactions of the charred solid phase and contribute to the formation of soot in the flame. Thermal light emission of soot particles determines the yellow-red color of the flame when burning biomass [55]. the combustion process of solid particles, escaping from the surface of a charred fuel, or forming in the sooting flame, is associated with the diffusion of the oxidizer (surface reactions) and particle transformations determined by the contraction model [54].

Ion formation in the process of thermochemical transformation of biomass is associated with chemical reactions of hydrocarbons [26], [27]. The flame reaction zone is characterized by a very high concentration of ion formation precursors, which predominately are the excited $\mathrm{C}_{2}$ and $\mathrm{CH}$ radicals. The formation of these excited radicals plays a major role in the natural process of flame chemo-ionization [52]. Chemical ionization depends not only on temperature but also on the nature 
of the chemical structure of the fuel, the type of chemical bonds between atoms, and their energy state [56]. According to some reports, electrons in a flame form up to $90 \%$ of the total negative charge [57], however, much more positive ions are formed in the flame than negative ones [14], [15]. The $\mathrm{CHO}^{+}$ion is the primary ion in flame [58], formed as a result of chemical ionization. However, in the presence of water vapor, this cation is almost completely converted into the more stable hydronium ion $-\mathrm{H}_{3} \mathrm{O}^{+}$[57], the concentration of which is observed along the entire length of the flame [59]. In a stoichiometric flame, $85 \%$ of the total positive charge density is formed by $\mathrm{H}_{3} \mathrm{O}^{+}, \mathrm{C}_{3} \mathrm{H}_{3}{ }^{+}$, and $\mathrm{C}_{2} \mathrm{H}_{3} \mathrm{O}^{+}$ions [60]. No other positive ion significant concentration is considered to be present at the base of the flame.

The main difference between a stoichiometric flame and a flame with an oxidizer deficit is the intense generation of a $\mathrm{C}_{3} \mathrm{H}_{3}{ }^{+}$[14], however, $\mathrm{CH}_{3} \mathrm{CO}^{+}$is the dominant ion for flames with strong air excess [61]. In the rich fuel mixture, hydrocarbon ions with a greater mass are formed from the main ions. Those ions are formed by increasing the hydrocarbon chain $\left(\mathrm{C}_{2 n} \mathrm{H}_{2 n+1}\right)$ or during the condensation processes $\left(\mathrm{C}_{2 \mathrm{n}} \mathrm{H}_{2 \mathrm{n}-1}\right)$ [61]. The hydrogen content in the molecule gradually decreases, and a polyaromatic structure is formed. As a result, such ions as $\mathrm{C}_{5} \mathrm{H}_{3}{ }^{+}, \mathrm{C}_{13} \mathrm{H}_{9}{ }^{+}, \mathrm{C}_{21} \mathrm{H}_{11}{ }^{+}, \mathrm{C}_{33} \mathrm{H}_{15}{ }^{+}$, and other polyaromatic ions $\left(\mathrm{PAH}^{+}\right)$are formed [62]. In a rich fuel mixture ( $\alpha$ less than 0.4 ) ions with high molecular weight $\left(\mathrm{PAH}^{+}\right)$replace all oxidized hydrocarbon ions [61]. When biomass is burned, a lot of soot and fly ash particles are emitted into a flame flow. In a flame with a high soot content, soot particles can be charged positively or negatively, regarding the charge transfer from positive/negative ions or electrons, respectively [63]. On the other hand, soot particles themselves can also serve as charge carriers. Nevertheless, the current of a soot-forming flame is much lower compared to a stoichiometric flame [64]. More about the mechanisms and kinetics of the flame reaction and the ion formation read in Sections 1.2 and 1.4 of the Thesis.

\subsection{Swirling flame structure}

Swirling flows are used to improve the biomass combustion processes, where the primary air flow is fed axially below the pellet bed to mix air with the products of the biomass thermal decomposition, and the vortex flow of the secondary air is fed tangentially to the walls of the combustion chamber to control and reduce harmful pollutant emissions. The swirling flow more efficiently mixes the components of the fuel and improves combustion characteristics [65].

Within the framework of the Thesis, for a specified configuration of the experimental setup, a symmetric-cylindrical converging vortex flow, with the swirl number $S$ of $\approx 0.6-0.9$, was used. The secondary airflow is supplied azimuthally, with an inlet angle ( $\measuredangle \theta$ inlet) of $40^{\circ}$, to the base of the flame. Such a flow has a pronounced contraction (Fig. $1-\mathrm{h}$ ) at the base of the flame with a slight expansion (Fig. 1 - j) towards the central part of the flame [66], [67]. As the combustion zone forms, the azimuthal flow velocity gradually decreases, forming a flame front cone.

A swirling flame flow is characterized by a special distribution of axial, azimuthal, radial velocity, and other vortex parameters in cylindrical coordinates. The flame swirl is characterized 
by a wide radial boundary layer, where the fuel mixture is thermally processed and premixed with a secondary, centrally directed airflow $\left(z \leftarrow 0\right.$ and $\left.u_{r} \approx \max \right)$ [10].

The formation of such a flow is characterized by a laminar flame core with a high content of combustible volatile substances in the central part of the flame $\left(r / r_{0} \leftarrow 0\right)$, where the azimuthal component of the velocity is minimal ( $\left.u_{\theta} \approx \min \right)$, but the axial component of the velocity, on the contrary, reaches its maximum value $\left(u_{\mathrm{z}} \approx \max \right)$. The vorticity of the swirling flow reaches its maximum value in the outer part of the flame, where the azimuthal component of the velocity increases to its maximum value [10].

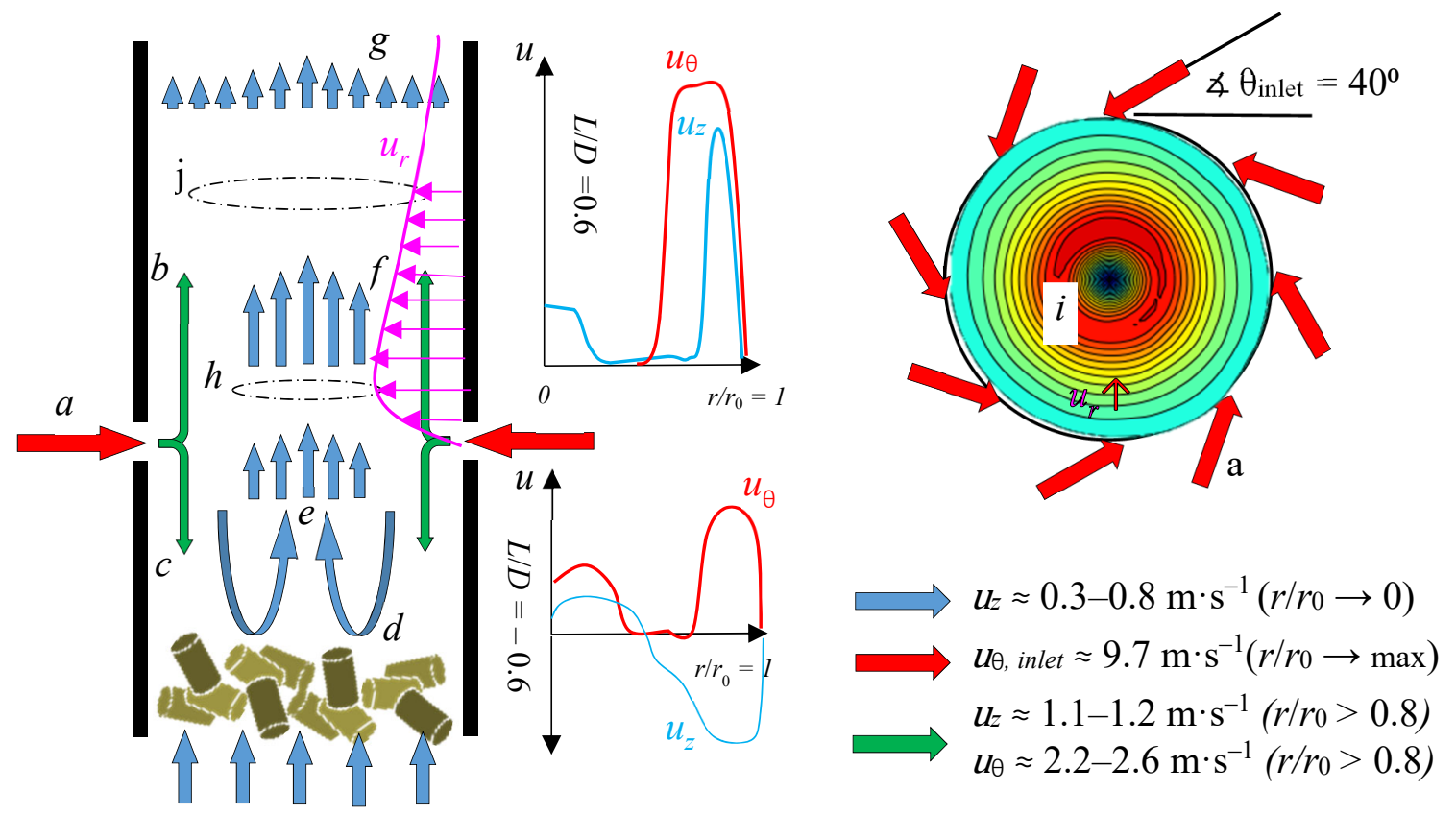

Fig. 1. Schematic of swirling flow formation in the experimental setup.

Previous studies on simulating the dynamics of swirling flow formation in a cylindrical channel led to the conclusion that the supply of a secondary air vortex at the base of the combustion zone (Fig. 1 - a) causes the secondary airflow to split with the formation of upward (b) and downward (c) air vortices along the combustion chamber wall. The downward vortex moves to the surface of the pellet bed (d) along the wall of the combustion chamber, creating a counterflow to the axial flow of products of biomass thermal decomposition, thus enhancing the mixing of combustible volatiles and the air vortex, but also gradually reducing the intensity of the downward vortex flow (e). Having reached the biomass layer, the downward vortex flow is reflected from the surface of the pellet bed with an increase in the axial velocity in the central part of the flow (f), where flow laminarization and the formation of an intense combustion process are observed [13]. The vorticity of the flow in the cylindrical configuration of the combustion chamber reaches its maximum value at $r / r_{0} \approx 0.3$ and decreases towards the center of the flow (i), where the dynamics of the laminar 
combustion process $(\mathrm{e}-\mathrm{g})$ is formed [68]. More about the structure of the swirling flame read in Section 1.3 and Subsection 2.1.2 of the Thesis.

\subsection{Interaction of electric field with flame}

In modern studies about the interaction of a direct current electric field with a hydrocarbon flame, it is assumed that the field of low intensity $\left(E_{\varphi}<3 \mathrm{kV} \cdot \mathrm{cm}^{-1}\right)$ does not interfere with the flame propagation speed and combustion kinetics [69], since the energy of the electric field applied to the flame is negligible comparing to the heat released at combustion reactions in the flame front [17]. Changes in the geometry of the flame are more dependent on the action of the volume force generated in the electric field, which manipulates the charged particles formed as a result of the natural ionization of the hydrocarbon flame. When an electric field is generated in the space between two electrodes, located outside the flame, charged species are transferred from the flame to the electrode. The amount of individual mass transfer depends on the mobility and life of the particular charged species. The volumetric electric force is proportional to the field intensity $E_{\varphi}$, the charges species molar fraction $n_{ \pm}$and their charge $q_{ \pm}$. Moreover, the field intensity is proportional to the applied bias potential of the electrode [16]:

$$
\pm F_{\varphi}=q_{ \pm} E_{\varphi} n_{ \pm}=q_{ \pm}(-\operatorname{grad} \varphi) .
$$

Variations of the electric volume force, neglecting convection and diffusion, can be described by the equation of the ion current $j$, where $\mu_{ \pm}$is the ion mobility [16]:

$$
j=q_{ \pm} n_{ \pm} \mu_{ \pm} E_{\varphi}=\left[q_{ \pm} n_{ \pm} \mu_{ \pm}=\text {const }\right] \sim \Delta \varphi .
$$

The mobility of charged species affects the voltage distribution between the electrodes and the total current generated. The mobility of ions and other charged particles decreases as increases their size. Therefore, electrons have the highest mobility [70]. Higher mobility of particles raises the probability of their collision in space between electrodes, so the total number of particle collisions in an electric field increases. Despite this, the higher mobility of charged particles by itself cannot provide a more pronounced interaction between the electric field and the flame, since the smallest particles with the greatest mobility have a low collision area [71]. The $\mathrm{H}_{3} \mathrm{O}^{+}$and $\mathrm{C}_{3} \mathrm{H}_{3}{ }^{+}$ions, in turn, are capable of transferring a sufficiently large momentum during a collision, initiating the directed motion of neutral particles in the field [72].

The volumetric force generated by an electric field can be adjusted by varying the intensity of the applied field. With an increase in the electric field strength, the electric current, which is formed due to the recombination of charged species on the surface of the electrode, increases parabolically. By analyzing the Volt-Ampere curves, the maximum ionic current can be determined, which assists in adjusting the most effective area of electrode exposure to the flame. Within the limits of the electric field intensity up to $1 \mathrm{kV} \cdot \mathrm{cm}^{-1}$, the rate of formation of charged species is much higher than the rate of their recombination [72].

The mass transfer in the direction of the electric field, caused by the collision of charged and neutral particles, is called the "ionic wind" [16]. The ionic wind theory states that ions and electrons 
in a flame are accelerated in response to the Lorentz force generated by an external electric field. Charged particles are transferred in the direction of the field and undergo elastic collisions (without chemical transformations) with neutral molecules, causing their acceleration and mass transfer in the direction of the field [22]. It is generally accepted that the ionic wind in a flame is mainly caused by the directed motion of the $\mathrm{H}_{3} \mathrm{O}^{+}$ions accelerated by the action of an electric field. To calculate the maximum speed of the "ionic wind", it is assumed that all possible energy - both gravitational and electrical - is converted into kinetic energy. Then the resulting equation has the form (where $\Delta x_{ \pm}$is the distance between the positive and negative electrodes) [16]:

$$
u_{\text {elec }}=\sqrt{\frac{2 j \Delta x_{ \pm}}{\rho \mu_{ \pm}}} .
$$

The calculated theoretical maximum ionic wind velocity according to this formula reaches 0.8 $5.5 \mathrm{~m} \cdot \mathrm{s}^{-1}$ [16], [18], [73]. Oppositely charged ions, electrons, and other particles induce movement in reverse directions. In numerical calculations, the motion of oppositely charged particles is often not taken into account. Therefore, the experimental maximum value of the "ionic wind" is usually found below the theoretical value [17], [18].

The flame is an electrical system with spatially separated positive and negative charges [15], [61], therefore, the variations in flame parameters can be observed if an external electric field is applied: in a parallel field - the changes in flame length [21], [74], but in a perpendicular field the flame bend or expansion [22], [75]. The influence of the electric field on the flame flow is vectorial. Therefore, the direction of the action of the volumetric force of the electric field is very important. The electric field can improve the diffusion rate of charged species by accelerating the diffusion of ambipolar electrons in the fuel mixing zone, improving heat transfer during the fuel thermal preparation, and thus promoting the ignition of the air-fuel mixture [21]. The "ionic wind" generated by the electrical volumetric forces also improves convective heat transfer to the combustion chamber cooling surfaces [75], [76]. More information on the theoretical aspects of the effect of interaction between an electric field and a flame read in Section 1.5 of the Thesis.

\subsection{Analytical assessment of the effect of electric volume force}

The physical model for an applied low-intensity electric field is governed by the Euler equations, which were modified and described by M. Belhi et al. [19], [77]. The system of equations describes the behavior of the reaction flow in the presence of the action of electrodynamic force and includes the conservation of mass (eq. (4)), momentum (eq. (5)), total energy (eq. (6)), and species density (eq. (7)) following Poinsot and Veynante:

$$
\begin{gathered}
\frac{\partial \rho}{\partial t}+\nabla \cdot(\rho \vec{u})=0, \\
\frac{\partial \rho \vec{u}}{\partial t}+\nabla \cdot(\rho \vec{u} \otimes \vec{u}+p \boldsymbol{I}-\boldsymbol{\tau})=\rho \sum_{i}^{N} w_{i} \overrightarrow{\boldsymbol{F}}_{\boldsymbol{i}}, \\
\frac{\partial \rho H}{\partial t}+\nabla \cdot(\rho \vec{u} H+\overrightarrow{\boldsymbol{h}}-(\boldsymbol{\tau}-p \boldsymbol{I}) \cdot U)=-\sum_{i}^{N} H_{i} \dot{m}_{i}+\rho \sum_{i}^{N} w_{i} \overrightarrow{\boldsymbol{F}}_{\boldsymbol{\varphi}, \boldsymbol{i}} \cdot\left(\vec{u}+\overrightarrow{\boldsymbol{V}}_{\boldsymbol{D}, \boldsymbol{i}}\right), \\
\frac{\partial \rho w_{i}}{\partial t}+\nabla \cdot\left(\rho\left(\vec{u}+\overrightarrow{\boldsymbol{V}}_{\boldsymbol{D}, \boldsymbol{i}}\right) w_{i}\right)=M_{r, i} \dot{m}_{i} .
\end{gathered}
$$


The equations describe the time-dependent $(t)$ variations of density $\rho$, velocity $\vec{u}$, the total energy $H$ and the mass fraction $w_{i}$ of $i$-th reacting chemical substance (both neutral and charged). The pressure $p$ in this system of equations is calculated from the system state equation. $\vec{h}$ is the energy flux calculated from Fourier's law of heat transfer. $\tau$ and $I$ are the viscous stress and identity tensors, but $\vec{u} \otimes \vec{u}$ is the result of multiplying two vector space tensors. $M_{r, i}$ is the molar mass of the $i$-th chemical reactant, $\vec{V}_{D, i}$ is the diffusion rate, $\dot{m}_{i}$ is the molar source term of formation of the $i$ th chemical substance, and $H_{i}$ is the enthalpy of formation of the $i$-th chemical substance, while $\vec{F}_{\varphi, i}$ is the electric volume force, which acts on the $i$-th substance in the flow. The electrodynamic force is described by eq. (8), where $\vec{E}_{\varphi}$ is calculated by Gaussian law [72]:

$$
\begin{gathered}
\vec{F}_{\varphi, i}=\sum_{i}^{N} q_{ \pm, i} \vec{E}_{\varphi} n_{ \pm, i}, \\
\nabla \cdot \vec{E}_{\varphi}=-\nabla^{2} \varphi=\frac{\sum_{i} q_{ \pm, i} n_{ \pm, i}}{\varepsilon_{0}} .
\end{gathered}
$$

The diffusion rate $\vec{V}_{D, i}$ depends mostly on the charge of the particle, while, in the electric field, the variations in the diffusion rate influence the mass fraction variations of the $i$-th charged particle in time and space, according to eq. (7). For neutral species, the diffusion rate is described by Fick's law, moreover, charged particles must also comply with additional mass drift flux due to its specific electrical mobility $\mu_{ \pm, i}$ :

$$
\rho w_{i} \vec{V}_{D, i}=-\rho V_{D, i} \frac{M_{r, i}}{M} \nabla \chi_{ \pm, i}+q_{ \pm} \rho w_{i} \mu_{ \pm, i} \vec{E}_{\varphi}
$$

where $\chi_{ \pm, i}$ is the molar fraction of the $i$-th charged particle, and $V_{D, i}$ is its thermal diffusion coefficient expressed by $\lambda\left(\rho c_{p}\right)^{-1}$, where $\lambda$ is the thermal conductivity coefficient, $c_{p}$ is the isobaric heat capacity of the gas mixture, and $M$ is the molar mass of the gas mixture [77].

\section{CONSTRUCTION, TESTING METHODOLOGY AND VALIDATION OF EXPERIMENTAL EQUIPMENT}

The second chapter of the Thesis describes the main equipment, instrumentation and measurement methodology for both experimental research and a pilot setup for technology approbation. Experimental studies are divided into two main stages: the study of the EFDFD technology on a batch experimental setup of low power $(4 \mathrm{~kW})$ and the approbation of the technology on an industrial pellet burner (up to $20 \mathrm{~kW}$ ). Figure 2 shows a comprehensive scheme of the experimental research methodology for the electrodynamic control of the biomass combustion process with a description of the critical stages and the main constant input and variable output parameters. See the full instrumental scheme in Appendix 9 of the Thesis.

In the experimental work, a positively charged, axially inserted, wire-type nichrome ( $\mathrm{NiCr})$ electrode with an uninsulated length of $100 \mathrm{~mm}$ and a diameter of $3 \mathrm{~mm}$ was used. The value of the potential applied to the electrode was controlled in the range from 0.6 to $1.8 \pm 0.06 \mathrm{kV}$. The ion 
current was limited to $7 \mathrm{~mA}$ using $248 \mathrm{k} \Omega$ resistance, thus limiting the formation of a discharge in the space between the electrode and the charred pellet surface. To validate the difference of the potential, a voltmeter with a voltage measurement range of up to $3 \mathrm{kV}$ and a measuring device error of no more than $\pm 0.5 \%$ was used. The value of the applied voltage was the main controllable variable input parameter in the experiment. Experimental studies of the electrodynamic control of biomass combustion were carried out under the same controlled initial parameters (air flow rate, swirling flame flow structure, heat input $P_{\text {prop }}=0.86 \mathrm{~kW}$, cooling water flow rate, physical $/$ chemical characteristics, and mass of biomass pellet samples).

As a result of a preliminary experimental study of the aerodynamic regime in the combustion chamber, carried out at IPUL [78], it was established that to ensure combustion of pelletized biomass of different origin, the optimal regime of the air supply is $G_{z} / G_{\theta} \approx 30 / 401 \cdot \mathrm{min}^{-1}$, where $G_{z}$ is the primary air supply of $0.6 \mathrm{~g} \cdot \mathrm{s}^{-1}\left(\alpha_{z} \approx 0.4-0.5\right)$ provided throughout the pellet bed to support the process of thermal decomposition of biomass, and $G_{\theta}$ is the secondary swirling air, which was provided above the pellet bed at $0.8 \mathrm{~g} \cdot \mathrm{s}^{-1}\left(\alpha_{\theta} \approx 1.2-1.5\right)$ constant supply. Testo $6441 \mathrm{DN} 15$ flow meters (manufactured by Testo SE \& Co KGaA, Germany) were used to control and regulate an airflow with an accuracy of $\pm 3-4 \%$. The structure of the swirling flame flow was determined by measuring the local distributions of the flame flow velocity. The swirling flame formation process could be controlled and monitored online, observing the temperature of the combustion zone, the thermal power of the experimental setup, and also visually.

To ensure a uniform flow of cooling water, periodic control was carried out using a $1000 \mathrm{ml}$ graduated cylinder with a minimum graduation of $10 \mathrm{ml}$. The water flow rate in the setup was controlled by flow valves with a regulation accuracy of $\pm 1 \%$.

Initial information on the parameters characterizing biomass pellet samples of different origins (elemental composition, moisture/ash content, FTIR, LHV, DTG/DTA, thermal decomposition kinetics, the composition of pyrolysis products) was prepared in cooperation with the LIWC. Commercially available biomass pellets (wheat straw, softwood, bog peat) were used for the experimental studies. Wheat straw pellets were produced by "EkoGrans" Ltd. following EUBIONET 14961-6 standard. Wood pellets purchased from "Kurzemes granulas" Ltd. comply with the German "DINplus quality" standard and the European "ENplus A1 premium" standard. Peat pellets were purchased from "Zelta zeme" Ltd. (Līvāni peat factory), prepared from a mixture of excavation samples from different depths of the Skrebelu high bog. The main characteristics of the biomass samples remained constant for all the experiments.

The weight of discrete portions of pelletized biomass: straw $-440 \mathrm{~g}\left(\rho_{\text {layer }}=557 \mathrm{~kg} \cdot \mathrm{m}^{-3}\right)$, wood $-470 \mathrm{~g}\left(612 \mathrm{~kg} \cdot \mathrm{m}^{-3}\right)$, and peat $-500 \mathrm{~g}\left(690 \mathrm{~kg} \cdot \mathrm{m}^{-3}\right)$, were controlled to maintain the height of the pellets bed layer to the height of the propane feed in the gasifier. Heat $\left(P_{\text {prop }}=0.86 \pm 0.01 \mathrm{~kW}\right)$ from the propane flame was managed to initiate the process of thermal decomposition of pellets and ignition of the produced volatiles. The propane feed was finished after 400 seconds $(500 \mathrm{~s}$ for peat), when a balance was established between the thermal decomposition and ignition, thus a self- 
sustaining combustion process was established. Complete thermochemical transformation of a discrete portion of straw, wood, or peat pellets (on $4 \mathrm{~kW}$ setup) takes about 2900-3800 s.

To control the repeatability and the accuracy of the experiment results, various output parameters (of the flame and flow composition) were evaluated online: temperature, oxygen $\left(\mathrm{O}_{2}\right)$, and carbon monoxide (CO) fracture in the flue gas. After each experiment, the results were evaluated and compared with the previous ones, evaluating the repeatability of the processes. At least five iterations were performed to check the results of various output parameters (for example, changes in flow dynamics, changes in plant power, changes in the composition of devolatilization and combustion products, etc.). About 60 individual experiments were carried out, a huge amount of data was processed and analyzed. Data was recorded once per second using online recorders for each measurement, which were then collected and processed using professional software.

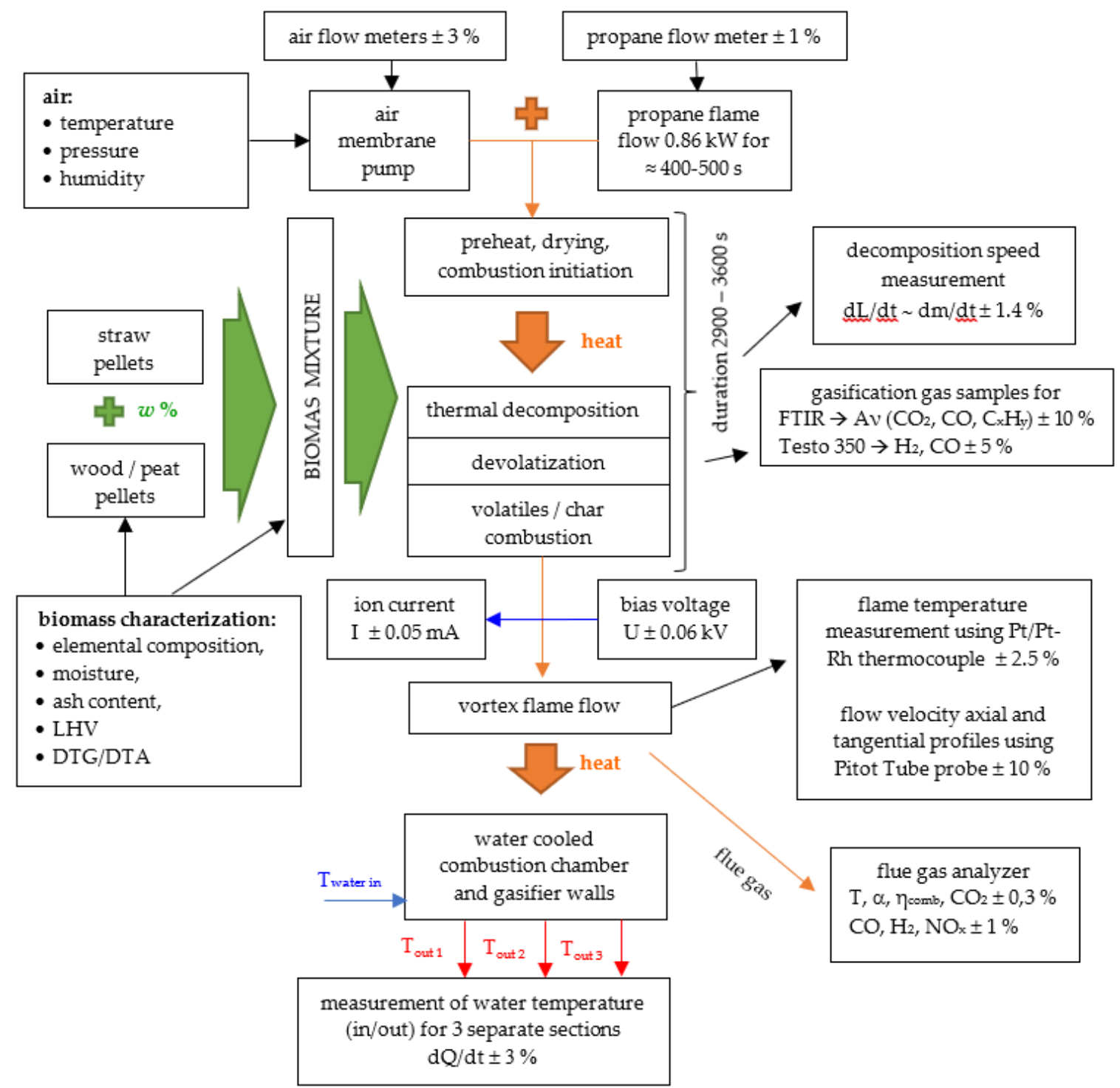

Fig. 2. Scheme of experimental research methodology. 
The measurements of the output parameters of the experiment were carried out considering the capabilities of the laboratory equipment of the IPUL. The used measurement methods can be divided into two groups - time-dependent measurements of flame parameters and averaged values of the measurements of local flow parameters.

Experimental studies of the effect of an electric field on the formation of the combustion process combine complex measurements of the components of the flame flow velocity $\left(u_{z}, u_{\theta}\right)$, flame temperature (T) and ion current distribution (I), the composition of the mixture of products of devolatilization ( $\left.\mathrm{CO}, \mathrm{H}_{2} \mathrm{C}_{2} \mathrm{H}_{2}, \mathrm{C}_{2} \mathrm{H}_{4}, \mathrm{CH}_{4}\right)$ and flue gas $\left(\mathrm{O}_{2}, \mathrm{CO}_{2}, \mathrm{CO}, \mathrm{H}_{2}, \mathrm{NO}_{x}\right)$, the rate of weight loss of pellet bed $\left(\mathrm{d} m / \mathrm{d} t, \mathrm{~g} \cdot \mathrm{s}^{-1}\right)$, the current flowing through the axial electrode, as well as the heat energy parameters of the combustion chamber.

\subsection{Description of the experimental setup and equipment}

The study of EFDFD technology on a batch unit (Fig. 3) includes: 1 - testing of the characteristics of biomass samples; 2 - the study of the process of thermal decomposition of pelletized biomass with a description of the combustion process without an electric field applied; 3 - the study of the electric field potential and flame current distribution; 4 - the study of the parameters of the swirling flame flow at the combustion of biomass, without and with an action of an external electric field; 5 - the study of variations in the processes of thermal decomposition, the formation of volatiles, the formation of emissions during combustion, the variations of heat power parameters with an external direct current electric field applied to the flame.

The experimental setup (Fig. 3) is a batch reactor with a total thermal power output of up to $4 \mathrm{~kW}$, where thermal decomposition of a discrete portion of pelletized biomass (aka gasification) is initiated and combustion of products of thermal decomposition is provided. The combustion chamber of the experimental setup is a sectional cylindrical channel with water cooling, an internal diameter $D=88 \mathrm{~mm}$, and a total length of $L_{\text {total }} \approx 750 \mathrm{~mm}$.

The main structural elements of the experimental setup are 1 - a cylindrical $140 \mathrm{~mm}$ long water-cooled, filled with biomass pellets, gasifier; 2 - propane burner designed to initiate the process of thermal decomposition and ignition of volatiles at the primary stage of biomass combustion; 3 - primary axial air supply $\left(G_{z}\right)$ to the lower part of the gasifier through a sieve with holes $\approx 2-3 \mathrm{~mm}$ to support thermal decomposition processes; 4 - secondary supply of swirling air $G_{\ominus}$ at the base of the combustion chamber through 8 tangentially directed nozzles with a diameter about $3.3 \mathrm{~mm}$ and an inlet angle $-40^{\circ} ; 5$ - two cylindrical sections of a water-cooled combustion chamber $250 \mathrm{~mm}$ each; 6 - axially symmetric $100 \mathrm{~mm}$ long nichrome electrode with $3 \mathrm{~mm}$ in diameter; 7 - diagnostic orifices for local measurements of flame parameters.

The position of the measurement instruments is determined by the $L / D$ factor, where $L$ is the position of the diagnostic orifice in relation to the secondary air supply nozzle, and $D$ is the inner diameter of the combustion chamber. More information on measurement tools and methodology is in Section 2.3. 


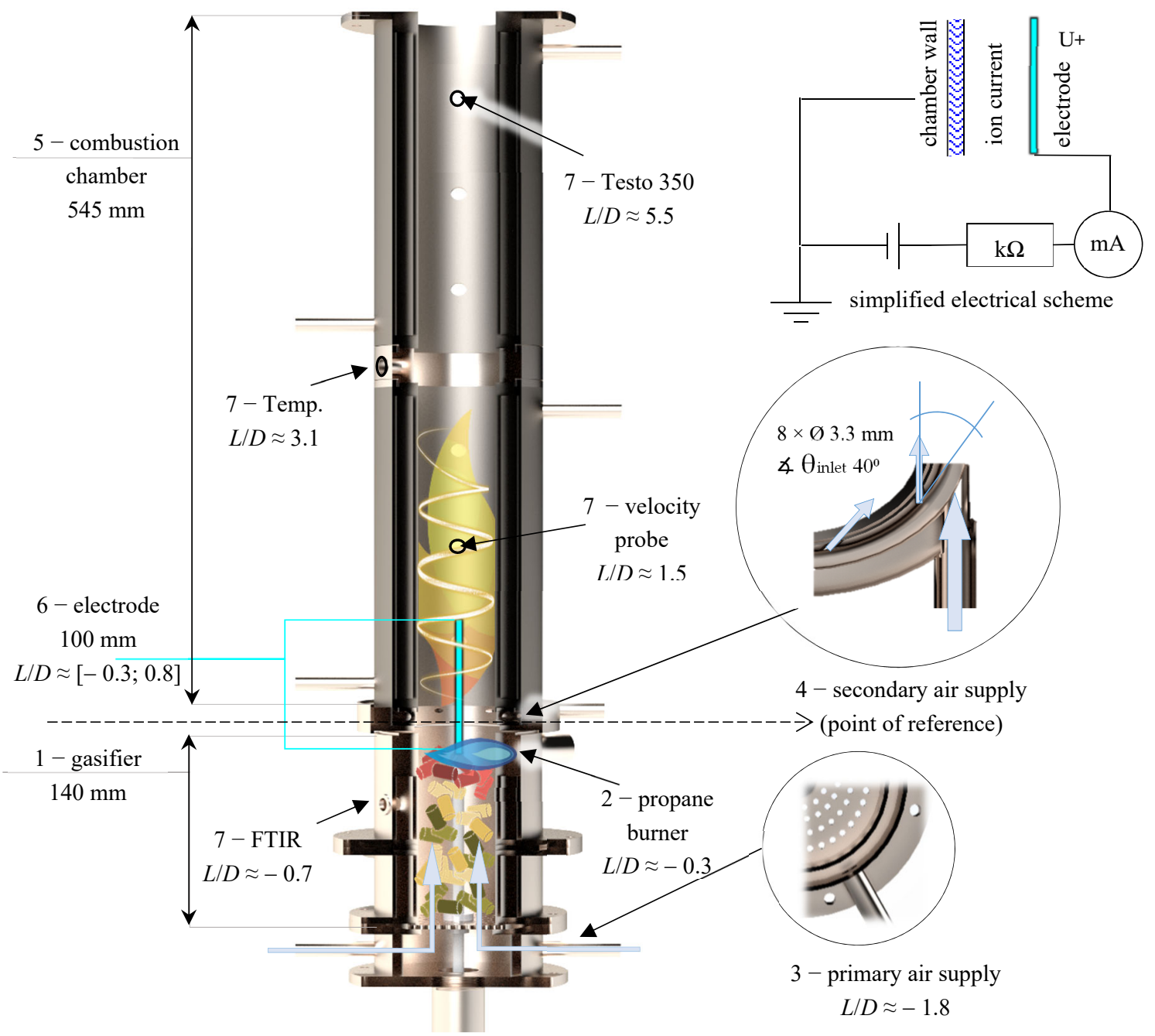

Fig. 3. 3D drawing of the experimental setup for technology development.

\subsection{Description of the equipment for approbation of technology prototype}

To approbate the electric field technology, a prototype boiler (Fig. 4) is developed based on a Peltech PV-20a burner $\left(P_{\max }=20 \mathrm{~kW}\right)$ with three water-cooled sections of the combustion chamber, ensuring the supply of biomass pellets to the burner at average speed $0.85-1.1 \mathrm{~g} \cdot \mathrm{s}^{-1}$.

The technological equipment consists of a pellet burner (Fig. 4-1) and a pilot setup boiler, which consists of a horizontal (Ø $150 \mathrm{~mm}, L=660 \mathrm{~mm}$ ) combustion chamber (Fig. 4. - 2) and two vertical (Ø $260 \mathrm{~mm}, L=950 \mathrm{~mm}$ ) cooling sections of the boiler (Fig. $4-3$, 4). The chamber is equipped with diagnostic offices for local measurements of flow rate, temperature, and composition of the swirling flame (Fig. 4-5,6,7,8). Flow temperatures $\left(T_{1}\right.$ and $\left.T_{2}\right)$ were measured at offices 6 and 7 in the center of the combustion chamber. Pelletized biomass is fed to the burner from the pellet tank (Fig. 4-9) using a screw feeder (Fig. 4-10). The primary and secondary airflows are supplied to the burner by a fan (Fig. $4-11$ ). The primary air is introduced through the pellet screw feeder channel. The secondary airflow is supplied through azimuthal holes 
in the perforated panel of the burner, providing a swirling flow in the combustion chamber. The primary heating of biomass is carried out by a ten-heating element. The electrode is installed on the central axis of the horizontal chamber, in the 3rd office, located $240 \mathrm{~mm}$ from the burner outlet. The effective length of the bare electrode surface towards the outlet of the burner is $60 \mathrm{~mm}$. The water cooling of the sections is carried out separately for the horizontal section and the vertical sections together. The water supply to the horizontal $\left(10 \mathrm{ml} \cdot \mathrm{s}^{-1}\right.$ at about $\left.300 \mathrm{~K}\right)$ and vertical chambers (4 ml. $\mathrm{s}^{-1}$ and $\left.3 \mathrm{ml} \cdot \mathrm{s}^{-1}\right)$ was regulated through feedwater valves. Calorimetric measurements of water are carried out on the feedwater and at the outlet from the horizontal and vertical sections separately.

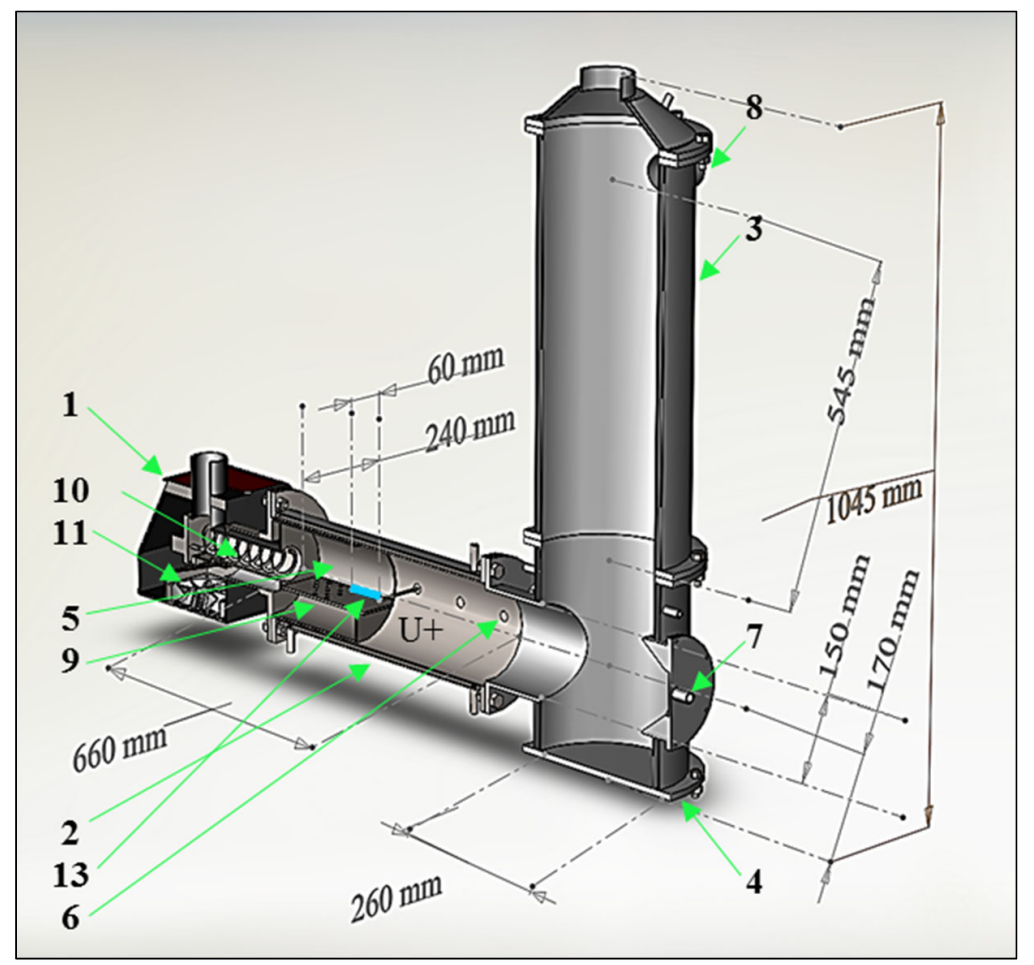

Fig. 4. 3D drawing of the setup for the approbation of the technology.

\subsection{Measurement methodology and tools}

Vario Macro apparatus (ELEMENTAR Analysensysteme, Germany) was used to measure the elemental composition of straw, wood, and peat according to the LVS EN 15104: 2011 standard. The ash content was determined by heating the sample in an ELF 11/6B oven (Carbolite Gero Ltd., United Kingdom) at 830 $10 \mathrm{~K}$, according to the LVS EN 14775:2010 method. HHV and LHV were calculated using the Friedl regression equation [8]. Biomass DTG/DTA analysis was performed in an oxidizing atmosphere at $50 \mathrm{ml} \cdot \mathrm{min}^{-1}$ airflows, $10 \pm 0.3 \mathrm{~K} \cdot \mathrm{min}^{-1}$ heating mode, in the 300-900 K temperature range using Star System TGA/SDTA 851e (Mettler Toledo AG, Switzerland). Both thermogravimetry and combined pyrolysis ( $770 \mathrm{~K})$ gas chromatography/mass spectrometry (PY-2020iD/AS1020E; manufacturer - Frontier Laboratories Ltd., United Kingdom) 
were used to determine the volatile matter and char phase amount, as well as for the analysis of the products of lignocellulose pyrolysis. $2 \mathrm{mg}$ biomass sample encapsulated in $\mathrm{KBr}$ tablet was used for FTIR analysis on a Spectrum One (Perkin Elmer Ltd., UK) in the $4000-400 \mathrm{~cm}^{-1}$ range.

Local measurements of flame and flow parameters have been performed using a micromanipulator $( \pm 1 \mathrm{~mm})$, which allows diagnostic tools (thermocouples, velocity probes, or gas sampling probes) to be moved radially in the combustion chamber. Local measurements of the flow velocity components were performed using a Pitot probe and Testo 435 (Testo SE \& Co KGaA, Germany) with a measurement error of up to $\pm 10 \%$. To reduce the measurement methodology error, 20 signals were processed with $1 \mathrm{~s}$ step to determine the value of one time-averaged measurement. The measurement of velocity components and signal registration during the experiment is performed when a self-sustaining stage of the combustion process is achieved.

S-type thermocouples (Pt/Pt-Rh) with a $[273 ; 1723] \mathrm{K}$ measurement range and a standard $\pm 1.5 \mathrm{~K}$ measurement error were used to measure the flame temperature. The error of the method for measuring the temperature distribution with an average temperature fluctuation of $20 \mathrm{~K}$ is about $\pm 2.5 \%$. The distribution measurements were carried out similarly to the methodology of measuring flow velocity component distribution.

An analog amperemeter with an accuracy of $\pm 0.005 \mathrm{~mA}$ at $[0.005 ; 0.75] \mathrm{mA}( \pm 0.05 \mathrm{~mA}$ at $[0.5 ; 7.5] \mathrm{mA}$ ) range was used to measure current, with a maximum measurement error $\pm 6 \%$. Data were recorded manually throughout the experiment with $50 \mathrm{~s}$ steps, thus calculating the average current over time. The Langmuir double probe method is used in the experiment to measure the radial and axial distribution of the total flame current (charges species flow) [75], [79]. The double probe consisted of two $\mathrm{NiCr}$ wires $(\varnothing 0.50 \mathrm{~mm}$ ) fixed in $\approx 4.5 \mathrm{~mm}$ distance between, which were then insulated using faience ceramic $\varnothing 2.90 \mathrm{~mm}$ tubes. The uninsulated part of the wires, which was $5 \mathrm{~mm}$ long, was placed parallel to the $z$-axis. A DC power supply was used to ensure the potential difference between the wires. The probe was placed in the center of the flame to capture the Volt-Ampere characteristics. By changing the power supply in the step of $0.06 \mathrm{kV}$ within $[0.30 ; 3.18] \mathrm{kV}$ range, the average current values were recorded. The average current value was averaged from the 5 ammeter readings recorded during the $20 \mathrm{~s}$ measurements. Regarding the data analysis of the Volt-Ampere curves, the current saturation ranged from $0.6 \mathrm{kV}$ to $1.6 \mathrm{kV}$ (bias voltage) was determined. $0.9 \mathrm{kV}$ voltage continued to be used for local flame current measurements. The flame current distribution at the specified length was measured by moving the probe with a micromanipulator ( $3 \mathrm{~mm}$ step) along the radius of the combustion chamber. At least 10 current signals were processed to determine the current distribution value at a point along the radius of the combustion chamber. Considering the average experimental value at current saturation $\approx 0.4 \mathrm{~mA}$ and the instrument error, the average measurement method error is $12 \%$.

FTIR method was used to determine the changes in the fractures of the products of biomass thermochemical decomposition at different stages of biomass combustion by measuring the variations in the absorption of these compounds in the mid-IR spectrum: $\mathrm{CO}_{2}\left(668 \mathrm{~cm}^{-1}\right), \mathrm{CO}$ $\left(2169 \mathrm{~cm}^{-1}\right.$ and $2115 \mathrm{~cm}^{-1}$ average), $\mathrm{C}_{2} \mathrm{H}_{2}-$ acetylene $\left(729 \mathrm{~cm}^{-1}\right), \mathrm{C}_{2} \mathrm{H}_{4}-$ ethylene $\left(949 \mathrm{~cm}^{-1}\right)$, 
$\mathrm{CH}_{4}$ - methane $\left(3017 \mathrm{~cm}^{-1}\right)$ and acids/aldehydes $\left(1758 \mathrm{~cm}^{-1}\right.$ and $\left.1733 \mathrm{~cm}^{-1}\right)$. A Varian Cary 640IR spectrometer (manufactured by Agilent Technologies Inc., USA) was used for measurements. Spectrometer settings provided signal intensity for an empty $225 \mathrm{ml}$ cuvette with two $\mathrm{KBr}(7 \mathrm{~mm}$ thick) windows about $6 \mathrm{Abs}$ to $6.5 \mathrm{Abs}$ (absorption in relative units). The lowest signal reading is about $0.05 \mathrm{Abs}$. The method error ranges from $3 \%$ to $11 \%$ for different compounds. Together with FTIR spectral analysis, $\mathrm{CO}$ and $\mathrm{H}_{2}$ concentrations $\left(\mathrm{g} \cdot \mathrm{cm}^{-3}\right)$ were also determined for samples of gas mixture sample from biomass thermal decomposition, using the Testo 350 gas analyzer.

A Testo 350 gas analyzer (Testo SE \& Co. KGaA, Germany) was used for the measurements of local temperature $T\left({ }^{\circ} \mathrm{C}\right)$ and composition $\left(\mathrm{O}_{2} \%, \mathrm{CO}_{2} \%, \mathrm{CO} \mathrm{ppm}, \mathrm{NO} \mathrm{ppm}, \mathrm{NO}_{2} \mathrm{ppm}\right.$, $\mathrm{NO}_{x}$ ppm, $\left.\mathrm{H}_{2} \mathrm{ppm}\right)$ of the flue gas, as well as air excess coefficient $(\alpha)$, combustion process efficiency $\left(\eta_{\text {comb }}, \%\right.$ ) and heat loss $Q_{\text {loss. }}$ The gas analyzer continuously measures the composition of the combustion products. $\mathrm{CO}_{2}$ detection limits is $[0 ; 50] \%$ and a measurement error is $\pm 0.3 \%$. $\mathrm{O}_{2}$ detection $[0 ; 25] \%$ limit achieved with $\pm 0.8 \%$ accuracy. The accuracy of $\mathrm{CO}$ and $\mathrm{H}_{2}$ is $\pm 10 \mathrm{ppm}$, however, within [0;500] ppm range the accuracy is $\pm 2 \mathrm{ppm}$. The accuracy of the $\mathrm{NO}_{x}$ $\left(\mathrm{NO}+\mathrm{NO}_{2}\right)$ determination is $\pm 5 \mathrm{ppm}$. The parameters were analyzed online during the process and compared regarding their averaged values, taking into account the correction for the response time of the measuring cells and evaluating the standard deviations of the signal. Testo 350 records one signal in $1 \mathrm{~s}$ step, so 30 signals could be collected to determine the radial distribution of the flow parameters. It is possible to record two distributions within the duration of one experiment.

Calorimetric measurements of cooling water were used to study the variations of the heat parameters (power and the total heat) of the setup at different stages of biomass thermochemical transformation. The heat power measurement method was reduced to measure the flow and temperature variations of the cooling water in the gasifier and combustion chamber sections. On average, water flow was regulated for gasifier about $12-15 \mathrm{ml} \cdot \mathrm{s}^{-1}$ (depending on pellet type) with inlet temperature about $289 \mathrm{~K}$, for the first section of combustion chamber $\approx 15 \mathrm{ml} \cdot \mathrm{s}^{-1}(\approx 295 \mathrm{~K})$, for the second section $\approx 14 \mathrm{ml} \cdot \mathrm{s}^{-1}(300 \mathrm{~K})$. Heat flow sensors AD590KF (OMEGA Engineering Inc., USA) with [218; 423] K temperature measurement limit were used for water flow temperature measurements (standard error $\pm 0.1 \mathrm{~K}$ ) at the inlet and outlet of each section. Signal registering and recording was performed online by calculating the mean of 10 signals of the thermal sensor in 1 second, thus reducing the signal-to-noise value. The calibration error is $\pm 3 \%$.

To determine the rate of thermal decomposition of the pelletized biomass, the variations in the height of the pellet bed in the gasifier were measured using a free-falling ceramic pointing rod. Considering the density of the pellet layer bed, and taking into account the frequency of measurements, the error of the methodology for determining the relative rate of thermal decomposition is $\pm 14 \%$.

The described tools were used in both $4 \mathrm{~kW}$ and $20 \mathrm{~kW}$ devices, however, there are slight differences in the number of simultaneously studied parameters, as well as in the methodology of the experiment. Due to the reduction in the volume of the description of the methodology for 
measuring the experiment in the summary of the Thesis, the description of measurements from the $4 \mathrm{~kW}$ device was taken as a basis. For more information on measurement tools, methodologies, accuracy, and repeatability read Section 2.2. of the Thesis.

\section{EXPERIMENTAL STUDIES OF HEAT PROCESSES}

The third chapter of the summary combines theoretical knowledge obtained by analyzing the technical and scientific literature and the results of the experimental study obtained during the research in order to examine the impact of external electric forces on the parameters of combustion of volatile products of biomass thermal decomposition.

\subsection{Characterization of straw, wood biomass, and peat samples}

The analysis of the characteristic properties of the biomass samples used in the experiment is given in Table 1. According to the DTG/DTA results (5. fig.), it was concluded that the thermal decomposition of wheat straw started faster (at $470 \mathrm{~K}$ ) than woody biomass and peat samples, due to its different structure of hemicellulose, which contains a xylan. The most intensive thermal decomposition maximum $\left(\approx 65 \mu \mathrm{g} \cdot \mathrm{s}^{-1}\right)$ is observed for softwood, which is determined by the high content of volatile substances in biomass.

Table 2

\section{Characteristics of pellet samples}

\begin{tabular}{|c|c|c|c|}
\hline & Wheat straw & Softwood & Bog peat \\
\hline Pellet diameter ${ }^{* *}, \mathbf{m m}$ & 8.1 & 6.15 & 7.8 \\
\hline Pellet density, $\mathrm{kg} \cdot \mathrm{m}^{-3}$ & $(550)$ & $(650-670)$ & $(780)$ \\
\hline Moisture content, $w \%$ & $9.11(9.6-10.6)$ & $6.32(5.6)$ & $11.44(8.3-11.3)$ \\
\hline Ash content * \% & $4.26(4.3-6.2)$ & $0.64(0.33-0.35)$ & $3.02(3.0)$ \\
\hline Ash melting point $T, \mathrm{~K}$ & $1073-1573$ & 1743 & 1455 \\
\hline Low Heating Value, MJ $\cdot \mathrm{kg}^{-1}$ & $15.52(15.3-15.65)$ & $16.61(18.11)$ & $17.24(17.4-18.55)$ \\
\hline $\mathrm{C}^{*}, \%$ & 46.62 & 49.79 & 53.83 \\
\hline $\mathrm{H}^{*}, \%$ & 5.09 & 5.15 & 5.12 \\
\hline $\mathrm{O}^{*}, \%$ & 42.72 & 44.24 & 36.93 \\
\hline $\mathrm{N} * \%$ & $1.31(2.35)$ & $0.18(0.05$ & $1.11(1.14)$ \\
\hline $\mathrm{S}, \%$ & $(0.11)$ & $(0.01)$ & $(<0.3)$ \\
\hline Volatile mfiger (pyrolysis), \% & $\approx 68 \%$ & $\approx 83 \%(81.01)$ & $\approx 57 \%$ \\
\hline Volatile mfiger (DTG), \% & $60.6 \%$ & $66.6 \%$ & $48.4 \%$ \\
\hline Char (DTG), \% & $26.4 \%$ & $25.7 \%$ & $39.7 \%$ \\
\hline Carbohydrates & $77.2 \pm 1.1$ & $78.4 \pm 1.1$ & $73.3 \pm 1.1$ \\
\hline Polyphenols & $21.5 \pm 0.4$ & $20.9 \pm 0.3$ & $16.5 \pm 0.4$ \\
\hline Lipids & $1.3 \pm 0.1$ & $0.6 \pm 0.1$ & $10.4 \pm 0.2$ \\
\hline Pellet Layer Density $* *, \mathrm{~kg} \cdot \mathrm{m}^{-3}$ & 557 & 612 & 690 \\
\hline Layer relative surface ${ }^{* *}, \mathrm{~m}^{2} \cdot \mathrm{kg}^{-1}$ & 0.66 & 0.69 & 0.51 \\
\hline
\end{tabular}


(...) - encapsulated manufacturer data; * - by dry weight; ** - measured by the method available at [80].

However, both woody and straw biomass samples produce a similar exothermic effect during their primary decomposition stage of combustion. Due to the low content of holocellulose and high content of heterocyclic aromatic compounds in peat samples, the process of thermal decomposition is shifted to higher temperatures where mostly the oxidation of the solid charred phase takes place.

The secondary stages of thermal decomposition of the experimental samples differ due to the diverse chemical composition of the biomass samples of different origins, which also determines the contrast in the amount of charred phase. It should be noted that the characteristics of the second decomposition stage of wheat straw are close to those of secondary decomposition of other tested pellet samples, suggesting that the biomass structure of charred straw has similarities to that of charred wood and peat.

However, the two secondary decomposition peaks of straw biomass are less intense compared to those of wood biomass and peat. Variations in primary weight loss for different biomass samples are related to the variations of the content of volatile matter and variations of the structure of their carbohydrates. A comparison of the amount of volatile matter, determined by various analytical methods, suggests that these differences indicate that only part of the carbohydrate mass is converted to volatile substances, but about $15 \%$ of hemicelluloses and cellulose mass remains in the solid phase, which together with the solid products of thermal decomposition of lignin forms biomass char.
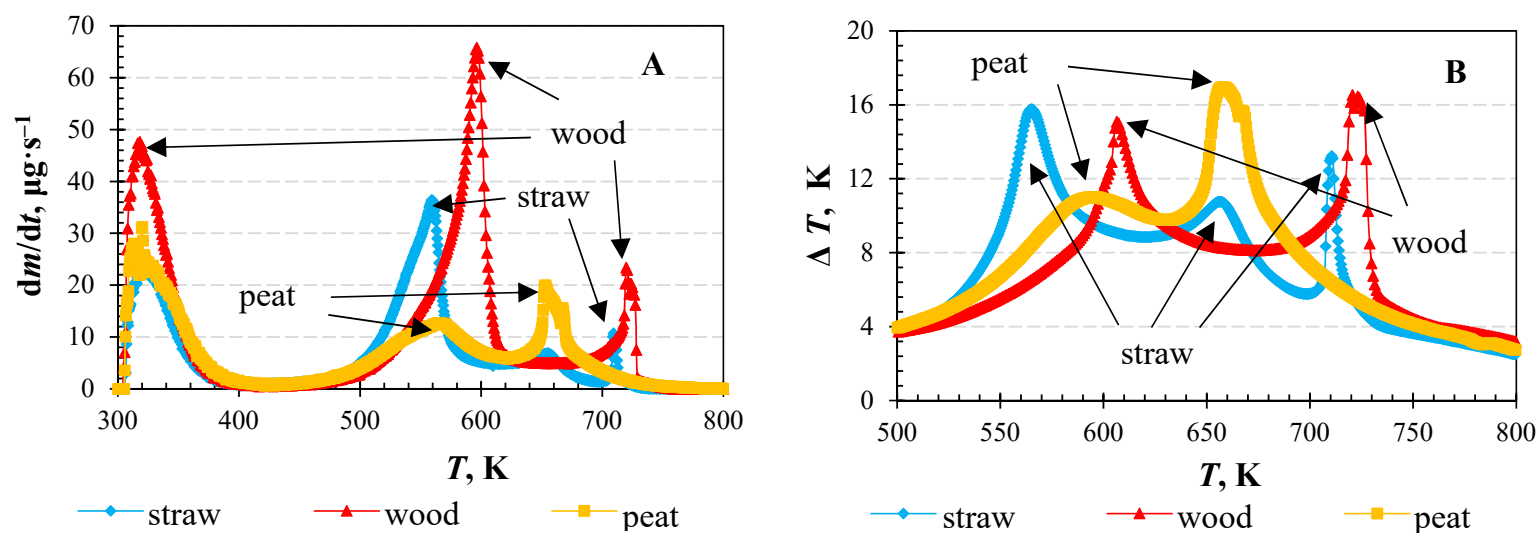

Fig. 5. DTG/DTA curves of biomass samples used in the experimental study.

\subsection{Pelletized biomass combustion process without an electric field applied}

In the experimental setup, the combustion of biomass causes a time-dependent uniform decrease of the height of the biomass layer, which makes it possible to analyze the development of various stages of combustion process (flame swirl formation, combustion of volatile substances, and char combustion stage). The combustion of pelletized biomass in the experimental setup takes place with the formation of various stages at different periods. In the period up to $400-500 \mathrm{~s}$, the additional heat is supplied to the surface of the biomass pellet bed, and, up to 700-900 s, the biomass drying takes place (Fig. $6-$ e). The development of endothermic and exothermic processes 
of biomass thermal decomposition (Fig. $6-$ d) takes place after. The intensive release and ignition of volatile substances determine the primary stage of flame swirl formation (Fig. 6-A).

According to heat power measurements (Fig. $7-\mathrm{B}, \mathrm{C}$ ), the formation of a self-sustaining combustion process is observed for woody and straw biomass after 800-900 s and for peat after 900-1000 s, when the exothermic heat effect of thermochemical transformations of volatile substances balances biomass heating, drying and endothermic processes of holocellulose thermal decomposition. The self-sustaining combustion process of straw and wood pellets continues until $2200-2300 \mathrm{~s}$, but for peat, it lasts up to $\approx 3200 \mathrm{~s}$. The self-sustaining combustion process includes two different combustion stages, which differ visually and according to the composition of the flame species. At the beginning of the self-sustaining stage, a sooting flame appears, which has a red-yellow color [81]: up to $\approx 1700-1800 \mathrm{~s}$ for straw/wood and up to $\approx 2000-2200 \mathrm{~s}$ for peat (Fig. 6 -B). Further (Fig. 6-C) the formation of a bluish-purple flame is observed. The combined measurements of IR spectra of volatile matter composition and mass loss rate of biomass thermal decomposition clarified the stages of biomass self-sustaining combustion process (see Section 3.2 of the Thesis) and confirmed that the flame color changes with a decrease in $\mathrm{C}_{2} \mathrm{H}_{2}$ in the flow.

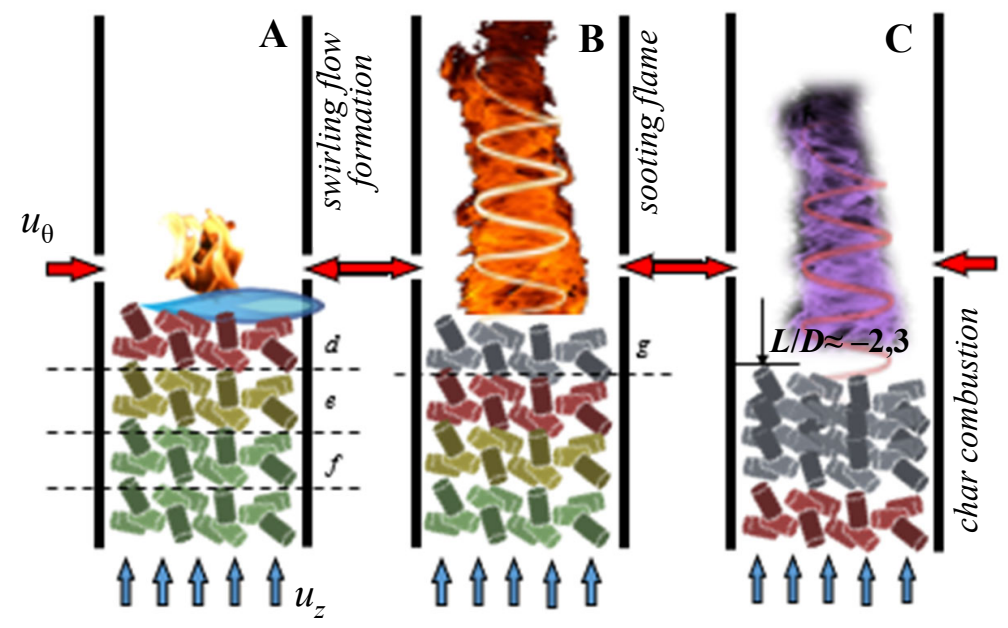

Fig. 6. Pellet combustion process development in the experimental setup.

During the wood combustion process, after $2100-3000 \mathrm{~s}$, the fracture of $\mathrm{C}_{2} \mathrm{H}_{2}, \mathrm{CH}_{4}$ and $\mathrm{CO}$ in the flow decrease to almost zero value, which coincides with the end of the thermochemical conversion process of unreacted pellets. On the other hand, straw and peat continue to form $\mathrm{CH}_{4}$ and $\mathrm{CO}$ in the reaction zone as the combustion regime changes, indicating the presence of a bluishpurple flame. It has been found that peat and straw pellets form a layer of semi-reacted char at the top. For peat, this layer is formed due to slow thermal decomposition due to the high density of pellets and high content of aromatic hydrocarbons, but for straw, this layer is formed due to the high ash content and its specific thermal properties. There is a correlation between the formation of this ash/char layer on the unreacted pellet surface and the formation of a bluish-violet flame.

The self-sustaining biomass combustion process ends when the flame in the combustion chamber disappears and the heat flow in the gasifier achieves its maximum value (Fig. 7 - A), the 
formation of which is determined by direct heat transfer from the coal roasting reaction zone to the gasifier walls. The onset of the charcoal roasting process can be detected by the rapid reduction of the $\mathrm{CH}_{4}$ content in the flow of volatiles mixture. In turn, $\mathrm{CO}$ continues to form in the flue gas, causing intensive emissions of atmospheric pollutants after $\approx 2200 \mathrm{~s}$.

Although variations in the elemental and chemical composition of biomass lead to changes in the kinetics of the biomass combustion process, it is possible to draw the main features of the thermochemical transformation of straw, wood biomass, and peat. Intensive thermal decomposition of wood pellets is determined by the high content of volatile matter (Table 1), specific hemicellulose structure, and high LHV, which promotes faster balance between exothermic and endothermic processes, providing the highest $(\approx 450 \mathrm{~mm})$ and hottest (Fig. $7-\mathrm{B}, \mathrm{C})$ swirling flame in comparison with other biomass samples. Intensive heat exchange between the flame swirl and biomass pellets ensures enhanced release of volatiles (Fig. $8-\mathrm{A}$ ), but the lowest nitrogen content (Table 2) results in lower $\mathrm{NO}_{x}$ (Fig. $8-\mathrm{B}$ ) if compared to emissions from straw and peat pellets.
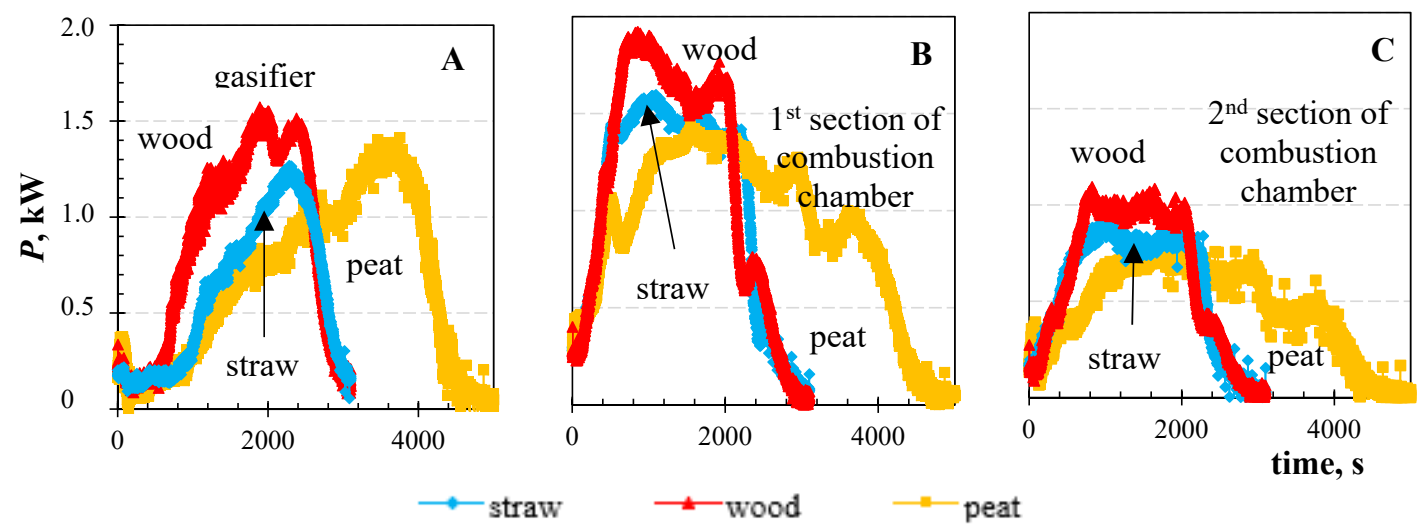

Fig. 7. Measurements of the power of the experimental setup.

The combustion process of wheat straw is characterized by the formation of a time-varying flame length (up to $\approx 250 \mathrm{~mm}$ ) due to the formation of a char-ash layer above the unreacted biomass layer, which gradually restricts air access to the reaction zone at the end of the self-sustaining process $(\approx 1700-2300 \mathrm{~s})$, thus cooling the char-ash surface and influencing the kinetics of flame formation. This characteristic of combustion causes problems at the roasting stage of straw char when the heat output in the gasifier decreases (Fig. $7-\mathrm{A}$ ), and a large amount of $\mathrm{CO}$ is found in the flue gas after $2400 \mathrm{~s}$ (Fig. $8-\mathrm{A}$ ). 

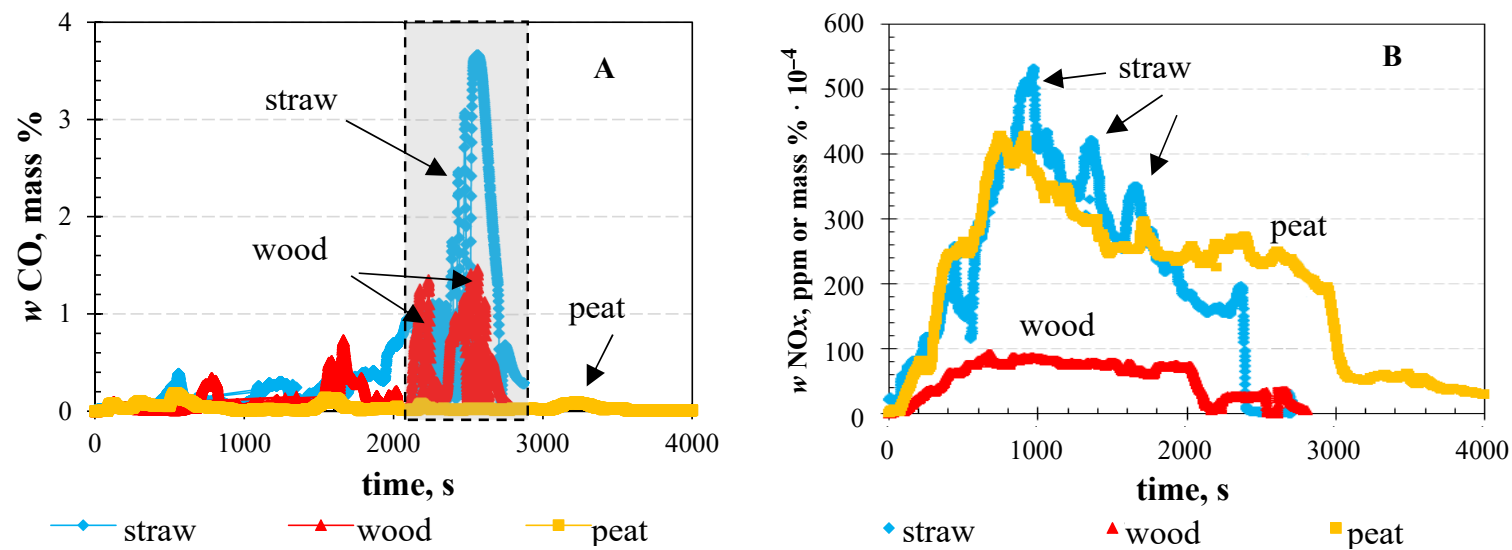

Fig. 8. Kinetics of $\mathrm{CO}(\mathrm{A})$ and $\mathrm{NO}_{x}(\mathrm{~B})$ emissions formation in the flue gas.

The thermal decomposition of peat is prolonged due to the relatively high density of peat pellets, the high moisture content, and the low volatile matter (Table 2), which causes difficulties during the formation of flame at the primary stage of biomass combustion. However, the combustion process of peat is more even, which is especially noticeable in the char combustion stage after $1500 \mathrm{~s}$. Unlike wood and straw, the peat combustion process is characterized by the shortest (up to $150 \mathrm{~mm}$ ) flame and prolonged roasting stage of charred pellets (Fig. $7-\mathrm{A}$ ), which is determined by the low volatile matter and high carbon content of peat pellets (Table 1).

\subsection{Experimental studies of flame current}

To make optimal improvement of the dynamics of biomass combustion using a direct current electric field, a feasibility study of ion current formation was performed to find the optimal size of the electrode and its location in the combustion chamber. To ensure the most effective electrical control of biomass combustion of different origins, it is necessary to place the electrode in the zone, where the ion current reaches its maximum value. In the process of combustion of biomass, the ionic current reaches a maximum value at the distance of 0 to $50 \mathrm{~mm}$ from the surface of the biomass pellet bed (Fig. $9-\mathrm{A}$ ). At this zone, in the $L / D \approx[-0.35 ;+0.2]$ flame area, thermochemical preparation of the air-fuel mixture takes place before its final ignition.

For experimental testing of EFDFD technology in a $4 \mathrm{~kW}$ device, the electrode length covering $L / D=[-0.30 ;+2.00]$ zone selected, thus providing an electric field at the flame length of intensive ion formation. A decrease in the ion current along the flame is associated with a decrease in the concentration of ion-forming hydrocarbon compounds in the combustion zone. It was experimentally proved that the formation of special flame kinetics during the combustion of straw has a lesser effect on ionic current than the relocation of the ion generating zone. The period before $1700 \mathrm{~s}$, at straw combustion, corresponds to the highest ion current, which is characterized by an increased content of $\mathrm{C}_{2} \mathrm{H}_{2}$ and $\mathrm{C}_{2} \mathrm{H}_{4}$ in the air-fuel mixture. 

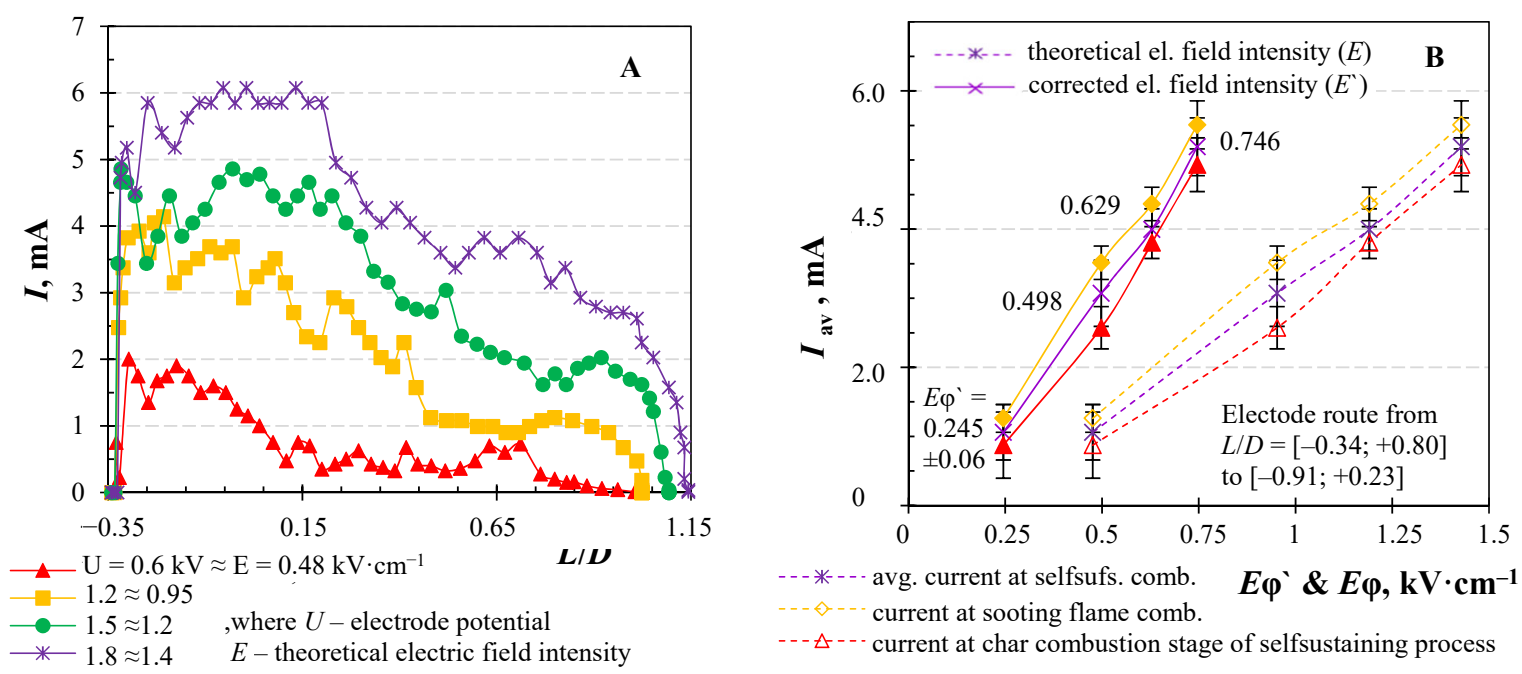

Fig. 9. A - Current variations in flame length during the straw burning process; $\mathrm{B}$ - a comparison of flame current values for theoretical and corrected electric field intensities.

The intensity of the electric field varies depending on the changes of the voltage drop in the Langmuir double layer and the electrical boundary layer, which in turn depends on ion-electron concentration at the boundary layer [82], [83]. As the concentration of electrons increases, the voltage drop at the boundary layer increases, thus reducing the intensity of the electric field in the combustion zone [72]. Figure $9 \mathrm{~B}$ shows the variations of flame current as a function of the corrected voltage value (eq. (12)) during the self-sustaining stage of straw biomass combustion compared to the theoretically calculated values of electric field intensity. To calculate the theoretical intensity of the electric field, equation (11) was used, where $U_{\varphi \text {,applied }}$ is the bias voltage provided to the central electrode by the power supply, but $\Delta x$ is the thickness of electrical boundary layer near the electrode surface, the formation of which is determined by ion-electron concentration and current dynamic pressure. The intensity of the electric field decreases with the increase of the distance from the positive electrode surface [82], [83]. Concerning the $4 \mathrm{~kW}$ experimental setup, the boundary layer with a maximum intensity of the electric field is suppressed at $\Delta x \approx 13 \mathrm{~mm}$ from the surface of the central electrode (within the range $r / r_{0}=[0 ; 0.3]$ ).

$$
\begin{gathered}
E_{\varphi}=\frac{U_{\varphi, \text { applied }}}{\Delta x} \\
E_{\varphi}{ }^{\prime}=E_{\varphi}-\frac{I_{\text {experimental }} \cdot R_{\Omega}}{\Delta x}
\end{gathered}
$$

During the studies of flow dynamics, it has been found, that for the given electrode configuration, the electric field effect is limited by the electrical conductivity of the environment, therefore, the average experimental ion current $I_{\text {exp }}$ (eq. (12)) has been used to calculate the electric field intensity (see Subsection 2.1.1 of the Thesis). The value of the applied electrode potential was corrected concerning the ohmic voltage (Fig. 9 - B). Respectively, the corrected electric field intensity in the combustion zone was regulated in the range from $0.25 \mathrm{kV} \cdot \mathrm{cm}^{-1}$ to $0.75 \mathrm{kV} \cdot \mathrm{cm}^{-1}$. 
Ion current statistics reported large scattering of average current values at different combustion stages due to instability caused by oscillation of the flame swirl, thermochemical transformations of the surface of the biomass pellets, the formation of the soot particles, generation of the fly ash (containing alkali metal), and also solid ash vitrification (at high temperatures) on the top of pellet bed, producing a current conductive solid surface along with a biomass char. The Volt-Ampere curves, which were taken in the most intensive ion-producing flame zone (at $L / D=0.15$ ), showed current saturation at about $2-3 \mathrm{kV} \cdot \mathrm{cm}^{-1}$. However, within the framework of this Thesis, current saturation was not achieved, because up to $50 \%$ of the applied voltage falls on the ohmic resistance, reducing the voltage drop in the combustion zone. Fortunately, a higher bias voltage of the electrode caused the current to breakdown.

\subsection{Effect of swirling flame flow expansion}

The air supply chosen in the experimental study promotes the mixing of fuel with air and the thermochemical decomposition of the biomass of various origins itself. Chosen air-supply determines the efficiency of the combustion process at $\eta_{\text {comb }} \approx 80-85 \%$ and stabilizes the combustion zone temperature in the central part of the flame. However, with this type of secondary air supply, an upward air vortex is formed (Fig. 1), where the part of azimuthal air flows unreacted along the walls of the combustion chamber, thus increasing the air excess $(\alpha)$ in the flue gas. This can be improved using the effects of an external electric field.

Measurements of the radial distribution of the axial $\left(u_{z}\right)$ and azimuthal $\left(u_{\theta}\right)$ velocities showed that more pronounced variations of the flow dynamics occur under the influence of the external electric field at $L / D \approx 1.5$ distance from the base of the combustion zone (Fig. $10-\mathrm{A}$ ).

In this flame zone, in the central part of the flow $r / r_{0}=[0 ; 0.3]$, as well as near the combustion chamber wall $r / r_{0}=[0.8 ; 1]$, a decrease in axial velocity is observed averagely by $50 \%$. The reduction of the azimuthal component of the flow rate, near the combustion chamber wall $r / r_{0}=[0.5 ; 1]$, is less pronounced and does not exceed $\approx 25 \%$. Considering the non-uniform variations of the components of flow velocities, an increase of the swirl number $S$ from 0.6 to $\approx 1.1$ is observed in the periphery of the flow. These variations are related to the changes in the radial $\left(u_{\mathrm{r}}\right)$ velocity distribution of the vortex. The measurement of the radial velocity at this design of the experimental setup is not possible. According to Lawton and Weinberg [16], the theoretical "ion wind" velocity values are calculated (Fig. $10-$ B). The calculated velocity of the "ion wind", close to the electrode, during the self-sustaining stage of combustion, can achieve $0.1 \mathrm{~m} \cdot \mathrm{s}^{-1}$, if the corrected field intensity is $E \varphi{ }^{`} \approx 0,75 \mathrm{kV} \cdot \mathrm{cm}^{-1}$. A stronger "ionic wind" can potentially be formed when the combustion process shifts from the sooting flame to the char combustion stage. 

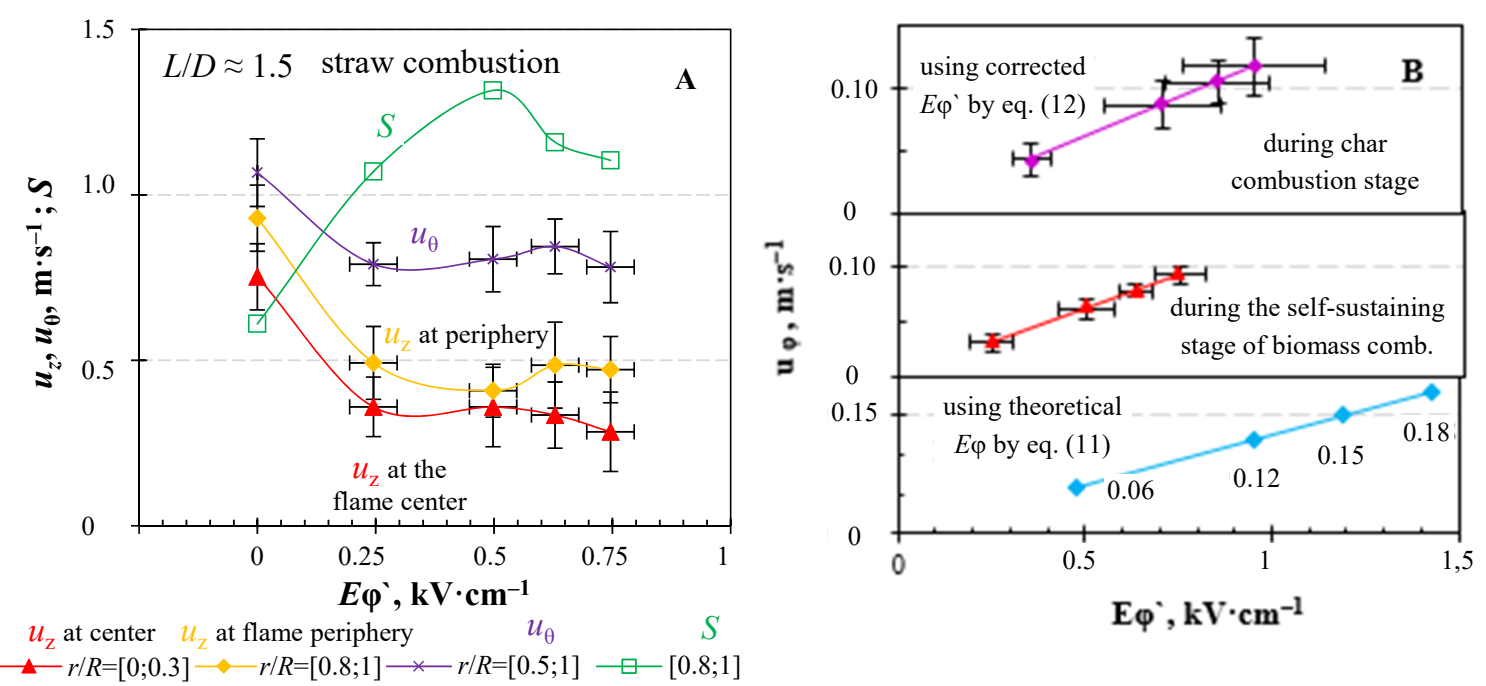

Fig. 10. A - Effect of the electric field on the variations of experimental values of average axial and azimuthal velocity components; B - the theoretically calculated "ion wind" velocity.

A detailed analysis of the field-flame interaction shows that the primary changes, caused by the action of volumetric force $\left(F_{\varphi}\right)$ of the external electrical field, can be attributed to the variations in flame flow dynamics (Fig. $10-$ A), determined by the flow continuity equations (eqs. (7) and $(10))$, which in turn cause the variations in the distribution of axial $\left(u_{z}\right)$, azimuthal $(u \theta)$ and radial $\left(u_{r}\right)$ velocities in the combustion zone, according to the law of impulse continuity (eq. (5)) and the Forthofer and Goodrick swirling flame formation equation [84]:

$$
\frac{\mathrm{d} \vec{\omega}}{\mathrm{d} t}=\underbrace{(\vec{\omega} \cdot \vec{\nabla}) \vec{u}-\vec{\omega}(\vec{\nabla} \cdot \vec{u})}_{\text {tilting and stretching }}+\underbrace{\frac{1}{\rho^{2}} \vec{\nabla} \rho \cdot \vec{\nabla} p}_{\text {Baroclinic }}+\underbrace{\vec{\nabla} \cdot \vec{F}}_{\text {Volume force }},
$$

The radial variations of the density gradient, which is formed by the influence of the electric volume force $\vec{\nabla} \cdot \overrightarrow{F_{\varphi}}$, cause the variation of the dynamic pressure in the flow $\frac{1}{\rho^{2}} \vec{\nabla} \rho \cdot \vec{\nabla} p$. Concerning the variations of the density gradient and the law of impulse continuity, the flow movement in the direction of the field is induced, thus increasing the flame swirl tilting $(\vec{\omega} \cdot \vec{\nabla}) \vec{u}$ and decreasing its stretching $\vec{\omega}(\vec{\nabla} \cdot \vec{u})$. Regarding the swirling flow properties, the field-induced mass transfer from the center to the direction of the wall of combustion chamber arouse, expanding the flame reaction zone and reducing the contraction effect in central flame part [85].

As a result of the action of the electric field force, the increase of the vorticity near the combustion chamber walls causes the pronounced mixing of the combustible volatiles with the swirling air flow. The improved mixing of an air and the products of biomass devolatilization promotes faster ignition of the fuel-air mixture, thus increasing the homogeneity of the flame vortex structure (Fig. $11-$ B). The decrease of the axial velocity component, both in the center of the flow and in the periphery of the combustion zone, causes a decrease in the length of the flame (Fig. $11-$ A). 

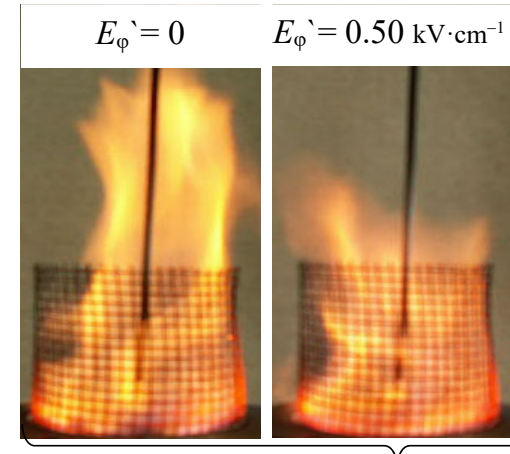

$\mathbf{A}^{2}$

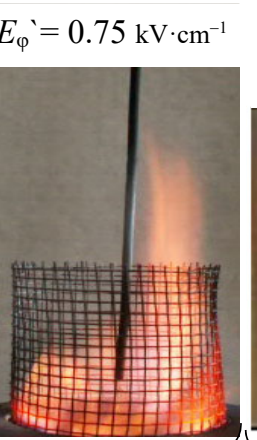

straw pellets combustion
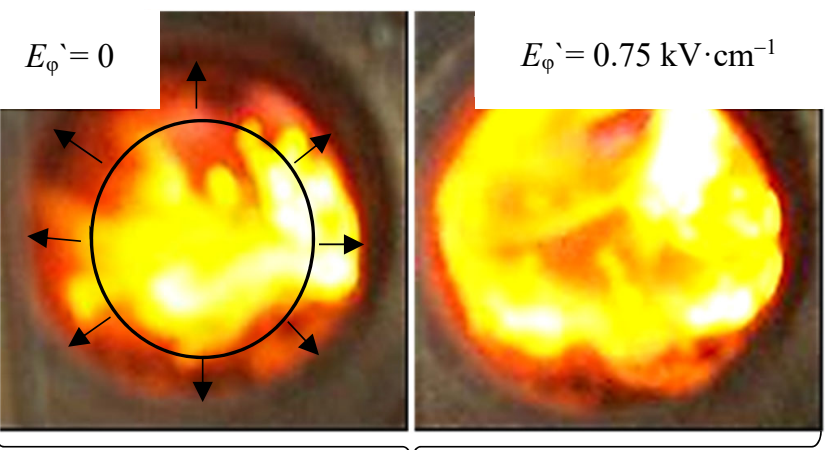

B

Fig. 11. A - Field-induced reduction of flame length and B - expansion of the combustion zone.

On the photos of the flame, a gradual stretching and expanding of flame can be noticed, which is determined by variations in the axial component of the swirling flame. This effect is envisaged considering the variations of the radial density gradient of the flame vortex (eq. (10)).

\subsection{Effect of flow temperature deviations}

Studies of the dynamics and structure variations of the swirling flame flow confirm the decrease of the upward vortex flow movement, which is determined by the increase of the amount of the downward vortex near the channel walls. Reverse flow generation near the chamber walls improves fuel-air mixing at the base of the combustor and ensures more complete burnout of the volatiles, which in turn, influences the temperature distribution of the combustion zone.

Measurements of the temperature kinetics of the granulated biomass combustion process, in the external electric field, at the base of the flame $(L / D=0.6)$, confirm a faster endothermic process of holocellulose decomposition, reducing the flow temperature at a time before $1000 \mathrm{~s}$ and slightly delaying flame formation. This temperature drop is determined by the temperature rise in the combustion zone at $L / D \approx 1.5$ (Fig. $12-\mathrm{A}$ ), where exothermic combustion processes prevail.

Due to the reduction of the axial flow rate, the residence time of the products of thermal decomposition of biomass increases, therefore shifting the maximum of the flame heat gradient closer to the surface of the biomass pellets. The expansion of the flame reaction zone is also observed in the electric field, which ensures a more even heat supply to the biomass layer and faster achievement of the self-sustaining stage of combustion. By intensifying the endothermic thermal decomposition biomass, a decrease in the average temperature values of the combustion zone is observed at the base of the flame vortex flow $(L / D=0.6)$ (Fig. $12-\mathrm{A})$. 

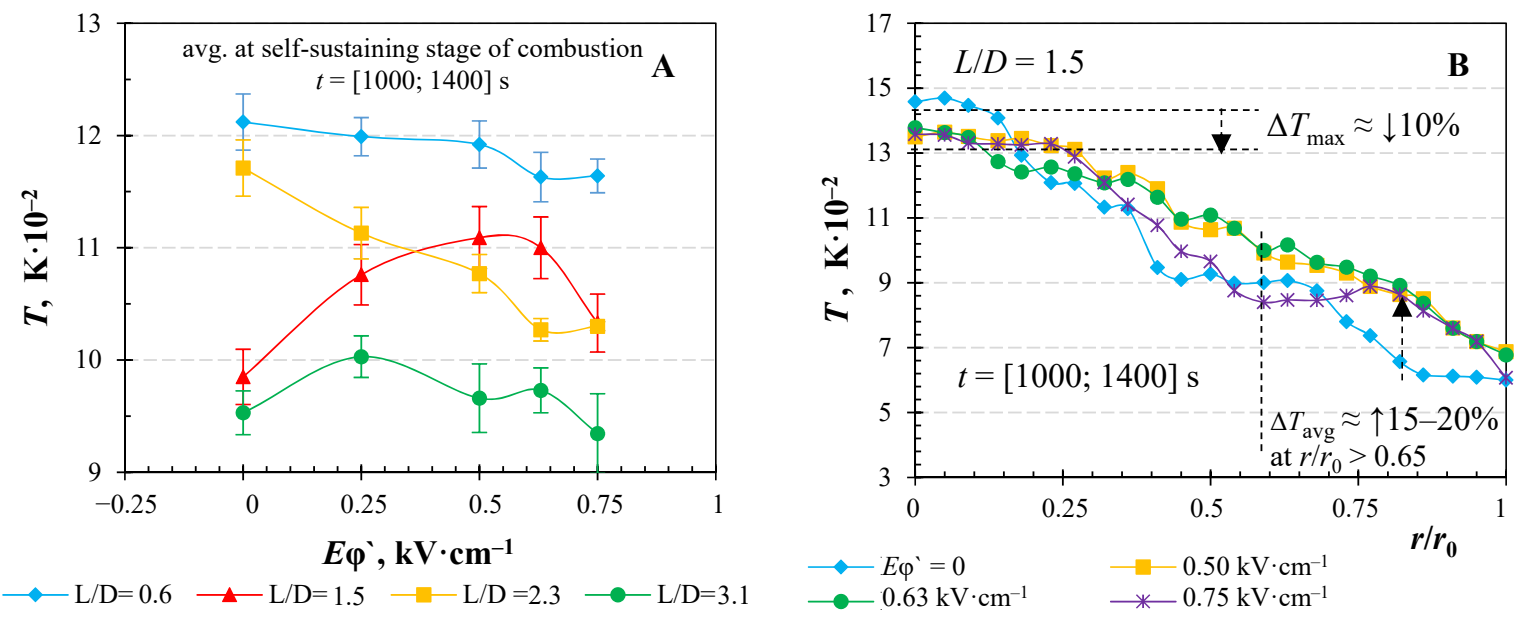

Fig. 12. A - Field-induced variations of the flame temperature kinetics in the center of the flame vortex; B - variations of flame vortex radial temperature distribution.

Although, as a result of the electric field action, an increase in the average temperature is observed in the central part of the swirling flame combustion zone $(L / D=1.5)$, a decrease in the average temperature is observed further along the flame length $(L / D>2.3)$ (Fig. $12-\mathrm{A})$, which is determined by the expansion of the reaction zone and the decrease of the flame length. The expansion of the swirling flame reaction zone in the electric field is also confirmed by the changes in the radial temperature distribution at $L / D=1.5$. The expansion of the flame causes a slight decrease in the maximum temperature values in the central part of the flame - at $r / r_{0}=[0 ; 0.2]$ on average by $\approx 10 \%$, but at $r / r_{0}>0.65$ causes a temperature increase by $15-20 \%$ (Fig. $12-$ B).

\subsection{Effect of biomass thermal decomposition intensification}

Summarizing the results of the study of the distribution of flow velocities and temperature variations of the flame, it has been found that using this swirl structure and electrode configuration the field-directed heat and mass transfer, induced by the electric field action, provoke the local variations of flow dynamics and flame temperature with subsequent changes in the rates of biomass thermal decomposition processes.

Analyzing the results of the complex study of the variations of the height of the biomass pellet layer and IR spectral analysis of the products of devolatilization, the intensification of the process of decomposition (Fig. 13 - A) and pronounced formation of volatiles is experimentally determined (Fig. $13-$ B). Calculating the average values of the variations in biomass weight loss in the electric field, it has been found that the largest increase in weight loss of wheat straw pellet (by $\approx 10 \%$ ) is observed at $E \varphi{ }^{`}=0.75 \mathrm{kV} \cdot \mathrm{cm}^{-1}$. In turn, increasing the voltage of the positively charged electrode, the increase of the thermal decomposition rate of woody biomass is $\approx 5 \%$ already after $E \varphi{ }^{`}=0.25 \mathrm{kV} \cdot \mathrm{cm}^{-1}$. The increase in the rate of peat pellet thermal decomposition is not uniform, however, at $E \varphi{ }^{`}=0.75 \mathrm{kV} \cdot \mathrm{cm}^{-1}$ it can reach $\approx 5 \%$. 

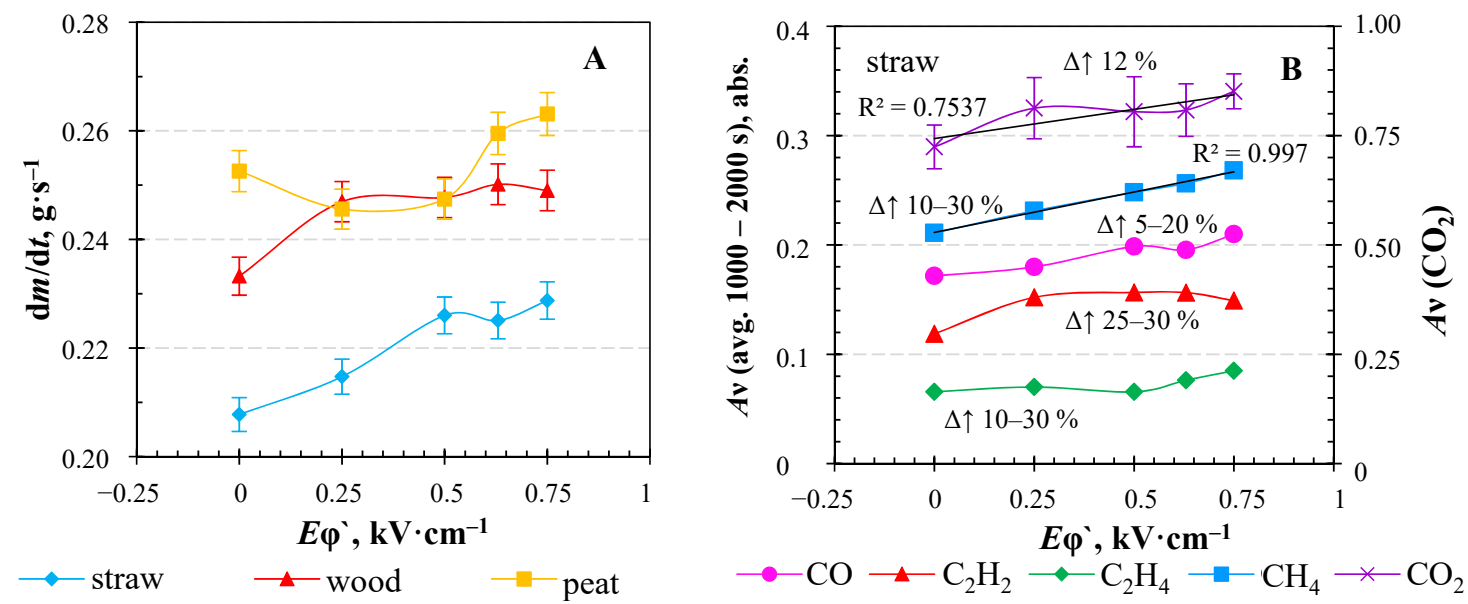

Fig. 13. A - Effect of electric field on the average value of pellet weight loss and B - the average amount of products of biomass thermal decomposition at the base of the combustor.

Comparing the average values of the IR absorption of the products of thermal decomposition, an increase in the concentration of volatiles at the base of the combustor is observed for straw and woody biomass (Fig. $13-$ B), depending on the intensity of the external electric field applied. The averaged concentrations of volatiles, at straw combustion, increase steadily from $\approx 10 \%$ to $30 \%$. Particularly, an intense increase of $\mathrm{C}_{2} \mathrm{H}_{2}$ and $\mathrm{CH}_{4}$ is observed.

A decrease of the average values of concentration of the products of thermal decomposition is observed at the base of the combustor during peat pellet combustion if the electric field is applied. As the combustion kinetics of peat biomass is characterized by the formation of a shorter flame (see Section 3.2), then, using the same electrode configuration, the effects caused by the electric field improve the mixing of air with the volatiles more effectively. This is observed both by a gradual decrease in the concentration of volatile compounds $\left(\mathrm{CO}, \mathrm{C}_{2} \mathrm{H}_{2}, \mathrm{CH}_{4}, \mathrm{C}_{2} \mathrm{H}_{4}\right)$ at the base of the combustor and air excess, assuming an increase in the concentration of $\mathrm{CO}_{2}$.

It was found that the time-dependent curves of the mass loss of biomass pellets of various origins transform in the electric field, and these transformations are different for all types of biomass, which is determined by differences in the structure, elemental and chemical composition of the components. As a result of the electric field action, the thermal decomposition of biomass is mainly intensified during the process of decomposition of holocellulose, causing a rapid decrease of the biomass pellet layer by an average of 35-40\%. 

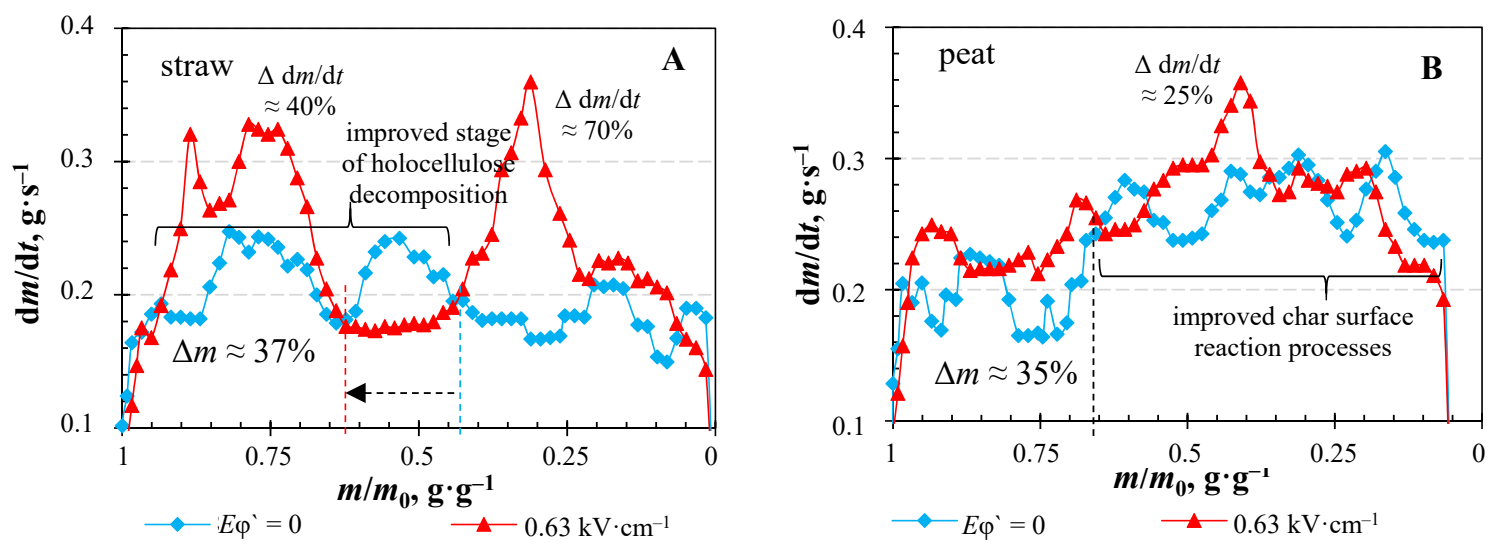

Fig. 14. Variations of the mass loss of straw biomass (A) and peat (B) pellets in the process of thermal decomposition caused by the application of the external electric field.

Variations in the mass loss of different biomass types at the thermal decomposition of holocellulose are linked to the different volatile content and the different chemical composition of hemicelluloses. The thermal decomposition of wood hemicellulose is the fastest, therefore, if the external electric field is applied, its decomposition rate is improved only by $20 \%$ during the initial stage of thermal decomposition (before $1000 \mathrm{~s} ; \mathrm{m} / \mathrm{mo}_{0} \approx 0.60$ ). The most intense variations of mass loss $(40 \%)$ were observed at straw combustion in the period before $1200 \mathrm{~s}$ (Fig. 14 - A), when intensification of the secondary stage of thermal decomposition of Glu-Uro-Ara-Xyl arose, causing the increase of the average rate of thermal decomposition by $10 \%$. Due to the reduced content of volatile matter (Table 2) in peat pellets at the combustion stage before $\approx 1500 \mathrm{~s}$ (Fig. $14-\mathrm{B}$ ), the intensification of thermal decomposition of polysaccharides is less pronounced (only by $10 \%$ ).

\subsection{Effect of enhanced heat transfer}

Variations of the swirling flame flow structure, induced by an action of an external electric force, contribute to the radial expansion of the combustion zone, thus increasing the average temperature values, but decreasing its maximum values. The radial expansion of the combustion zone increases the flame temperature on the periphery, with a correlated intensification of the heat transfer to the cooling surface of the combustion chamber. The reduction of the flame length improves the heat exchange between the central part of the flame swirl and the biomass pellet layer, accelerating the thermal decomposition. The effect of electric field and flame interaction promotes the release of combustible volatiles, prolongs the residence time of these components in the reaction zone (Fig. $10-\mathrm{A}$ ), improves their ignition, and, as a result, enhances heat release during the combustion, thus increasing the heat transfer to the combustion chamber walls. 

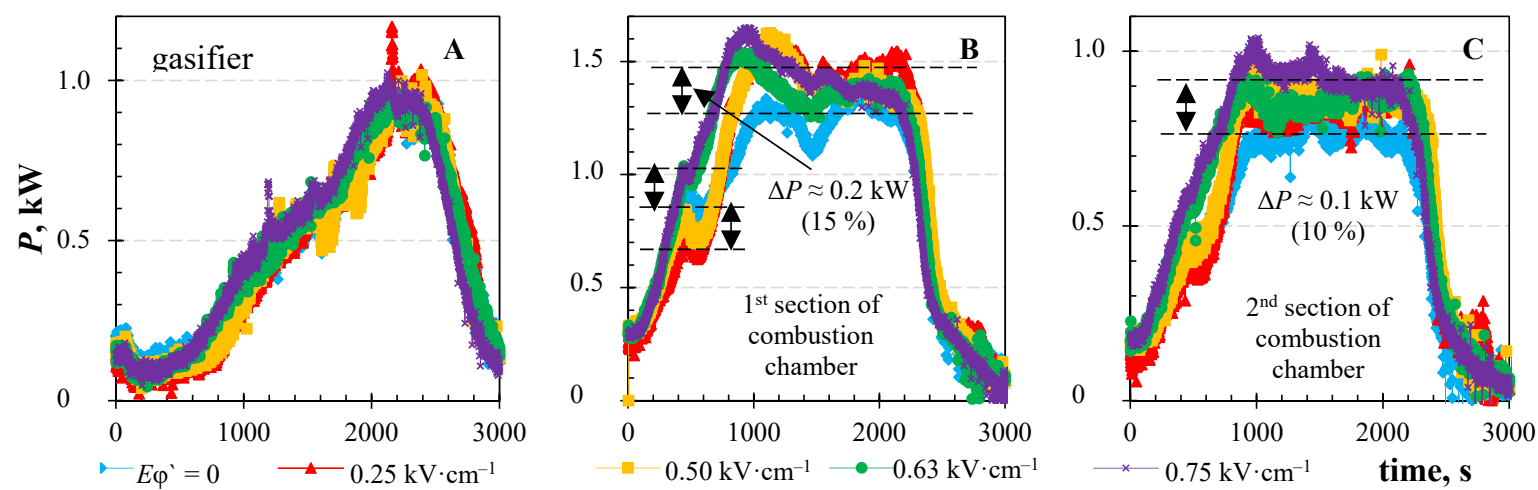

Fig. 15. Variations of heat power kinetics of various sections of the experimental setup in the process of combustion of straw pellets if the electric field is applied.

In the electric field up to $0.5 \mathrm{kV} \cdot \mathrm{cm}^{-1}$, the intensification of thermal decomposition of straw and woody holocellulose is observed at the stage before $1000 \mathrm{~s}$ (for peat $-1500 \mathrm{~s}$ ), which is assumed by the endothermic effect at the beginning of the combustion process (Fig. 15 - B).

Growing the electric field intensity, the exothermic effect of the volatiles ignition and combustion formation prevails, subsequently changing the kinetics of heat power of the experimental setup. At $E \varphi{ }^{`} \geq 0.63 \mathrm{kV} \cdot \mathrm{cm}^{-1}$, in the period before $1000 \mathrm{~s}$, a faster increase of heat power is observed (averagely by $20 \%$ ). In the period from $1000 \mathrm{~s}$ to $\approx 2200 \mathrm{~s}$ of the self-sustaining combustion stage, the electric field improves the heat transfer in the first and second sections of the combustion chamber, increasing their heat power by 10-15\% (Fig. 15 - B, C). A larger increase in heat power $(0.2 \mathrm{~kW}$ versus $0.1 \mathrm{~kW})$ is observed in the first section, where the flame current reaches its maximum value and a radial expansion of the flame swirl is mostly pronounced (Fig. 11 - B). In turn, the variations of the heat power of the gasifier as a result of electric field action are minimal (Fig. $15-\mathrm{A}$ ) because the heat transfer in the gasifier is determined by the direct heat conductivity and radiation from the charred biomass layer. This type of process dominates in the combustion of straw pellets after $1800 \mathrm{~s}$, when the transition from flame combustion to char roasting processes is observed in the experimental setup (Fig. $8-\mathrm{A}$ ).

The mass transfer induced by "ion wind" in the direction of the electric field improves the convective heat transfer, increasing the heat power of the setup at the self-sustaining combustion stage and the total amount of heat produced burning the discrete mass of the pellet sample. In the process of straw biomass combustion, as a result of electric field exposure, an increase in the amount of total heat was observed by $6-10 \%$ with a deviation of the average $\pm 4 \%$ (Fig. $16-\mathrm{A}$ ). The increase of the heat power of the experimental setup during the combustion of straw biomass reaches $11-16 \%$ with a $\pm 4 \%$ deviation of the average (Fig. $16-\mathrm{B}$ ). At $E \varphi{ }^{`}>0.5 \mathrm{kV} \cdot \mathrm{cm}^{-1}$, the total amount of heat produced in the process of wood biomass combustion increases by $5-6 \%$ with a $\pm 2 \%$ deviation (Fig. $16-C$ ).

The average increase of the heat power of the unit in the self-sustaining process is $6-8 \% \pm 2 \%$ (Fig. $16-\mathrm{D}$ ). Considering the length of the flame during the experiment of the wood combustion process, the heat transfer to the furnace walls was not effective. Due to the electric field-induced 
intensification of the thermal decomposition of biomass, a greater amount of volatiles is produced, especially $\mathrm{CO}$, which does not have time to fully react along the length of the flame and to produce heat. In the process of combustions of wood pellets, it is necessary to use a longer electrode and increase the heat exchange area.

The change in flame length in the electric field during the process of combustion of peat pellets is visually not observed because the length of peat flame is considerably small at $E \varphi{ }^{`}=0$. Therefore, in the process of peat pellets combustion, variations of the heat power of the setup can only be observed in the first section of the combustion chamber.
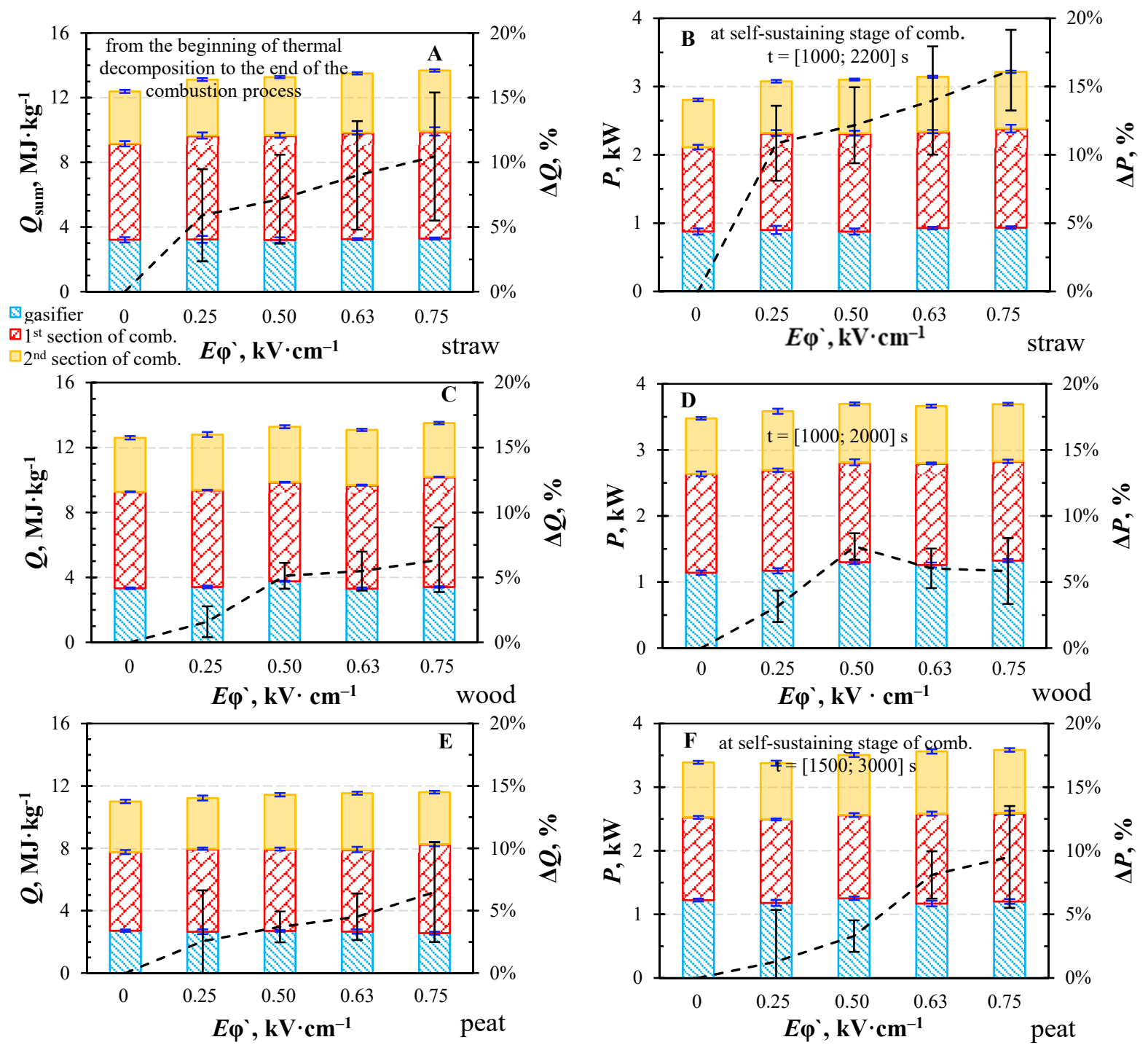

Fig. 16. Variations of the total heat produced and the average setup power if the electric field is applied during the combustion of straw $(A, B)$, wood $(C, D)$ biomass and peat $(E, F)$.

In the studies of peat combustion processes with the applied electric field, an increase of the total heat by $3-6 \%$ has been found with a $\pm 3 \%$ deviation of the average value (Fig. $16-$ E). However, the increase of the average heat power of the plant, in peat combustion experiments with 
the electric field, was found only at $E \varphi{ }^{`}>0.5 \mathrm{kV} \cdot \mathrm{cm}^{-1}$, reaching $8-10 \%$ with $\pm 3 \%$ deviation (Fig. $16-\mathrm{F})$. Considering the deviations of the average values of variations of heat parameters, it can be concluded that the effect of the electric field on the heat power of the equipment is stable only at higher electric field intensities.

\subsection{Effect of harmful emissions reduction}

The expansion of the flame reaction zone under the influence of the electric field causes a shift in the temperature profile and also in the radial distribution of the oxygen concentration and the efficiency of combustion processes at the periphery of the flow $r / r_{0}=[0.6 ; 0.85]$, with a subsequent increase in the average efficiency of combustion process and a decrease in average concentration of oxygen at the periphery by $4-10 \%$ (Fig. $17-\mathrm{A}$ ).

Due to the intensification of thermal decomposition of holocellulose (Fig. 14), a small increase in CO mass fraction (Fig. $17-\mathrm{C}$ ) at the flow periphery $r / r_{0}=[0.5 ; 0.8]$ appears. After $1500 \mathrm{~s}$, when the transition of sooting flame kinetics to char combustion is observed, the electric field action induces a decrease of $\mathrm{CO}$ by $20-45 \%$, considered by the variations in the radial distribution of CO fraction (Fig. 17 - D). This suggests improved combustion conditions.
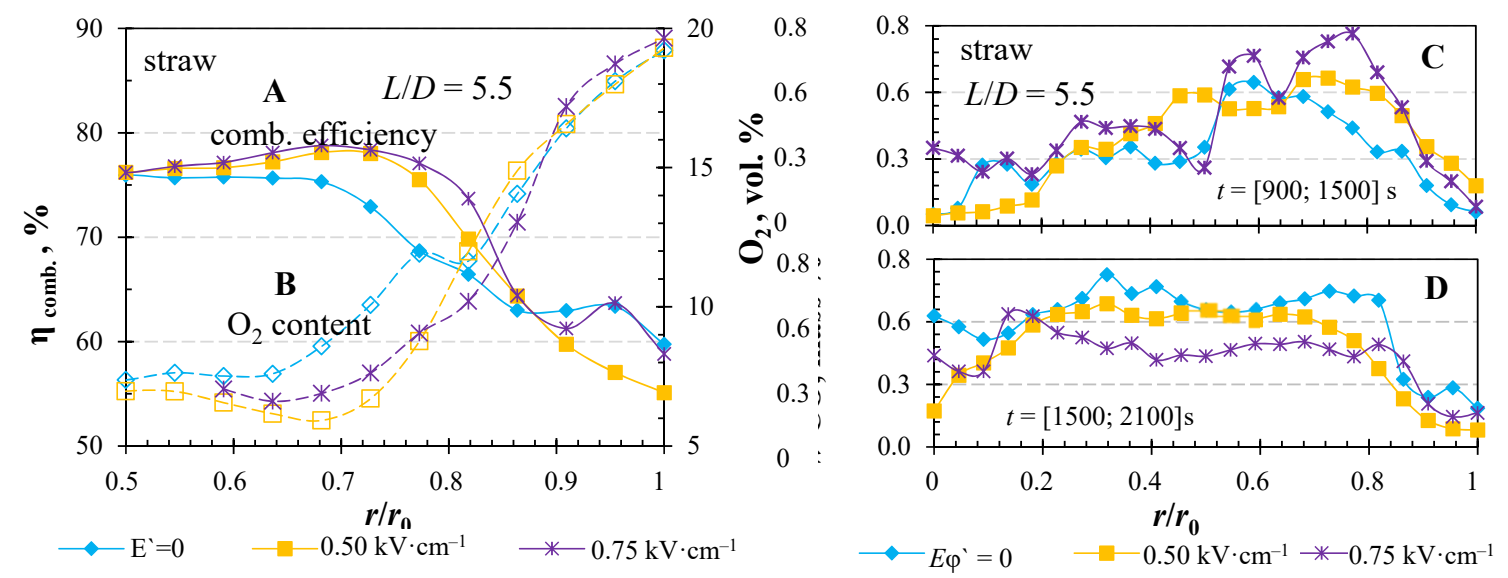

Fig. 17. Changes in the radial distribution of combustion efficiency (A), oxygen (B) and carbon monoxide $(\mathrm{C}, \mathrm{D})$ concentration in the combustion chamber by applying the electric field.

As a result of variations in the swirling flow structure caused by the electric field, as well as changes in heat generation and heat transfer processes, relative $\mathrm{CO}_{2}$ emissions (eq. (14)) are reduced (Fig. $18-$ A), which is unambiguously related to the improved thermochemical conversion of the volatiles, including $\mathrm{CO}$ (Fig. $18-\mathrm{B}$ ). The variations in the composition of relative emissions from wood combustion show a slight decrease in $\mathrm{CO}_{2}$ emissions (up to $4 \%$ ) and a sharp decrease in $\mathrm{CO}$ emissions (up to $32 \%$ ).

$$
\mathrm{mCO}_{2} \mathrm{eq} / \mathrm{Q}_{\text {collected }}=\frac{\sum_{\text {end }}^{0} m \mathrm{CO}_{2, \text { TESTO }} / m_{\text {pellets }}}{\sum_{\text {end }}^{0} P_{\text {experimental device }}} .
$$



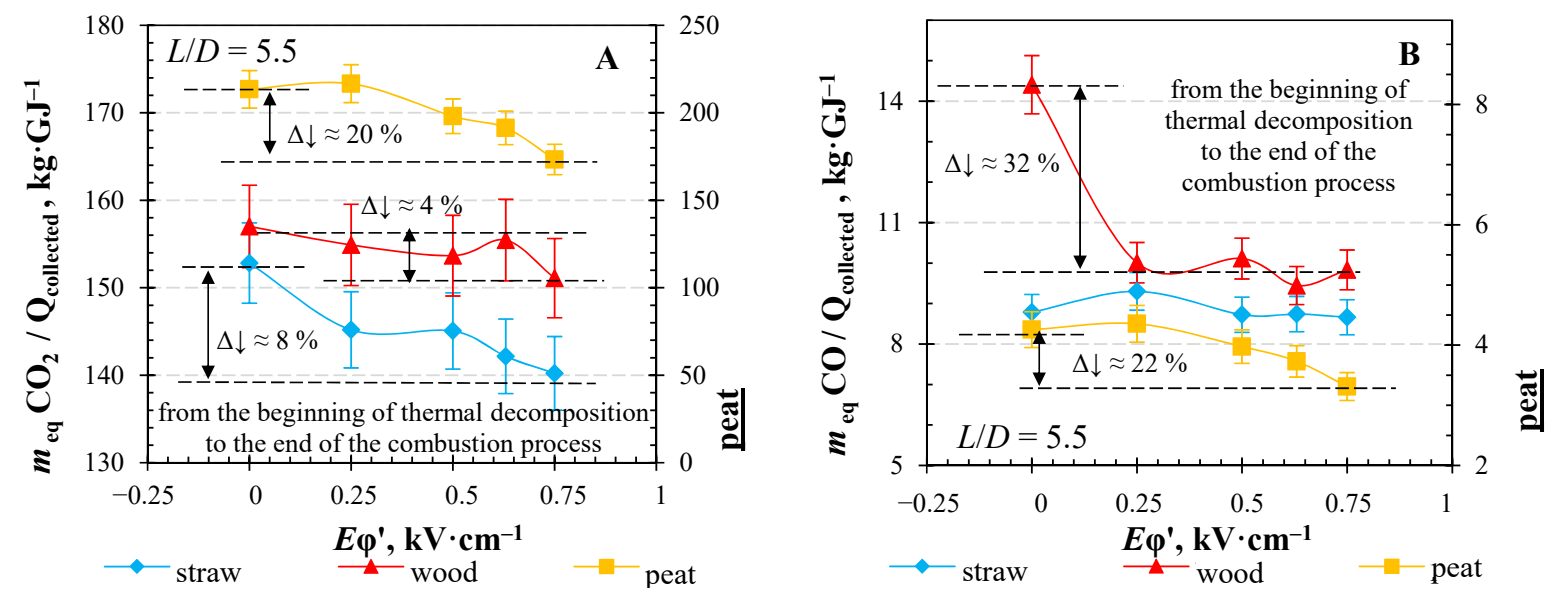

Fig. 18. Variations of the relative amount of $\mathrm{CO}_{2}(\mathrm{~A})$ and $\mathrm{CO}(\mathrm{B})$ emissions during combustion.

The effect of reducing the relative amount of $\mathrm{CO}$ emissions (by $22 \%$ ) and $\mathrm{CO}_{2}$ emissions (by $\approx 20 \%$ ) in the electric field is also observed during the peat combustion process, which is determined by the improved char roasting. In peat combustion, the reduction of $\mathrm{CO}$ emissions during the roasting stage is severe, as the oxidation stage of charred peat can reach up to $30 \%$ of the total duration of the combustion process. On the other hand, in the process of burning straw pellets with the external electric field applied, the variations in the relative amount of $\mathrm{CO}$ emissions are not significant, which is due to the formation of a solid ash layer on the biomass surface, limiting air diffusion to the surface of the reaction zone. Regarding the intensified process of thermal decomposition of straw pellets and combustion of volatiles, as well as improved heat generation and transfer processes, relative $\mathrm{CO}_{2}$ emissions can be reduced by $8 \%$.

Significant changes associated with the acceleration of biomass nitrogen-containing volatiles release and their oxidation to NOx at the gasifier outlet were not observed (Fig. $19-\mathrm{A}$ ). Measurements of the composition of straw and peat combustion emissions at $L / D=5.5$ found that the total NOx content in the flue gas decreases as a result of electric field impact: for straw the reduction is $4-5 \%$ and for peat it is $2-11 \%$ (Fig. $19-\mathrm{B}$ ), which is determined by a decrease in the maximum values of temperature in the center of the combustion zone (Fig. $12-\mathrm{B}$ ). Changes in NOx fraction (recalculated to the variations in the thermal power) show a marked improvement in the overall process of the interaction between the electric field and the flame, achieving a reduction in NOx emissions up to $18 \%$ per $\mathrm{kW}$ of thermal power.

The field-induced changes of NOx emission, due to the intensification of the thermal decomposition of biomass, the release and oxidation of chemically bound nitrogen-containing compounds have also been observed burning the wood biomass. In the process of wood combustion, the formation of a relatively hotter and longer flame is observed. According to Zeldovich's thermal NOx formation mechanism, a higher flame temperature determines a $10 \%$ increase in NOx emission firing softwood pellets (Fig. $19-\mathrm{B}$ ). 

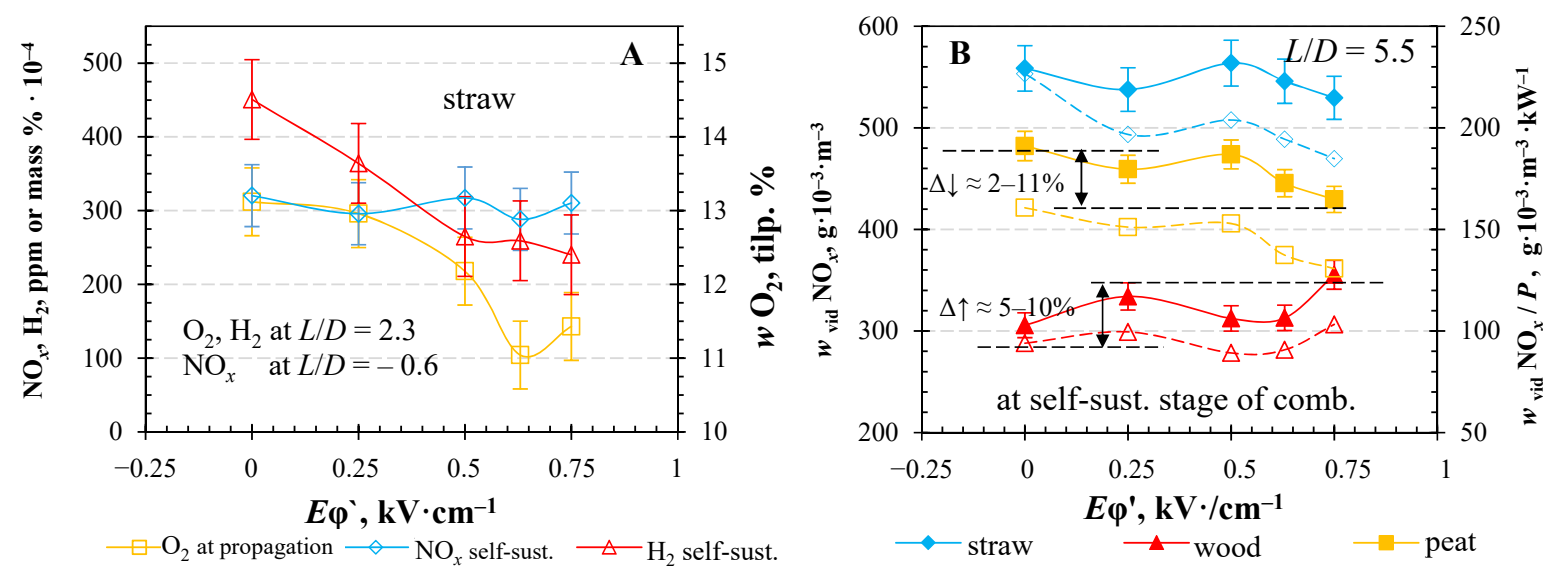

Fig. 19. Reduction of NOx emissions at the combustion of different types of pellets.

In summary, the intensification of the process of thermal decomposition of holocellulose together with the improved formation of volatile substances determines the decrease of air oxygen concentration at the stage of formation of biomass combustion (Fig. $19-$ A). The increase of the average flame temperature in the reaction zone at $L / D=1.5$ (Fig. $12-\mathrm{A}$ ) determines the promoted ignition of volatiles, which is assumed regarding the decrease of $\mathrm{H}_{2}$ mass fraction in the flame core during the self-sustaining stage of combustion. The $\mathrm{OH}$ radicals formed during the hydrogen combustion accelerate the kinetics of $\mathrm{CO}$ oxidation and promote the formation of $\mathrm{CO}_{2}$ in the reaction zone.

\section{APPROBATION AND EVALUATION OF NEW TECHNOLOGY PROTOTYPE WITH INDUSTRIAL PELLET BURNER}

Transferring the electrodynamic control technology of pelletized biomass combustion processes from $4 \mathrm{~kW}$ power experimental setup to industrial prototype $20 \mathrm{~kW}$ equipment, performed within the framework of the Doctoral Thesis, five pelletized wood biomass combustion testings were performed for each electrode potential $U \varphi_{+}=[0 ; 1.8] \mathrm{kV}$.

The results of the approbation of the industrial prototype correspond to the results obtained with a low-power experimental setup. The results of the testing confirm that the electric field influence in the period from $200 \mathrm{~s}$ to $500 \mathrm{~s}$ accelerates the ignition of biomass volatile substances, increasing the average temperature in the flame reaction zone by $10-20 \%$ and the temperature of flue gas by $\approx 10 \%$. The increase of the average temperature of the combustion zone, which is determined by the effect of field-induced flame radial expansion and the intensification of the biomass thermal decomposition, is also observed at the stationary stage of combustion. However, the increase in the average temperature does not exceed $4 \%$.

The improved ignition of volatile compounds, as well as an increase in the overall efficiency of the combustion process as a result of electric field exposure, has been observed in the technological prototype regarding the 3-5\% increase in the average $\mathrm{CO}_{2}$ concentration in the flue 
gas (Fig. $20-$ A). The amount of harmful CO emission $(\approx 420 \mathrm{ppm})$ decreased between $38 \%$ and $77 \%$ during the initial stage of pellet combustion by changing the electrode potential from zero to $1.8 \mathrm{kV}$. However, in the stationary stage of combustion, changes in $\mathrm{CO}$ emissions $(\approx 250 \mathrm{ppm})$ are less pronounced, decreasing by about $10 \%$ from the initial value at $U \varphi_{+}=0$. However, the average NOx emissions $(\approx 50-60 \mathrm{ppm})$ remain virtually unchanged both in the initial stage of the combustion and in the stationary stage of the combustion process. The obtained results conclude that the increase of harmful pollutant concentration in combustion products is mainly related to the intensification of the thermal decomposition process of biomass and not to the increase of flame temperature because the flame temperature increase is relatively neglectable to provoke the increase of heat-sensitive NOx concentration.
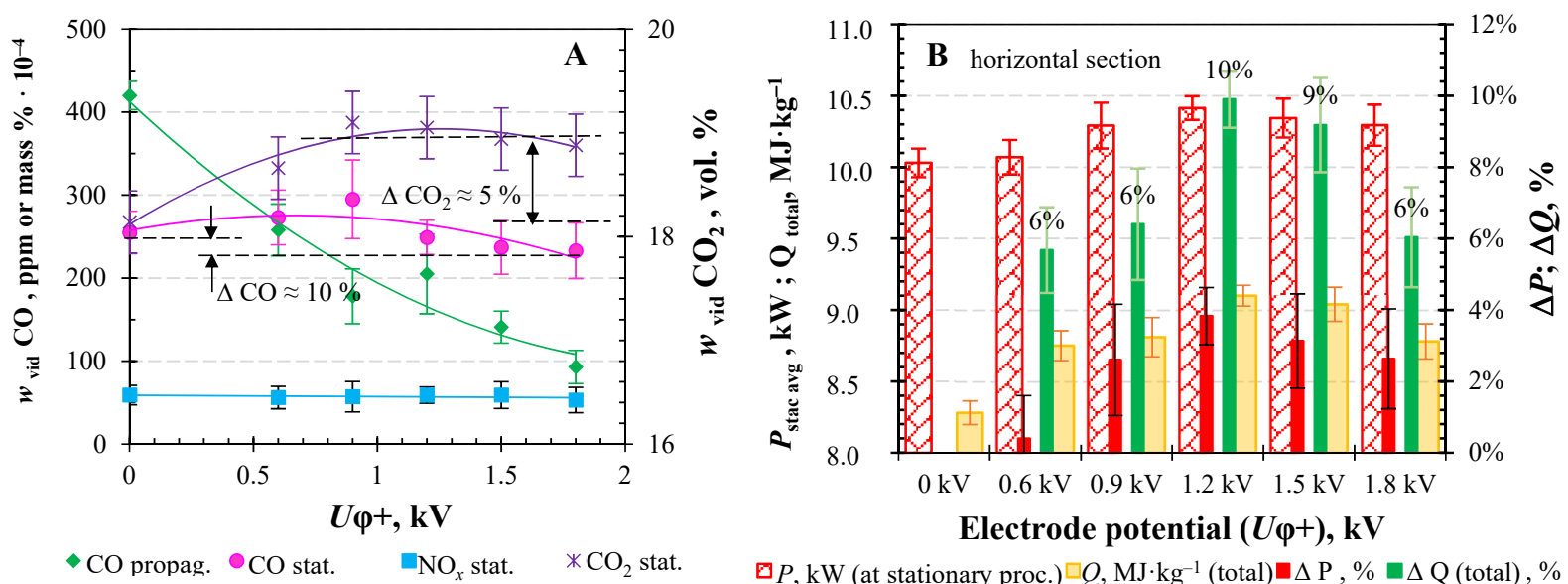

Electrode potential $(U \boldsymbol{\varphi}+), \mathbf{k V}$

$\square P, \mathrm{~kW}$ (at stationary proc.) $\square Q, \mathrm{MJ} \cdot \mathrm{kg}^{-1}$ (total) $\Delta \mathrm{P}, \% \square \Delta \mathrm{Q}$ (total),$\%$

Fig. 20. The electric field-induced $\mathrm{CO}_{2}, \mathrm{CO}, \mathrm{NO} x$ emission variations (A), and heat parameters of the furnace (B) of the technological prototype setup during woody pellets combustion.

Regarding the average flue gas temperature of $600-630 \mathrm{~K}$, it has been established that in the technological prototype the heat from the flue gas has not been fully utilized. The greatest effect of the electric field on the combustion and heat transfer processes has been found in the horizontal section (furnace) of the technological equipment. The increase of the power of the stationary combustion process does not exceed 3-4\%, however, in the experiments with $4 \mathrm{~kW}$ setup the average increase of heat power during the self-sustaining combustion process was higher, reaching $6-8 \%$ with a $\pm 2 \%$ average deviation.

It also should be noted, however, that it was not possible to adjust the air and fuel supply in a commercial pellet burner, as the burner was fully automated and these parameters were preinstalled for the combustion of A-quality wood pellets. The use of other types of biomass pellets was limited by the manufacturer's warranty agreement. For the following reasons, the field-induced combustion of straw biomass and peat pellets was not approbated on a $20 \mathrm{~kW}$ burner. 


\subsection{Techno-economical assessment of EFDFD implementation}

Expenses for the implementation of EFDFD technology are related to the reconstruction of the combustion chamber of a boiler. When designing a boiler with the specified capacity, it is possible to predict the choice of the optimal high-voltage power supply unit because the costs associated with the use of EFDFD technology are based on the installation of the electrical part and the cost of electricity consumption for high-voltage power supply.

To determine the average prices for the high voltage DC power supply, electrode fabrication, electrode insulation, and installation/assembly, the market investigation was carried out. It should be noted that the industrial plant does not require a unit with high control accuracy, moreover, the unit can be combined with burner automation to regulate the bias electrode voltage according to the burner operating power. The efficiency of high-voltage DC power supplies usually does not exceed $60 \%$, so when choosing the optimal power supply relying on the price, it is necessary to study the current saturation and electrical breakdown limit to correctly select the maximum output current of power supply. The market investigation has shown that the price of a high voltage power supply varies according to the required power parameters, usually from 2680 EUR to 3980 EUR [86]. Then the total cost of installation of the technology in the pellet burner varies from 4147 to 6033 EUR. Conducting the testing of the technology, a power supply unit was used with the maximum supply voltage $-3 \mathrm{kV}$ and the maximum load current about $10 \mathrm{~mA}$. A similar solution on the market is APS-1915 (T\&M Atlantic Inc, USA), which costs between 260 EUR and 500 EUR. Then the total cost of technology is $\approx 884-1380$ EUR.

Considering the efficiency of the power block used in the testing at various electrode potentials and the corresponding time-averaged current values (experimental), electricity consumption was calculated (eqs. (15) and (16)), and, according to eq. (17), the relative electricity consumption was calculated concerning the increase of the total heat produced at the horizontal section of the prototype setup. The most efficient ( $\eta_{\text {avg }} \approx 96 \%$ ) use of technology to energy balance was observed with $U \varphi_{+}=[0.9 ; 1.5] \mathrm{kV}$ electrode potential because the relative electricity consumption is only $\approx 2-6 \%$ of the increase of the total heat produced $\left(\Delta Q_{\text {heat }}\right)$.

$$
\begin{gathered}
P_{e l}=\frac{U_{\varphi+} \cdot \mathrm{I}}{\eta_{\text {supply }}}=\left[\eta_{\text {supply }}=60 \%\right]=\frac{1,8 \cdot 10^{3} \cdot 7,25 \cdot 10^{-3}}{0,6}=26,1[\mathrm{~W}], \\
W_{e l}=P_{e l} \cdot t_{\text {eksperiment }}=26,1 \cdot 10^{-3} \cdot 1,07=0,028[\mathrm{kWh}], \\
\Delta W_{\%}=\frac{W_{e l}}{\Delta P_{\text {thermal }} \cdot t}=\frac{0,028}{0,26} \approx 11[\%], \\
\text { Economy }=V_{\text {fuel }}\left[\mathrm{kg} \cdot \mathrm{h}^{-1}\right] \cdot \text { cena }_{\mathrm{vid} .}\left[\mathrm{EUR} \cdot \mathrm{kg}^{-1}\right] \cdot \frac{\mathrm{d} V}{\mathrm{~d} Q}=4,13 \cdot 0,182 \cdot 5 \%=0,0376[\mathrm{EUR} \cdot \\
\left.\mathrm{h}^{-1}\right], \\
\text { Payback period }=\frac{\text { Capital costs }}{\text { Economy } \cdot \text { h per year }}=\frac{[884 \rightarrow 1380]}{0,0376 \cdot 8760}=2,7 \rightarrow 4,2[\text { years }] .
\end{gathered}
$$


Taking into consideration the discovered fuel "d $V / \mathrm{d} Q$ " savings of about $5 \%$ (Fig. 21), the average price of wood pellets on the market in 2020 was $0.182 \mathrm{EUR} \cdot \mathrm{kg}^{-1}$, the calculated costs of electrodynamic control technology, a calculation of technology`s payback period is performed (eqs. (18) and (19)), during which the expenses related to the installation of electrodynamic control of the combustion process will be reimbursed.

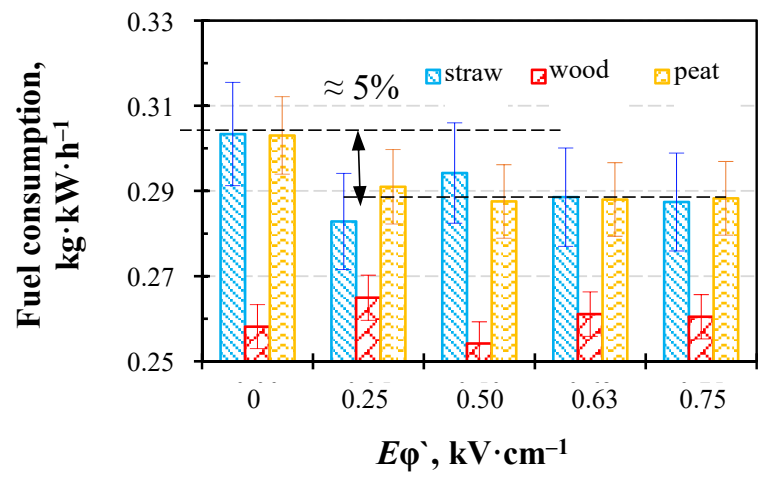

Fig. 21. Relative pellet fuel consumption using the effect of an external electric field.

According to the results of the calculation, it is determined that the payback period for the implementation of the technology in a $20 \mathrm{~kW}$ boiler is from 2.7 to 4.2 years. Assuming that fuel economy was maintained by linear extrapolation in respect to the pellet burner power, it can be concluded that the technology's payback period would possibly be reduced to about 1 year if the technology is applied for the operation of a $300 \mathrm{~kW}$ wood pellet burner, even without taking into account savings on emission quota. Scaling up the positive effect of the use of electrodynamic control technology in boilers with a capacity of more than $20 \mathrm{~kW}$, there are significantly increased costs associated with the choice of power supply unit of increased capacity and higher electricity consumption. According to Purmalis et al. [87], when performing a linear scaling of electrodynamic control technology's use in a 3-4 MW boiler, the fuel economy effect can reach $\approx 5 \%$, consuming only $0.14 \mathrm{~kW}$ of electric power (at $\approx 0.9 \mathrm{kV} \cdot \mathrm{cm}^{-1}$ intensity of the electric field). Therefore, it is assumed that the calculation represents the payback period regarding the negative forecast. However, by choosing the optimal power supply for a particular burner power, better cost savings can be achieved, which confirms the previous theses, that electrodynamical control technology should be anticipated already at the boiler design stage and its implementation should be optimized to achieve the lowest possible technology costs.

\section{CONCLUSIONS}

1. The variety of elemental and chemical composition of granular biomass of different origin (straw, peat, wood) determines significant differences in the gasification and combustion processes. 
2. An experimental study of the swirling flow of flames of the combustion process of granular biomass (without an applied electric field) has shown that the optimal mode of the swirling flow is formed when an angle of entry of the secondary air ( $\left.\measuredangle \theta_{\text {inlet }}\right)$ is $40^{\circ}$ and the number of vortices $(S)$ is $0.6-0.9$, which provides maximum average flame temperature, more heat of the device and lower emissions.

3. During the experimental study of the combustion of biomass of various origins, the ion current reaches its maximum value (up to $6 \mathrm{~mA}$ ) at a distance of 0 to $50 \mathrm{~mm}$ from the surface of the biomass pellets layer. For effective control of the swirling structure of the flame the optimal electrode length should be at least $63 \mathrm{~mm}$.

4. In a low-intensity electrostatic field (up to $1 \mathrm{kV} \cdot \mathrm{cm}^{-1}$ ), the influence of the "ionic wind" provokes an increase in the swirl number $(1.1-1.3)$ of the downward flow vortex. Induced by the electric field, a combustion zone of the products of thermal decomposition of biomass expands by $15-20 \%$, the flame length decreases up to $50 \%$, causing a decrease in the maximum temperature in the center of the flame stream by $\approx 10 \%$ and an increase in the average temperature at the flame periphery. As a result of changes in the swirling dynamics, the axial flow velocity decreases in the combustion zone (up to $0.3-0.5 \mathrm{~m} \cdot \mathrm{s}^{-1}$ ), increasing the residence time of the air-fuel mixture, improving the combustion of volatile substances with a subsequent decrease in the air excess ratio for different types of biomass by $15-30 \%$.

5. Considering the average field-induced variation in the biomass mass loss, an increase in the rate of thermal decomposition of wheat straw pellets is observed by $\approx 10 \%$ at $E \varphi{ }^{`}=0.75 \mathrm{kV} \cdot \mathrm{cm}^{-1}$. In turn, the maximum increase in the rate of thermal decomposition of woody biomass and peat reaches $\approx 5 \%$.

6. An increase in $\mathrm{CO}_{2}$ in the flame reaction zone up to $\approx 36-37 \%$, as well as an increase in the efficiency of the combustion process by $4-10 \%$ close to the chamber walls indirectly indicates an increase in convective heat transfer from the reaction zone to the cooling walls of the combustion chamber, thus increasing the average amount of heat collected during combustion process by $6-10$ $\pm 4 \%$ for straw biomass, by $5-6 \pm 2 \%$ for woody biomass, and by $3-6 \pm 3 \%$ for peat. Consequently, a decrease in the relative fuel consumption by an average of $5 \%$ has been calculated due to the effect of an external electric field applied.

7. Swirling flow deviations caused by the electric field contribute to a better burnout of volatiles, reducing relative $\mathrm{CO}_{2}, \mathrm{CO}$ and $\mathrm{NO} x$ emissions (especially during char combustion stage) for different types of biomass pellets by $\approx 4-20 \%, 20-30 \%$ and 5-10\%, respectively.

8. Approbation of the electrodynamic control technology on an industrial pellet burner $(20 \mathrm{~kW})$ confirmed the positive effect of the applied electric field, increasing the average combustion temperature in the reaction zone by $\approx 3-5 \%$, improving the burnout of the products of thermal decomposition of biomass $(\mathrm{CO})$ by $\approx 10 \%$, with a subsequent increase in the thermal power of technological prototype by $\approx 3-4 \%$, an increase in the average heat amount produced by $6-8 \%$ with an average deviation of $\pm 2 \%$. 
9. According to the calculations of power consumption in the feasibility study of the technology, if the potential of $+1.8 \mathrm{kV}$ is applied to the electrode, the current reaches the value of $7.25 \pm 0.45 \mathrm{~mA}$, and the maximum power consumption of the power supply is $0.028 \mathrm{kWh}$. The electricity consumed to create the field is about $2.5 \%$ of the thermal power of the horizontal sections of the technological prototype. In addition, the relative electricity consumption is only $\approx$ $2-6 \%$ of the increase in heat amount produced.

\section{BIBLIOGRAPHY}

[1] European Commission, "2030 climate \& energy framework." [Online]. Available: ec.europa.eu/clima/policies/strategies/2030_en. [Accessed: 26-Oct-2020].

[2] AEBIOM, "Bioenergy Europe Statistical Report 2018," Brussels, 2018.

[3] FAOSTAT, "Crops," 2017. [Online]. Available: www.fao.org/faostat/en/\#data/QC/. [Accessed: 01-Nov-2019].

[4] S. V. Vassilev, D. Baxter, and C. G. Vassileva, "An overview of the behaviour of biomass during combustion: Part I. Phase-mineral transformations of organic and inorganic matter," Fuel, vol. 112, no. May, pp. 391-449, 2013.

[5] T. G. Bridgeman, J. M. Jones, I. Shield, and P. T. Williams, "Torrefaction of reed canary grass, wheat straw and willow to enhance solid fuel qualities and combustion properties," Fuel, vol. 87, no. 6, pp. 844-856, May 2008.

[6] N. Gao, A. Li, C. Quan, L. Du, and Y. Duan, "TG-FTIR and Py-GC/MS analysis on pyrolysis and combustion of pine sawdust," J. Anal. Appl. Pyrolysis, vol. 100, pp. 26-32, Mar. 2013.

[7] C. Ryu, Y. B. Yang, A. Khor, N. E. Yates, V. N. Sharifi, and J. Swithenbank, "Effect of fuel properties on biomass combustion: part I. Experiments - fuel type, formuivalence ratio and particle size," Fuel, vol. 85, pp. 1039-1046, 2006.

[8] A. Friedl, E. Padouvas, H. Rotter, and K. Varmuza, "Prediction of heating values of biomass fuel from elemental composition," Anal. Chim. Acta, vol. 544, pp. 191-198, 2005.

[9] I. Barmina et al., "Effect of Microwave Pre-Processing of Pelletized Biomass on its Gasification and Combustion," Latv. J. Phys. Tech. Sci., vol. 50, no. 4, pp. 34-47, 2013.

[10] A. Tohidi, M. J. Gollner, and H. Xiao, "Fire Whirls," Annu. Rev. Fluid Mech., vol. 50, no. 1, pp. 187-213, 2017.

[11] Ecotec SWEDEN AB, "Technical data Bioline 20-25 - Pellet burner from Ecotec," 2017. [Online]. Available: www.ecotec.net/bostad/sma-villor/bioline-20-25-pelletsbrannare/. [Accessed: 02-Nov-2019].

[12] I. Barmina, M. Zake, and R. Valdmanis, "Electric field-induced variations of combustion dynamics," Chem. Eng. Trans., vol. 39, pp. 1531-1536, 2014.

[13] M. Zake, I. Barmina, and A. Meijere, "The electric field-forced formation of the swirling flame flow field," in The15th Riga and 6th PAMIR Conference on Fundamental and Applied MHD, 2005, pp. 115-118.

[14] J. M. Goodings, D. K. Bohme, and N. G. Chun-Wai, "Detailed ion chemistry in methaneoxygen flames. I. Positive ions," Combust. Flame, vol. 36, pp. 27-43, Jan. 1979.

[15] J. M. Goodings, D. K. Bohme, and N. G. Chun-Wai, "Detailed ion chemistry in methaneoxygen flames. II. Negative ions," Combust. Flame, vol. 36, pp. 45-62, Jan. 1979. 
[16] J. Lawton and F. J. Weinberg, Electrical Aspects of Combustion, In Russian. Moscow: Energija, 1976.

[17] V. S. Karnani, "Electric field-driven flame dynamics," University of California, Irvine, 2011.

[18] J. A. Tinajero, "Flame dynamics and chemi-Ion flows driven by applied electric fields," University of California, Irvine, 2017.

[19] M. Belhi, B. J. Lee, F. Bisetti, and H. G. Im, "A computational study of the effects of DC electric fields on non-premixed counterflow methane-air flames," J. Phys. D. Appl. Phys., vol. 50, no. 49, p. 494005, Dec. 2017.

[20] Y.-C. Chien, "Electrical Aspects of Impinging Flames," UNIVERSITY OF CALIFORNIA, IRVINE, 2014.

[21] P. R. Salvador and K. G. Xu, "Electric field modified bunsen flame with variable anode placement," J. Thermophys. Heat Transf., vol. 31, no. 4, pp. 956-964, 2017.

[22] J. Lawton, P. J. Mayo, and F. J. Weinberg, "Electrical control of gas flows in combustion processes.," Proc. R. Soc. London, vol. 303, no. 1474, pp. 275-298, 1968.

[23] H. F. Calcote and C. H. Berman, "Increased methane-air stability limits by a DC electric field," in Proc. ASME Fossil Fuels Combustion, 1989, pp. 25-31.

[24] J. Colannino, "Electrodynamic combustion control TM technology, A clear Sign white paper," Sefigle, 2012.

[25] H. F. Calcote, "Ion and electron profiles in flames," Symp. Combust., vol. 9, no. 1, pp. 622637, 1963.

[26] A. M. Starik, A. M. Savel'ev, and N. S. Titova, "Kinetic processes in the plasma formed in combustion of hydrocarbon fuels," J. Eng. Phys. Thermophys., vol. 84, no. 1, pp. 100-124, Jan. 2011.

[27] A. M. Starik and N. S. Titova, "Kinetics of ion formation in the volumetric reaction of methane with air," Combust. Explos. Shock Waves, vol. 38, no. 3, pp. 253-268, 2002.

[28] H. Zhang, "Numerical combustion of commercial fuels and soot formation," The University of Utah, 2005.

[29] K. Werner, L. Pommer, and M. Broström, "Thermal decomposition of hemicelluloses," $J$. Anal. Appl. Pyrolysis, vol. 110, pp. 130-137, 2014.

[30] H. Yang, R. Yan, H. Chen, D. H. Lee, and C. Zheng, "Characteristics of hemicellulose, cellulose and lignin pyrolysis," Fuel, vol. 86, no. 12-13, pp. 1781-1788, 2007.

[31] D. Shen, L. Zhang, J. Xue, S. Guan, Q. Liu, and R. Xiao, "Thermal degradation of xylanbased hemicellulose under oxidative atmosphere," Carbohydr. Polym., vol. 127, pp. 363$371,2015$.

[32] D. K. Shen, S. Gu, K. H. Luo, A. V. Bridgwater, and M. X. Fang, "Kinetic study on thermal decomposition of woods in oxidative environment," Fuel, vol. 88, no. 6, pp. 1024-1030, Jun. 2009.

[33] S. A. El-Sayed and M. Khairy, "An experimental study of combustion and emissions of wheat straw pellets in high-temperature air flows," Combust. Sci. Technol., vol. 190, no. 2, pp. 222-251, 2018.

[34] X. Zhou, W. Li, R. Mabon, and L. J. Broadbelt, "A critical review on hemicellulose pyrolysis," Energy Technol., vol. 5, no. 1, pp. 52-79, 2017.

[35] S. Wang and C. N. Mulligan, "Effect of natural organic matter on arsenic release from soils and sediments into groundwater," Environ. Geochem. Health, vol. 28, no. 3, pp. 197-214, Jun. 2006.

[36] A. G. Barneto, J. A. Carmona, J. A. Conesa Ferrer, and M. J. Díaz Blanco, "Kinetic study 
on the thermal degradation of a biomass and its compost: Composting effect on hydrogen production," Fuel, vol. 89, no. 2, pp. 462-473, Feb. 2010.

[37] Y. B. Zeldovich, Selected Works of Yakov Borisovich Zeldovich, Volume I, Russian Tr. Moscow: Nauka, 1992.

[38] A. V. Talantov, The theory of combustion, In Russian., vol. 1. Kazan, Russia: Kazan Aviation Institute, 1975.

[39] D. Shen, R. Xiao, S. Gu, and H. Zhang, "The overview of thermal decomposition of cellulose in lignocellulosic biomass," in Cellulose - Biomass Conversion, InTech, 2013.

[40] F. A. Williams, Combustion Theory: The Fundamental Theory of Chemically Reacting Flow Systems, 2nd ed. California, USA: The Benjamin/Cummings Publishing Company, 1985.

[41] T. G. Bridgeman, J. M. Jones, I. Shield, and P. T. Williams, "Torrefaction of reed canary grass, wheat straw and willow to enhance solid fuel qualities and combustion properties," Fuel, vol. 87, no. 6, pp. 844-856, May 2008.

[42] R. C. Pettersen, "The Chemical Composition of Wood," in Journal of Polymer Science, vol. 51, no. 155,1984 , pp. 57-126.

[43] C. H. Fuchsman, Peat: Industrial Chemistry and Technology, 1st Ed. New York: Academic Press Inc., 1980.

[44] M. Amutio, G. Lopez, R. Aguado, M. Artetxe, J. Bilbao, and M. Olazar, "Kinetic study of lignocellulosic biomass oxidative pyrolysis," Fuel, vol. 95, pp. 305-311, May 2012.

[45] E. Daouk, L. Van de Steene, F. Paviet, E. Martin, J. Valette, and S. Salvador, "Oxidative pyrolysis of wood chips and of wood pellets in a downdraft continuous fixed bed reactor," Fuel, vol. 196, pp. 408-418, 2017.

[46] R. J. Yokelson, R. Susott, D. E. Ward, J. Reardon, and D. W. T. Griffith, "Emissions from smoldering combustion of biomass measured by open-path Fourier transform infrared spectroscopy," J. Geophys. Res. Atmos., vol. 102, no. 15, pp. 18865-18877, 1997.

[47] O. Purmalis, D. Porsnovs, and M. Klavins, "Differential thermal analysis of peat and peat humic acids," Mater. Sci. Appl. Chem., vol. 24, pp. 89-94, 2011.

[48] A. N. Hayhurst and M. S. Parmar, "Does solid carbon burn in oxygen to give the gaseous intermediate $\mathrm{CO}$ or produce $\mathrm{CO} 2$ directly? Some experiments in a hot bed of sand fluidized by air," Chem. Eng. Sci., vol. 53, no. 3, pp. 427-438, 1998.

[49] X. Jiang, D. Chen, Z. Ma, and J. Yan, "Models for the combustion of single solid fuel particles in fluidized beds: A review," Renew. Sustain. Energy Rev., vol. 68, no. 1, pp. 410431, 2017.

[50] H. P. Miller, R. Mitchell, M. Smooke, and R. Kee, "Towards a comprhensive chemical kinetic mechanism for the oxidation of acetylene: comparison of model predictions with results from flame and shock tube experiments," in Proceedings of the Nineteenth Symposium (International) on Combustion, 1982, pp. 181-196.

[51] F. L. Dryer, High temperature oxidation of carbon monoxide and methane in a turbulent flow reactor, no. AD746284. New Jersey: University of South Carolina, 1972.

[52] G. P. Smith et al., "Methane-air reaction mechanism, GRI Mech 3.0," 2018. [Online]. Available: http://combustion.berkeley.edu/gri-mech/. [Accessed: 14-Oct-2019].

[53] H. Marsh and K. Kuo, "Kinetics and catalysis of carbon gasification," in Introduction to Carbon Science, Newcastle, UK: Elsevier, 1989, pp. 107-151.

[54] A. Ouedraogo, J. C. Mulligan, and J. G. Cleland, "A quasi-steady shrinking core analysis of wood combustion," Combust. Flame, vol. 114, no. 1-2, pp. 1-12, 1998.

[55] H. A. Michelsen, C. Schulz, G. J. Smallwood, and S. Will, "Laser-induced incandescence: Particulate diagnostics for combustion, atmospheric, and industrial applications," Prog. 
Energy Combust. Sci., vol. 51, pp. 2-48, 2015.

[56] H. F. Calcote, "Mechanisms for the formation of ions in flames," Combust. Flame, vol. 1, no. 4, pp. 385-403, 1957.

[57] J. Prager, U. Riedel, and J. Warnatz, "Modeling ion chemistry and charged species diffusion in lean methane-oxygen flames," Proc. Combust. Inst., vol. 31 I, no. 1, pp. 1129-1137, 2007.

[58] M. P. Gardner, C. Vinckier, and K. D. Bayes, "Identification of the primary chemi-ion in hydrocarbon oxidations," Chem. Phys. Lett., vol. 31, no. 2, pp. 318-320, 1975.

[59] J. A. Green and T. M. Sugden, "Some observations on the mechanism of ionization in flames containing hydrocarbons," Symp. Combust., vol. 9, no. 1, pp. 607-621, 1963.

[60] R. C. Brown and A. N. Eraslan, "Simulation of ionic structure in lean and close-tostoichiometric acetylene flames," Combust. Flame, vol. 73, no. 1, pp. 1-21, 1988.

[61] A. N. Eraslan and R. C. Brown, "Chemiionization and ion-molecule reactions in fuel-rich acetylene flames," Combust. Flame, vol. 74, no. 1, pp. 19-37, 1988.

[62] A. B. Fialkov and K. H. Homann, "Large molecules, ions, radicals, and small soot particles in fuel-rich hydrocarbon flames - Part VI: Positive ions of aliphatic and aromatic hydrocarbons in a low-pressure premixed flame of n-butane and oxygen," Combust. Flame, vol. 127, no. 3, pp. 2076-2090, 2001.

[63] A. M. Savel'ev, A. M. Starik, N. S. Titova, and O. N. Favorskii, "Mechanism of the electric charging of soot particles upon the combustion of hydrocarbon fuels," Dokl. Phys., vol. 49, no. 8, pp. 441-446, 2004.

[64] A. Fialkov, "Investigations on ions in flames," Prog. Energy Combust. Sci., vol. 23, no. 56, pp. 399-528, 1997.

[65] R. K. Cheng and D. Littlejohn, "Laboratory Study of Premixed H2-Air and H2-N2-Air Flames in a Low-Swirl Injector for Ultralow Emissions Gas Turbines," J. Eng. Gas Turbines Power, vol. 130, no. 3, May 2008.

[66] Y. Wang, "A numerical study of combustion in meso-scale vortex chambers," The Pennsylvania State University, 2006.

[67] A. K. Gupta, D. G. Lilley, and N. Syred, Swril Flows, Russian Translation. Moscow: Mir, 1987.

[68] I. Barmina, R. Valdmanis, H. Kalis, and M. Marinaki, "Experimental and numerical study of the development of swirling flow and flame dynamics and combustion characteristics at biomass thermo-chemical conversion," Eng. Rural Dev., vol. 16, no. 1, pp. 68-74, 2017.

[69] H. C. Jaggers and A. von Engel, "The effect of electric fields on the burning velocity of various flames," Combust. Flame, vol. 16, no. 3, pp. 275-285, 1971.

[70] F. Bisetti and M. El Morsli, "Calculation and analysis of the mobility and diffusion coefficient of thermal electrons in methane/air premixed flames," Combust. Flame, vol. 159, no. 12, pp. 3518-3521, 2012.

[71] T. Wyttenbach, C. Bleiholder, and M. T. Bowers, "Factors contributing to the collision cross section of polyatomic ions in the kilodalton to gigadalton range: Application to ion mobility measurements," Anal. Chem., vol. 85, no. 4, pp. 2191-2199, 2013.

[72] J. Lawton and F. J. Weinberg, "Maximum ion currents from flames and the maximum practical effects of applied electric fields," Proc. R. Soc. A Math. Phys. Eng. Sci., vol. 277, no. 1371, pp. 468-497, 1964.

[73] K. G. Xu, "Plasma sheath behavior and ionic wind effect in electric field modified flames," Combust. Flame, vol. 161, no. 6, pp. 1678-1686, 2014.

[74] T. Asakawa, "Effect of an electrical field on liquid fuel combustion processes," in Combustion Questions, Russian Tr., Moscow: Metallurgizdat, 1963, pp. 419-426. 
[75] E. M. Stepanov and B. G. D'yachkov, Ionization in Flames - The Electric Field, In Russian. Moscow: Metallurgizdat, 1968.

[76] Y. C. Chien and D. Dunn-Rankin, "Electric field induced changes of a diffusion flame and heat transfer near an impinging surface," Energies, vol. 11, no. 5, 2018.

[77] M. Belhi, P. Domingo, and P. Vervisch, "Modelling of the effect of DC and AC electric fields on the stability of a lifted diffusion methane/air flame," Combust. Theory Model., vol. 17, no. 4, pp. 749-787, 2013.

[78] M. Abricka, I. Barmina, V. Suzdalenko, and M. Zake, "Combustion dynamics at biomass thermochemical conversion downstream of integrated gasifier and combustor," in Engineering For Rural Development, 2013, pp. 638-642.

[79] O. V. Kozlov, Electric probe in plasma, In Russian. Moscow: Atomizdat, 1969.

[80] C. Igathinathane et al., "Simple and inexpensive method of wood pellets macro-porosity measurement," Bioresour. Technol., vol. 101, no. 16, pp. 6528-6537, Aug. 2010.

[81] X. Cheng, L. Chen, F. Yan, and S. Dong, "Study on soot formation characteristics in the diesel combustion process based on an improved detailed soot model," Energy Convers. Manag., vol. 75, pp. 1-10, Nov. 2013.

[82] T. J. C. Dolmansley, C. W. Wilson, and D. A. Stone, "Electrical modification of combustion and the affect of electrode geometry on the field produced," Model. Simul. Eng., vol. 2011, 2011.

[83] H. Duan et al., "Effects of electric field intensity and distribution on flame propagation speed of $\mathrm{CH}_{4} / \mathrm{O}_{2} / \mathrm{N}_{2}$ flames," Fuel, vol. 158, pp. 807-815, 2015.

[84] J. M. Forthofer and S. L. Goodrick, "Review of vortices in wildland fire," J. Combust., vol. 2011, pp. 1-14, 2011.

[85] I. Barmina, A. Kolmickovs, R. Valdmanis, M. Zake, and H. Kalis, "Experimental and numerical studies of electric field effects on biomass thermo-chemical conversion," Chem. Eng. Trans., vol. 50, 2016.

[86] DSC-Electronics Germany GmbH, "DP-PH series high-voltage laboratory power supplies." [Online]. Available: dsc-electronics.com/products/dc-laboratory-power-supplies/dp-phseries/. [Accessed: 24-Jan-2020].

[87] I. Barmina, M. Purmalis, R. Valdmanis, and M. Zaķe, "Electrodynamic control of the combustion characteristics and heat energy production," Combust. Sci. Technol., vol. 188, no. 2, pp. 190-206, Feb. 2016. 


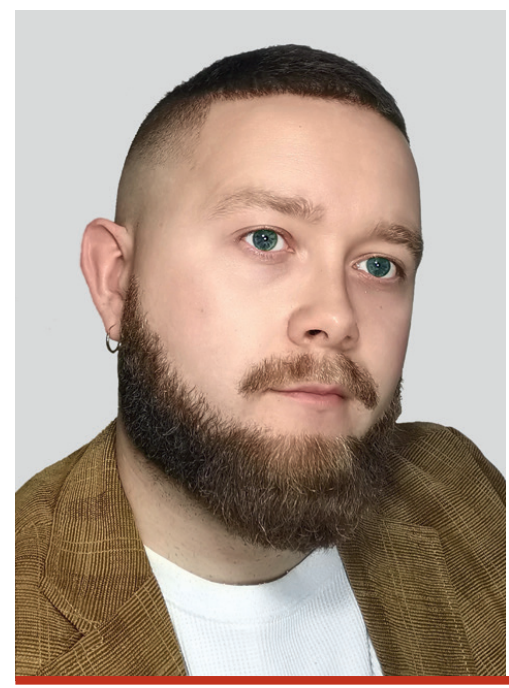

Antons Kolmičkovs was born in 1990 in Ventspils. He holds a Bachelor's degree in Chemical Engineering (2013) and a Master's degree in Heat Power and Thermal Engineering (2016) from Riga Technical University. In the period from 2014 to 2020, he was an assistant and later a researcher with the Institute of Physics of University of Latvia. In 2016, he was included in the RTU Gold Fund for excellence in studies and success in research and was also awarded a JSC "Latvenergo" Diploma of the competition for the best final study papers.

Antons Kolmičkovs is currently a planning engineer of the Infrastructure Development Department of the municipal government corporation "Rīgas Ūdens". 